\title{
STRAIN RATE EFFECTS ON ULTRA HIGH PERFORMANCE FIBER REINFORCED CONCRETE (UHP-FRC) WITH VARIOUS FIBER CONTENTS
}

by

Sayed-Mohammad Banitabaei-Koupaei

B.Sc., Islamic Azad University of Najafabad, Iran, 1996

\author{
A report \\ presented to Ryerson University \\ in partial fulfillment of the \\ requirements for the degree of \\ Master of Engineering \\ in the Program of \\ Civil Engineering
}

Toronto, Ontario, Canada, 2016

${ }^{\circ}$ Sayed-Mohammad Banitabaei-Koupaei, 2016 


\section{Author's Declaration}

I hereby declare that I am the sole author of this project. This is a true copy of the project, including any required final revisions, as accepted by my examiner.

I authorize Ryerson University to lend this project to other institutions or individuals for the purpose of scholarly research.

I further authorize Ryerson University to reproduce this project by photocopying or by other means, in total or in part, at the request of other institutions or individuals for the purpose of scholarly research.

I understand that my project may be made electronically available to the public. 


\begin{abstract}
STRAIN RATE EFFECTS ON ULTRA HIGH PERFORMANCE FIBER REINFORCED CONCRETE (UHP-FRC) WITH VARIOUS FIBER CONTENTS
\end{abstract}

\author{
Sayed-Mohammad Banitabaei-Koupaei \\ Master of Engineering (MEng) in Civil Engineering \\ Ryerson University, Toronto, Canada, 2016
}

Ultra High Performance Fiber Reinforced Concrete (UHP-FRC) was introduced in the mid-1990s and has made striking advances in recent years. Ductal ${ }^{\circledR}$ is a UHP-FRC technology that offers a unique combination of characteristics including but, not limited to ductility, strength and durability, while providing highly moldable products with quality surfaces. Compressive strengths, and equivalent flexural strengths reach up to 200 and $40 \mathrm{MPa}$, respectively. UHP-FRC also shows an outstanding performance under dynamic loading in structures subjected to extreme loading conditions such as impact, earthquake and blast. Moreover, UHP-FRC indicates an optimized combination of properties for a specific application. Three series of tests including compression, indirect tension, and flexure were conducted under various strain rates from quasistatic to dynamic loading with low strain rates. The objective of this project is to enhance knowledge of strain rate effects on UHP-FRC with various fiber contents and to report Dynamic Increase Factor (DIF).

Keywords: Ultra High Performance Fiber Reinforced Concrete (UHP-FRC), strain rate, Dynamic Increase Factor (DIF), quasi-static, dynamic, compressive strength, tensile strength, flexural strength, impact. 


\section{Acknowledgement}

"If I can see farther it is only because I stand on the shoulders of giants."

Isaac Newton (1642-1727)

I would like to thank Professor H. Marzouk, PhD, P.Eng. for the provision of laboratory facilities in the Department of Civil Engineering at Ryerson University. I would also like to express my sincere gratitude to him as my supervisor for his encouragement and inspirational guidance throughout this work. His enthusiasm and encouragement have been a great motivation to me.

I am extremely grateful to Mr. Hesham Othman for his help and useful discussions during the course of my project. I would also appreciate sincere efforts of structural lab technicians at Ryerson University for providing technical supports throughout my project.

Finally, I would also like to thank all civil engineering graduate students in the structural laboratory at Ryerson University for their assistance and supports. 


\section{Dedication}

Lovingly dedicated to my wonderful mother for her measureless support, encouragement, and constant love that have sustained me throughout my life. 


\section{Table of Contents}

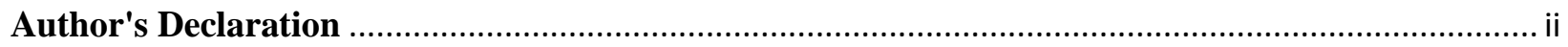

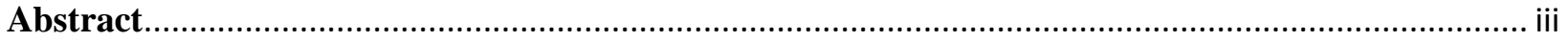

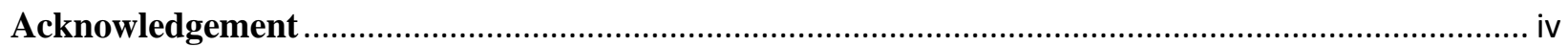

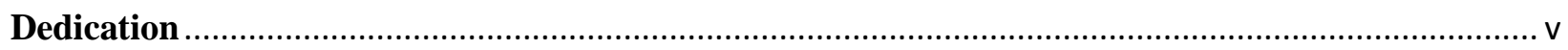

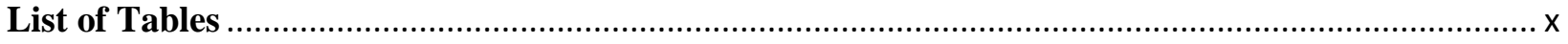

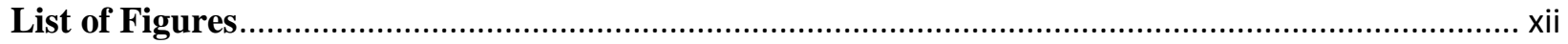

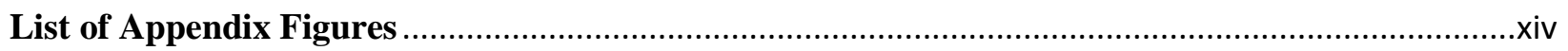

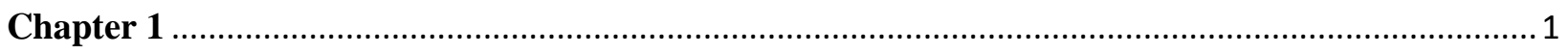

INTRODUCTION

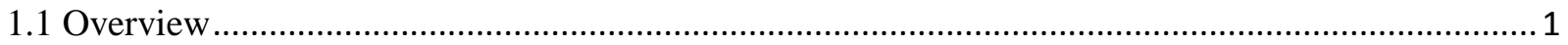

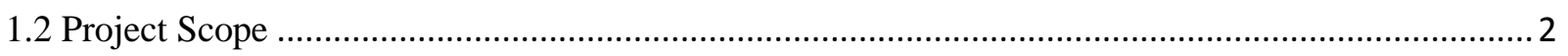

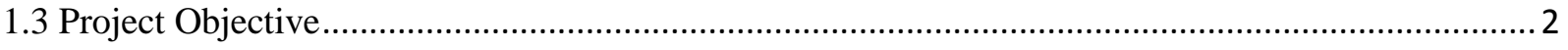

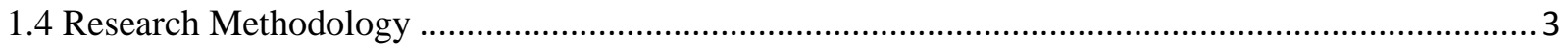

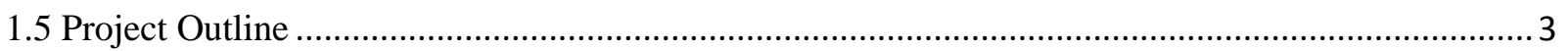

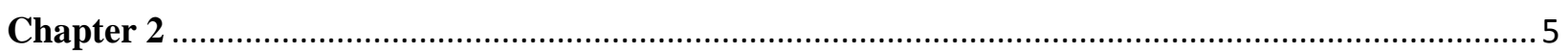

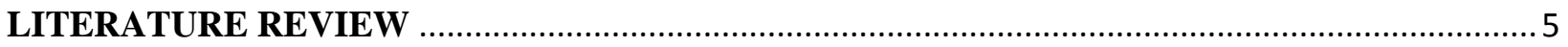

2.1 Ultra High Performance Fiber Reinforced Concrete (UHP-FRC) …............................................ 5

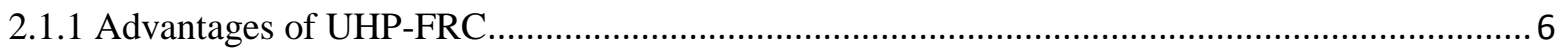

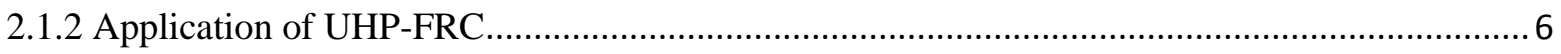

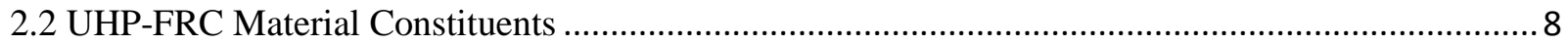

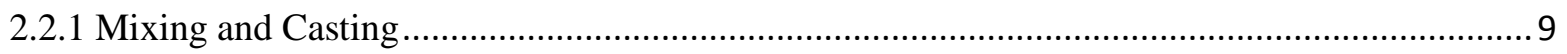

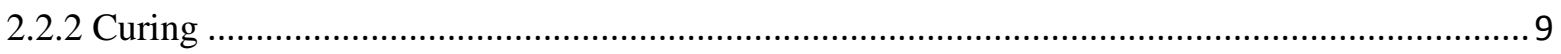

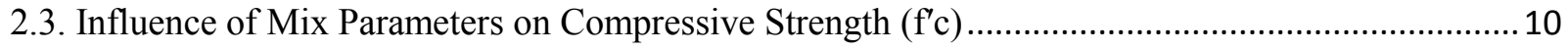

2.3.1 Influence of Water-Cement Ratio (w/c) ............................................................................ 10

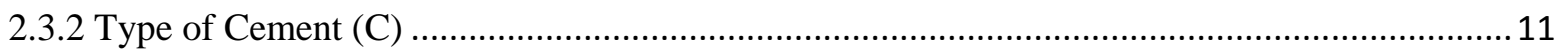

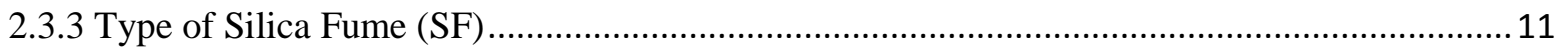

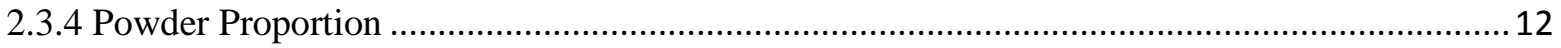

2.3.5 Influence of Type and Amount of HRWR ...................................................................... 12

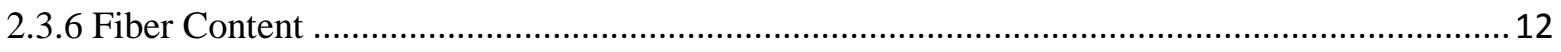




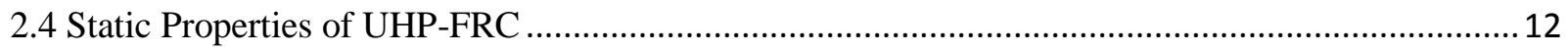

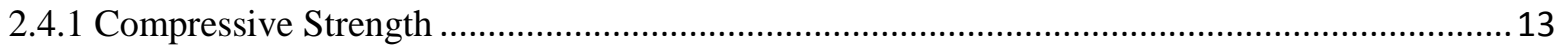

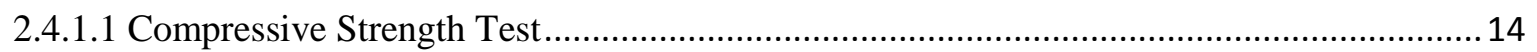

2.4.2 Indirect Tensile Strength Test (Splitting Test or Brazilian Test) .........................................15

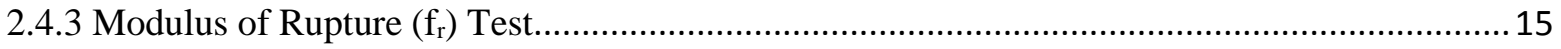

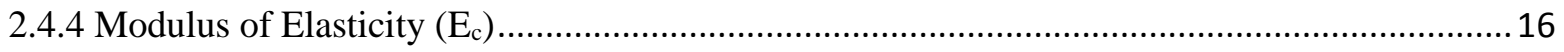

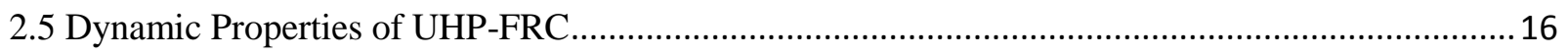

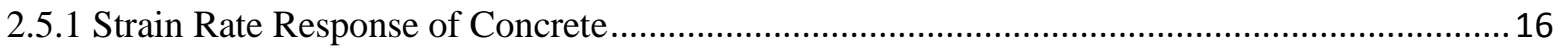

2.5.2 Strain Rate Effects on the Strength of Concrete …........................................................... 17

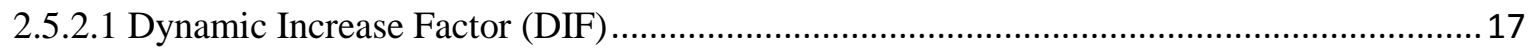

2.5.2.2 Strain Rate Properties of Concrete in Compression ........................................................19

2.5.2.3 Strain Rate Properties of Concrete in Tension ............................................................. 19

2.5.2.4 Comparison of the Strain Rate Responses of Concrete in Compression and Tension ........19

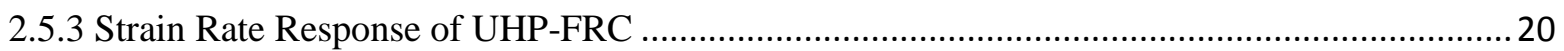

2.6 Testing Methods for Concrete under Variable Strain Rates ......................................................2 21

2.6.1 Testing Methods for Concrete in Tension under Quasi-Static Loading.................................21

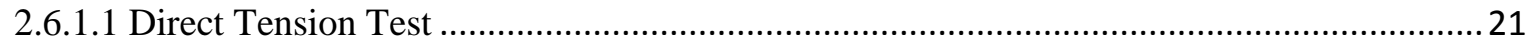

2.6.1.2 Indirect Tensile Strength Test (Splitting Test or Brazilian Test) ....................................23

2.6.2 Testing Methods for High Strain Rate Loading ............................................................... 23

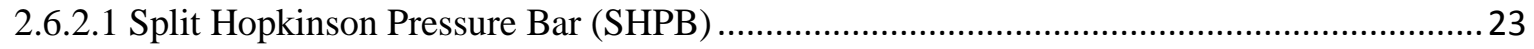

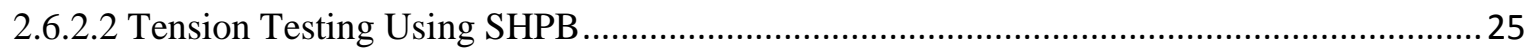

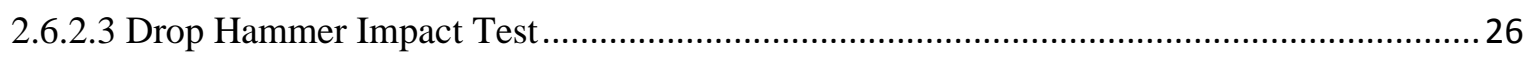

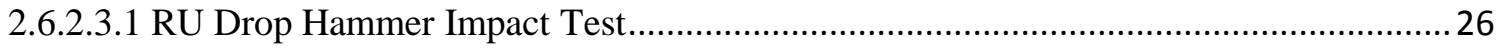

2.6.2.3.2 U of T Drop Hammer Impact Test......................................................................... 28

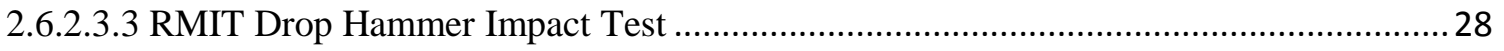

2.6.2.3.4 The 1kJ Drop Hammer Impact Test ................................................................... 30

2.6.2.3.5 Liverpool Drop Hammer Impact Test ......................................................................... 31

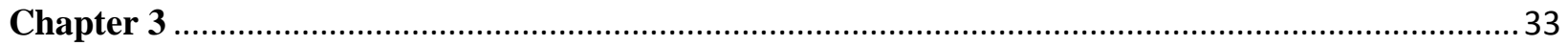

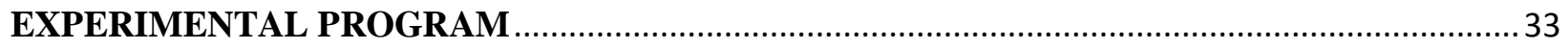

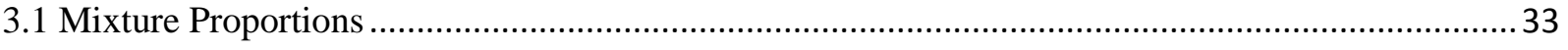

3.1.1 UHP-FRC with Steel Fibers at 1\% by Volume fraction .......................................................3 33

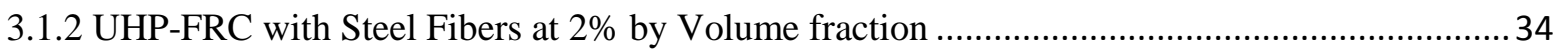


3.1.3 UHP-FRC with Steel Fibers at 3\% by Volume fraction ..................................................... 34

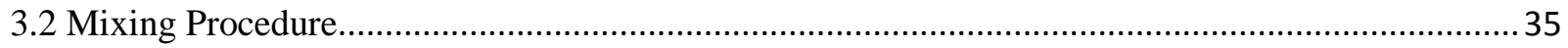

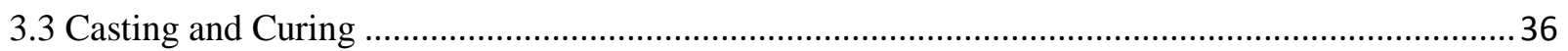

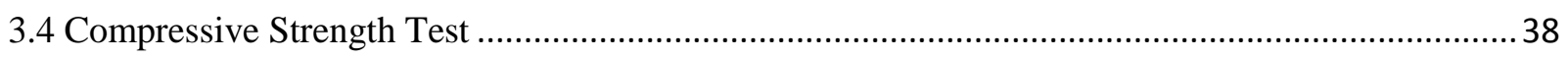

3.4.1 Compressive Strength Test under Quasi Static and Dynamic Loading ...................................39

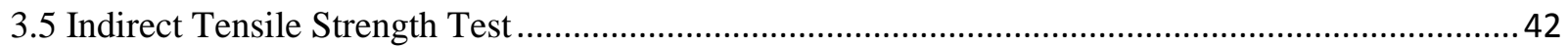

3.5.1 Indirect Tensile Strength Test under Quasi Static and Dynamic Loading .............................. 43

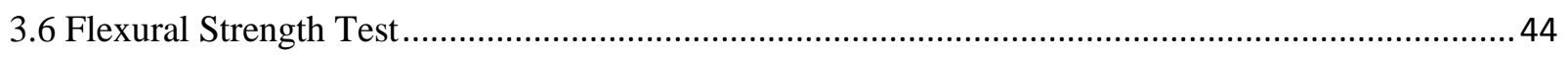

3.6.1 Flexural Strength Test under Quasi static and Low Speed Loading Rates .............................45

3.6.2 Flexural Strength Test under Dynamic (Impact) Loading ...................................................47

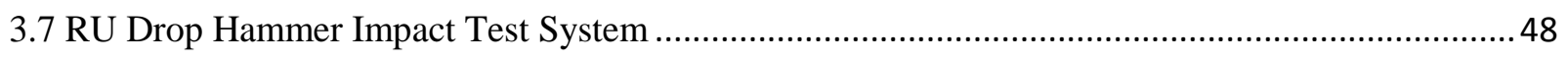

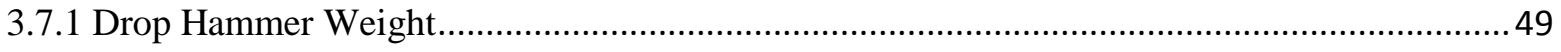

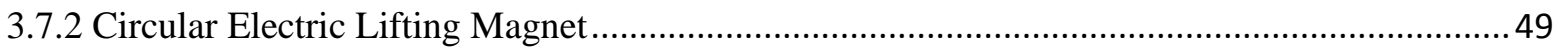

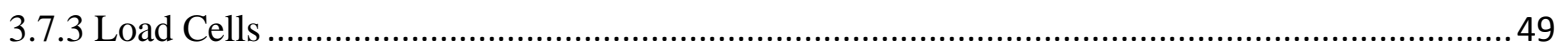

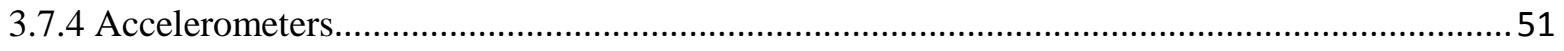

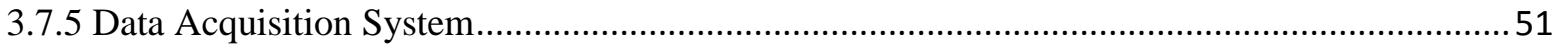

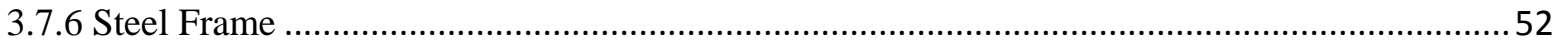

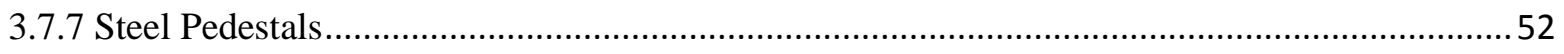

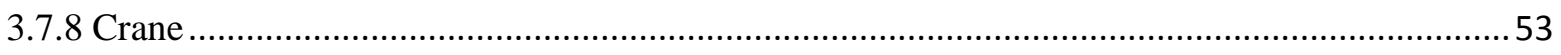

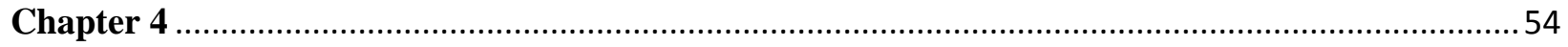

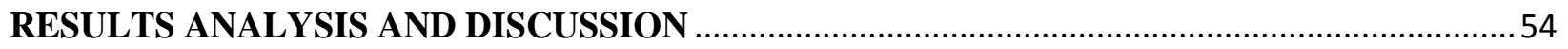

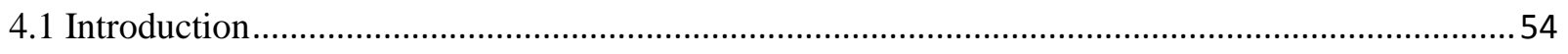

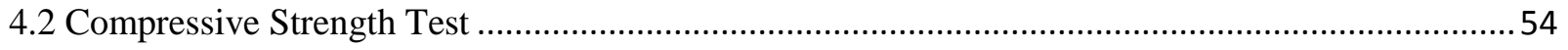

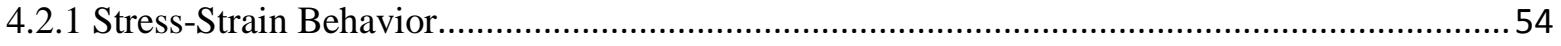

4.2.2 Compressive Strength Test under Quasi-Static Loading ...................................................54

4.2.3 Compressive Strength Test under Dynamic Loading .......................................................56

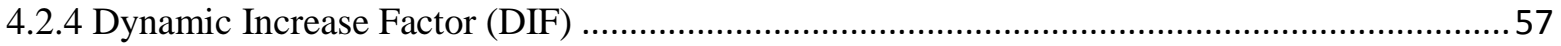

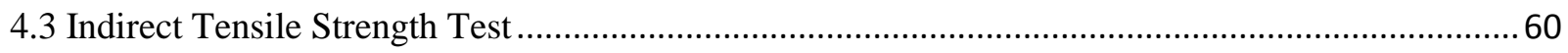

4.3.1 Indirect Tensile Strength Test under Quasi-Static and Low Speed Loading Rates ..................60

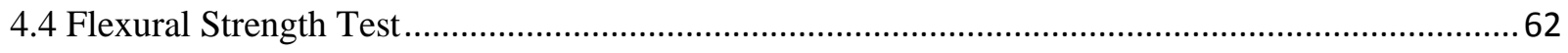

4.4.1 Flexural Strength Test under Quasi-Static and Low Speed Loading Rates .............................62

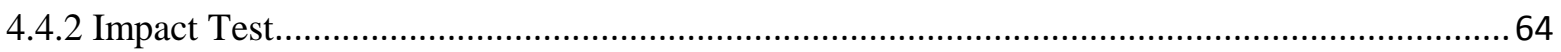




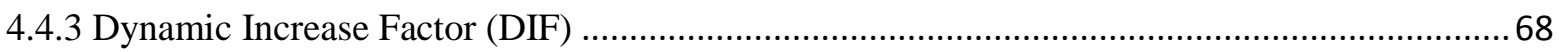

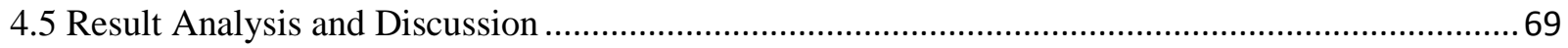

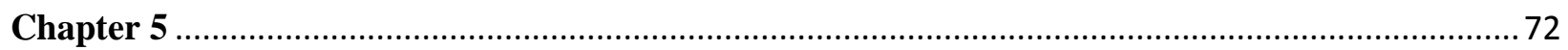

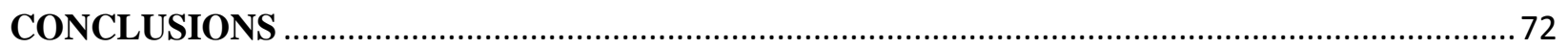

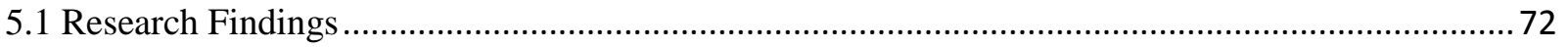

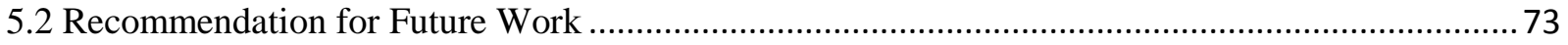

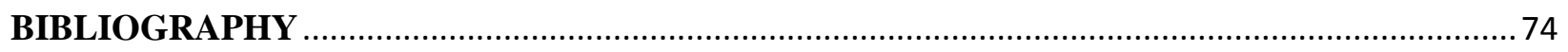

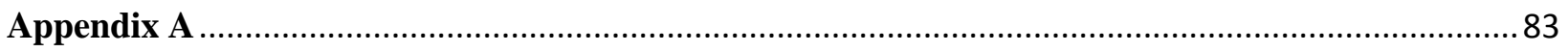

Sample of Test Results - Compressive Strength Test .................................................................. 83

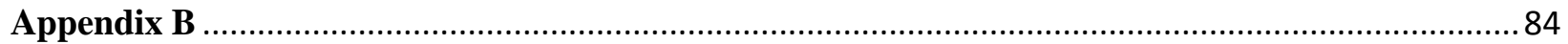

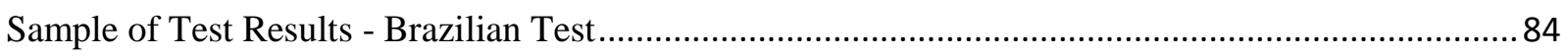

Appendix C

Sample of Test Setup - Flexural Strength Test under Quasi-Static, and Low Speed Loading Rates .....85

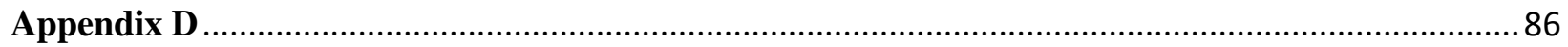

Sample of Test Results - Flexural Strength Test under Quasi-Static, and Low Speed Loading Rates ..86 Appendix E

Sample of Test Results - Flexural Strength Test under Dynamic (Impact) Loading. .......................... 87 


\section{List of Tables}

Table 2.1: UHP-FRC Applications in Canada ............................................ 7

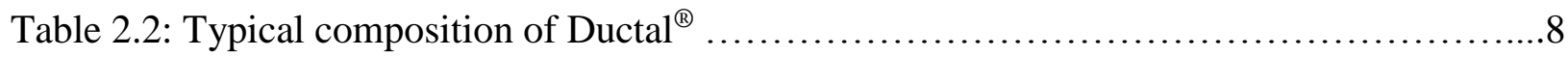

Table 2.3: Summary of cement designation and properties $\ldots \ldots \ldots \ldots \ldots \ldots \ldots \ldots \ldots \ldots \ldots \ldots \ldots \ldots \ldots \ldots \ldots \ldots$

Table 2.4: Range of UHP-FRC material properties .................................... 13

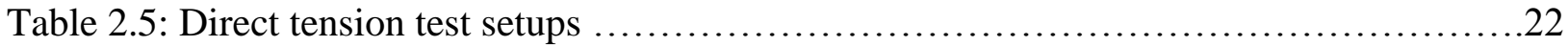

Table 3.1: Quasi-static strain and displacement rates for compressive strength test ............40

Table 3.2: Dynamic strain and displacement rates for compressive strength test .............40

Table 3.3: Displacement and loading rates for Brazilian test ............................44

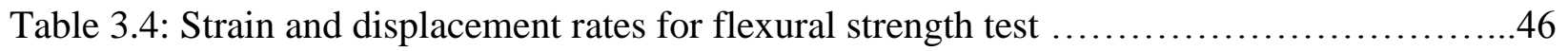

Table 3.5: Number of tested specimens and drop heights $\ldots \ldots \ldots \ldots \ldots \ldots \ldots \ldots \ldots \ldots \ldots \ldots \ldots \ldots$

Table 4.1: Compressive strength of UHP-FRC with 1\% fiber, under quasi-static loading .......55

Table 4.2: Compressive strength of UHP-FRC with 2\% fiber, under quasi-static loading .......55

Table 4.3: Compressive strength of UHP-FRC with 3\% fiber, under quasi-static loading .......55

Table 4.4: Compressive strength of UHP-FRC with 1\% fiber, under dynamic loading ..........56

Table 4.5: Compressive strength of UHP-FRC with 2\% fiber, under dynamic loading ..........56

Table 4.6: Compressive strength of UHP-FRC with 3\% fiber, under dynamic loading .........57

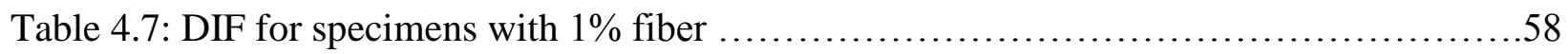

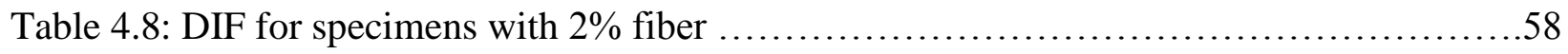

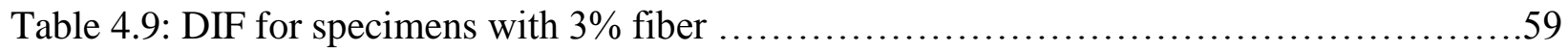

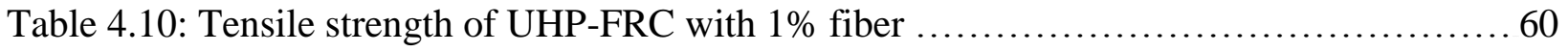

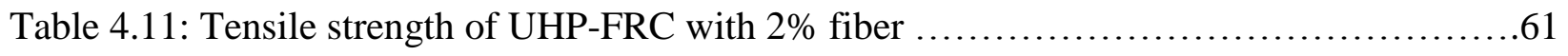

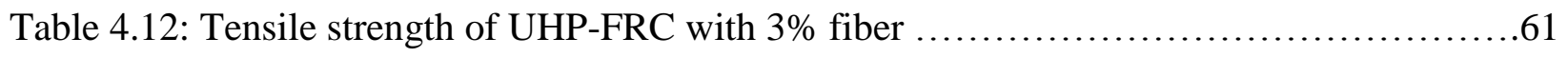

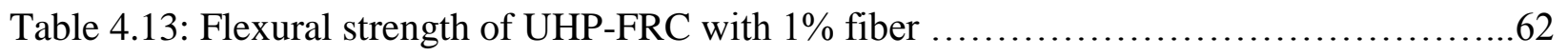

Table 4.14: Flexural strength of UHP-FRC with $2 \%$ fiber ................................62 


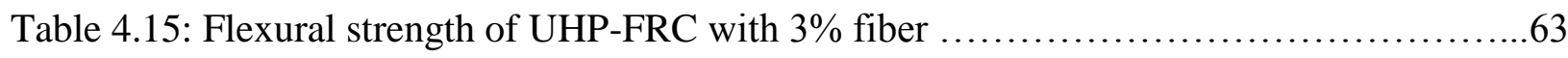

Table 4.16: Loading and strain rates for UHP-FRC with $1 \%$ fiber ........................65

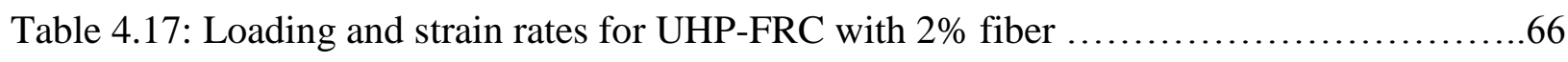

Table 4.18: Loading and strain rates for UHP-FRC with $3 \%$ fiber .........................66

Table 4.19: Dynamic flexural stress for UHP-FRC with different fiber contents ..............67

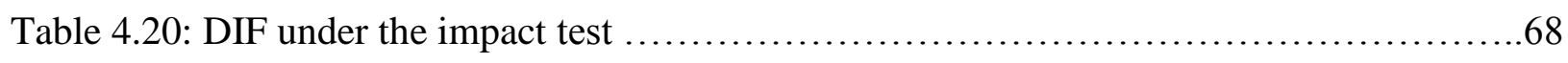




\section{List of Figures}

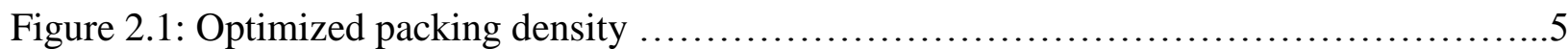

Figure 2.2: Effect of W/C on compressive strength of UHP-FRC $\ldots \ldots \ldots \ldots \ldots \ldots \ldots \ldots \ldots \ldots$

Figure 2.3: Stress-strain curve for UHP-FRC ............................................. 14

Figure 2.4: Indirect tensile test (Brazilian test or splitting test) .......................... 15

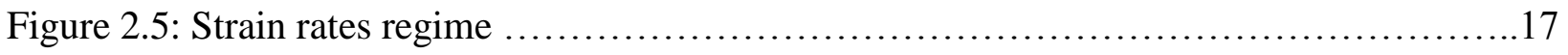

Figure 2.6: Comparison of strain rate effect on tensile and compressive strengths ............20

Figure 2.7: Schematic view of the Split Hopkinson Pressure Bar (SHPB) ...................24

Figure 2.8: SHPB setup for testing concrete specimens under compression ...................25

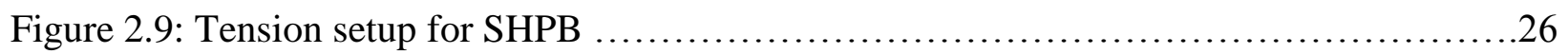

Figure 2.10: Schematic view of the drop hammer impact test system used at Ryerson University in 2014 ...........................................27

Figure 2.11: Drop hammer impact test apparatus at RMIT University .....................29

Figure 2.12: Schematic view of the medium impact machine (1,000 J capacity) at UBC .......30

Figure 2.13: Drop-weight impact machine with 1,000 J capacity at UBC ...........................31

Figure 2.14: Drop hammer impact test machine at University of Liverpool ...............................32

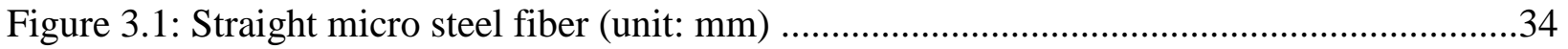

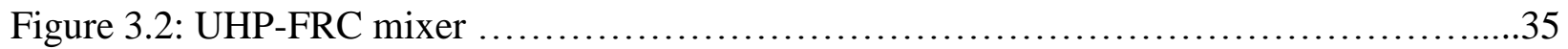

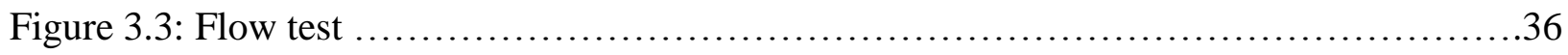

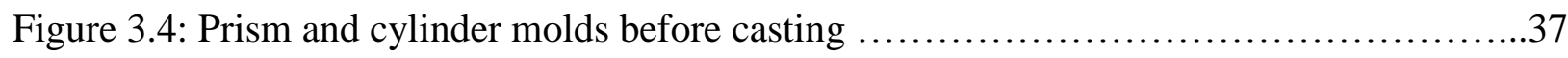

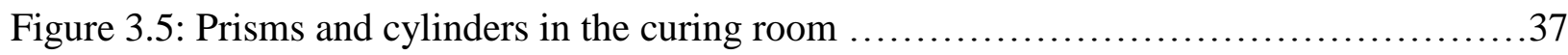

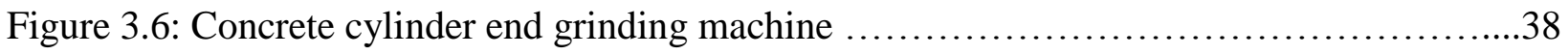

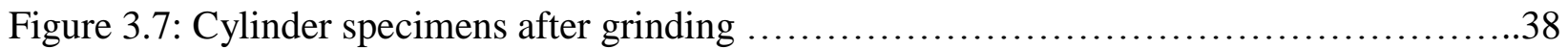

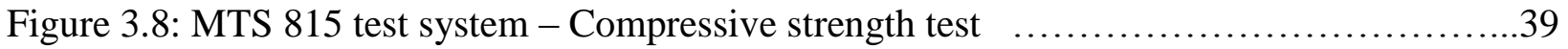


Figure 3.9: Cylindrical specimens after compressive strength test

Figure 3.10: Geometry and loading of the specimen for splitting tension test ..................42

Figure 3.11: MTS 815 test system - Indirect tensile strength test ........................43

Figure 3.12: Cylindrical specimens after indirect tensile strength test ......................44

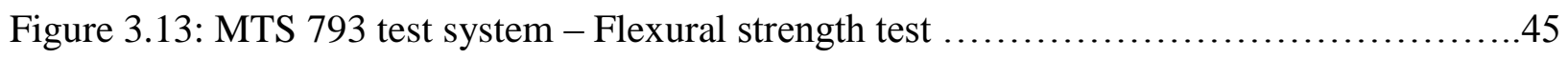

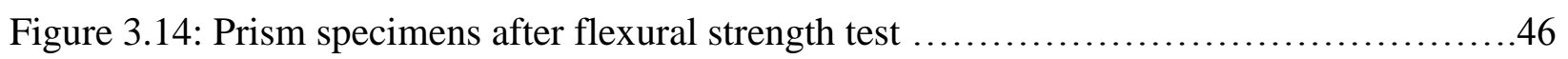

Figure 3.15: Hoist with circular electric lifting magnet (left), and steel drop hammer (right) ...47

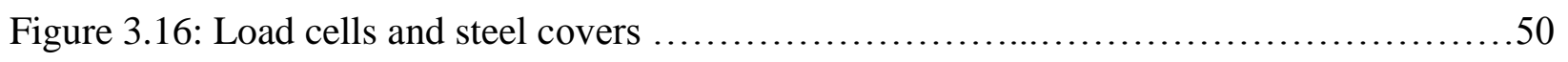

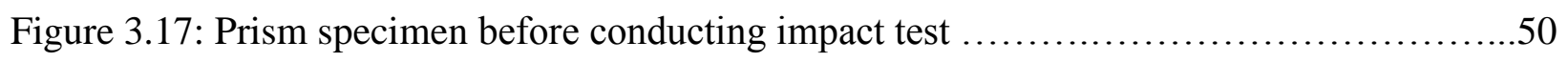

Figure 3.18: Installation of the accelerometers on the drop weight $\ldots \ldots \ldots \ldots \ldots \ldots \ldots \ldots \ldots \ldots . . .51$

Figure 3.19: Data acquisition system, computer, and connections .........................52

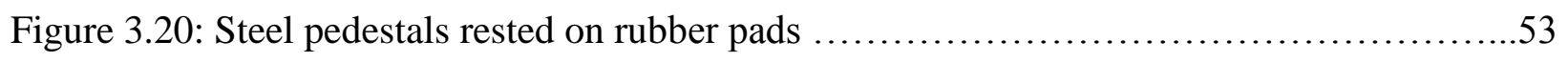

Figure 4.1: Experimental DIF-strain rate fitted lines for compressive strength of UHP-FRC ....59

Figure 4.2: Load-displacement curves for UHP-FRC at $0.018 \mathrm{~mm} / \mathrm{min}$ rate .................63

Figure 4.3: Stress-displacement curves for UHP-FRC at $0.018 \mathrm{~mm} / \mathrm{min}$ rate ................64

Figure 4.4: A UHP-FRC prism specimen after impact test ............................64

Figure 4.5: UHP-FRC prism specimens with $1 \& 2 \%$ fiber, after impact test

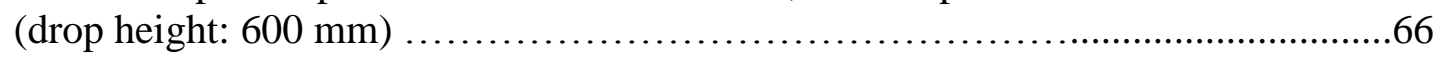

Figure 4.6: UHP-FRC prism specimens with 1, $2 \& 3 \%$ fiber, after impact test

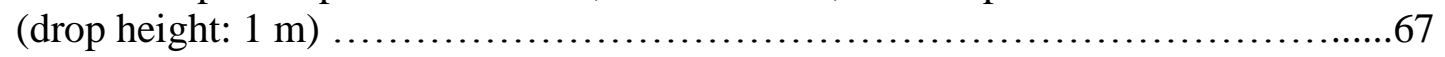

Figure 4.7: Experimental DIF-strain rate fitted lines for flexural strength of UHP-FRC under impact loads ... 


\section{List of Appendix Figures}

Figure 1: Stress-strain curve for UHP-FRC with different fiber contents at $360 \mathrm{~mm} / \mathrm{min}$ rate

Figure 2: Stress-displacement curve for UHP-FRC with different fiber contents at 0.6 $\mathrm{mm} / \mathrm{min}$ rate

Figure 3: Station manager software setup for conducting flexural strength test ..............85

Figure 4: Load-displacement curve for UHP-FRC with 1\% fiber and different strain rates ......86

Figure 5: Stress-displacement curve for UHP-FRC with 1\% fiber and different strain rates ......86

Figure 6: Force-time curve for UHP-FRC with 1\% fiber and $600 \mathrm{~mm}$ drop height ............87 


\section{Chapter 1}

\section{INTRODUCTION}

"We still do not know one thousandth of one percent of what nature has revealed to us."

Albert Einstein (1879-1955)

\subsection{Overview}

Ultra High Performance Fiber Reinforced Concrete (UHP-FRC) was introduced in the mid-1990s. Its compressive strength exceeds $150 \mathrm{MPa}$ and its flexural strength is over $30 \mathrm{MPa}$ [1]. Ductal ${ }^{\circledR}$ offers a unique combination of characteristics including but, not limited to ductility, strength and durability with compressive strengths, and equivalent flexural strengths up to 200 and $40 \mathrm{MPa}$, respectively. UHP-FRC includes the distinctive properties of the ultra-high performance concrete as well as high tensile strength steel fibers. As a sustainable, durable, and construction material with considerable tensile capacity, UHP-FRC is suitable for using in the fabrication of precast members [1].

Specific treatments including heat curing, pressure, and extreme vibration is usually necessary for reaching compressive strengths beyond $150 \mathrm{MPa}$. However, researchers are interested in enhancement of UHP-FRC with no specific treatment and using construction materials that are commercially accessible on the market. The development of performance to overcome the low tensile strength of concrete is done by optimizing the packing density of the matrix using high strength steel fibers. Steel fibers are added to reduce brittleness of concrete and raise energy absorption capacity [2].

UHP-FRC consists of cement (C), water (W), silica sand, silica fume (SF), superplasticizer (SP) high cement content, silica sand, silica fume, superplasticizer, and fibers. Very low watercement ratio along with the optimized packing density of the matrix are significant for increasing the compressive strength in UHP-FRC [2]. Addition of steel fibers enhance flexural and tensile strengths of UHP-FRC. 
UHP-FRC has many advantages including high compressive strength, durability, stiffness, ductility, toughness, freeze-thaw resistance, stability, fire resistance, tightness, corrosion resistance, energy absorption, very low permeability, aesthetic, constructability, quality control, sustainability, economic benefits, and user friendliness [3].

UHP-FRC also shows an outstanding performance under dynamic loading in structures subjected to extreme loading conditions such as impact, earthquake and blast. These benefits produce great demands for designing of structures such as nuclear plants, military structures, power plants, contaminant shields, earthquake resistant structures, fuel tanks, crash barriers, and water retaining structures $[4,5]$. However, the studies conducted on the behavior of UHP-FRC under dynamic loading is not comparable with those subjected to static loading conditions. More emphasis has been placed on the compressive behavior of UHP-FRC compared to its tensile response.

The influence of strain rate on compressive and tensile strengths of concrete is specified as a Dynamic Increase Factor (DIF). DIF is defined as the ratio of the dynamic to static yield (or ultimate) stress [6]. DIF is the most common method for considering the strain rate effects on UHP-FRC. In this project, strain rate response, as well as DIF of UHP-FRC specimens under various load cases have been studied.

It is hoped that this project will make UHP-FRC more accessible to the research and professional community, and remove the impression that UHP-FRC needs very specific treatment or conditions that only the experts can succeed in it.

\subsection{Project Scope}

The scope of this project is to study and evaluate the strain rate effects on various UHP-FRC mix designs with $1 \%, 2 \%$, and $3 \%$ steel fiber content by volume.

\subsection{Project Objective}

The objectives of this project can be described as:

- To develop a better understanding of UHP-FRC response at various strain rates,

- To improve the mechanical properties of UHP-FRC, 
- To enhance the mechanical properties of UHP-FRC under dynamic loading,

- To review the strain rate effects on UHP-FRC,

- To study the static and dynamic properties of UHP-FRC, and

- To evaluate the dynamic increase factor in compression and tension.

\subsection{Research Methodology}

In order to fulfill the requirements for this project, a series of tests were planned in the structural lab to study the effects of strain rates on UHP-FRC. The plan will develop a deep understanding of UHP-FRC sensitivity to various strain rates using experimental tests. For the purpose of this project, three types of UHP-FRC including 1\%, $2 \%$, and 3\% steel fibers by volume have been investigated.

Three series of tests including compression test, Indirect tensile test (splitting test or Brazilian test), and flexural test were conducted under different strain rates including $3 \times 10^{-5}$ and $3 \times 10^{-4} \mathrm{~s}^{-1}$ as quasi-static strain rates for compressive strength test, and $3 \times 10^{-3}, 1 \times 10^{-2}, 3 \times 10^{-2}$, and $1 \times 10^{-1}$ $\mathrm{s}^{-1}$ as dynamic strain rates for compressive strength test, and $1 \times 10^{-6} \mathrm{~s}^{-1}$ as quasi-static strain rate for flexural strength test, and $1 \times 10^{-5}$ and $1 \times 10^{-4} \mathrm{~s}^{-1}$ as low speed strain rates for flexural strength test. Also, indirect tensile test were conducted under loading rates of $0.2,2,20,200 \mathrm{kN} / \mathrm{s}$ and displacement rates of $6 \times 10^{-3}, 6 \times 10^{-2}, 6 \times 10^{-1}$, and $6 \mathrm{~mm} / \mathrm{min}$. Tests for quasi-static rates have been performed by MTS testing machine and tests for dynamic strain rates have been conducted using the drop hammer. Finally, the test results were assessed and the findings were discussed. Test procedures and results are described in this project.

\subsection{Project Outline}

This project consists of five chapters, as well as appendices for providing supporting data. Chapter 1 is introduction and includes overview, project scope, project objective, research methodology, and project outline.

Chapter 2 covers literature review and includes general information about UHP-FRC, its advantages, its applications, its constituents, mixing and casting, curing, influence of mix parameters on compressive strength $\left(\mathrm{f}_{\mathrm{c}}^{\prime}\right)$, static properties of UHP-FRC, dynamic properties of UHP-FRC, and testing methods for concrete under variable strain rates. 
Chapter 3 explains the experimental program including mixture proportions, mixing procedure, casting and curing, compressive strength test, indirect tensile strength test, flexural strength test, and RU drop hammer impact test system.

Chapter 4 reviews and analyzes the test results for three types of UHHP-FRC with different fiber contents, using graphs and tables, as well as evaluates the dynamic increase factor.

Chapter 5 includes conclusions. Important findings have also been discussed in this chapter and finally recommendations for future studies have been offered. 


\section{Chapter 2}

\section{LITERATURE REVIEW}

"The true sign of intelligence is not knowledge, but imagination."

Albert Einstein (1879-1955)

\subsection{Ultra High Performance Fiber Reinforced Concrete (UHP-FRC)}

During the last three decades, reinforcing the concrete with steel fibers has been studied. One of the significant findings was enhancing the UHP-FRC [7]. UHP-FRC is a type of Fiber Reinforced Concretes (FRC) with strain hardening behavior along with multiple cracking which is a required characteristic for reaching high ductility [8]. Moreover, filling all the voids in matrix with tiny particles such as silica fume leads to an optimized packing density of the matrix and as a result, UHP-FRC has a very low permeability compared to other types of concretes such as High Performance Fiber Reinforced Cement Composites, High Strength Concrete (HSC), and Normal Strength Concrete (NSC) [9, 10]. Figure 2.1 shows modelling and optimizing packing density. Generally speaking, UHP-FRC can be considered as a combination of Ultra High Performance Concrete (UHPC) and Fiber Reinforced Concrete (FRC) which demonstrates enhanced mechanical properties including high compressive strength, ductility, and durability [11, 12]. Fiber content has a significant role in UHP-FRC to exhibit ductile behavior up to flexural failure.

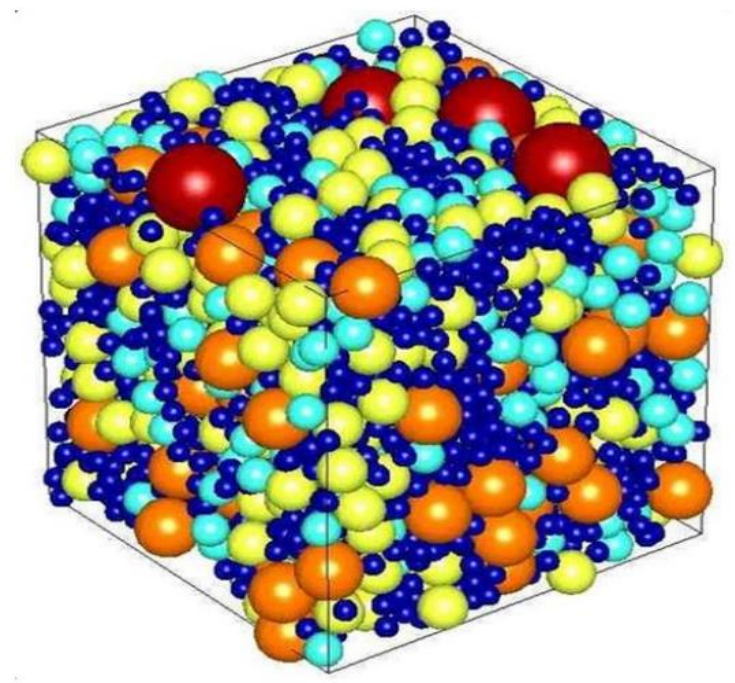

Figure 2.1: Optimized packing density [33]. 


\subsubsection{Advantages of UHP-FRC}

The major advantage of UHP-FRC after high compressive strength is the low permeability resulted from an optimized packing density of the cementitious matrix. Impermeability together with strain hardening enhance the durability of UHP-FRC [13, 14]. Furthermore, UHP-FRC shows enhanced mechanical properties such as high energy absorption, and high resistance to spalling and scabbing under impact loading. Therefore, these characteristics make UHP-FRC a preferable material for using in structures subjected to impact, earthquake, and explosive loadings [9].

Engineering of cementitious matrix, along with optimization and fine-tuning of the ultimate proper ties have been developed through nanoindentation testing. Nanotechnologies and specifically nanosensors have facilitated the evolution of the micromechanical properties on a smaller scale than the scale of the initial particles. Indentation tests conducted on Ductal ${ }^{\circledR}$, at nanometric scales demonstrate that merely the Calcium Silicate Hydrate $(\mathrm{C}-\mathrm{S}-\mathrm{H})$ phase shows a viscous strain. The test results clarify the strong relationship between shrinkage and creep. Once the hydration rate descends, most of the shrinkage strain is the viscoplastic response of C-S-H to the capillary forces exerted by water to the pore surface. Very low creep property of high strength concrete can be described by consumption of a potential creep strain due to the shrinking stage [76].

UHP-FRC combines a large volume fraction of highly dense cementitious matrix with microscale fibers. The dense matrix in Ultra High Performance Concrete (UHPC) can efficiently interconnect with nanoscale and microscale reinforcement to compensate the fragility of UHPC. Nanoscale reinforcement together with microscale fibers can prepare strengthening at a finer level, and develop the bond and pullout properties of microscale fibers [77].

\subsubsection{Application of UHP-FRC}

UHP-FRC can be used in the following cases $[9,10]$ :

- Super high rise buildings,

- Rehabilitation of deteriorated concrete bridges,

- Earthquake resistant structures,

- Offshore bucked foundations,

- Fabrication of precast members, 
- Protective defense constructions,

- Blast resistant structures,

- water retaining structures,

- Hybrid bridges,

- Military structures,

- Nuclear plants,

- Power plants,

- Fuel tanks,

- Crash barriers, and

- Marine concrete structures.

Over the past years, several structures have been built using UHP-FRC. US, Canada, France, Japan, Germany, and South Korea are countries that have used this type of concrete. The Shawnessy light rail transit station has been constructed in Calgary, Alberta, using UHP-FRC in 2004 [15]. Table 2.1 shows some of the most recent applications of UHP-FRC in Canada.

Table 2.1: UHP-FRC applications in Canada [16].

\begin{tabular}{|c|c|c|l|}
\hline Name & Country & Year & \multicolumn{1}{|c|}{ Application } \\
\hline Melgund Creek Bridge & Canada & 2013 & $\begin{array}{l}\text { Joint fill between adjacent box beams and } \\
\text { between precast curbs. }\end{array}$ \\
\hline Little Wabigoon Bridge & Canada & 2013 & $\begin{array}{l}\text { Joint fill between adjacent box beams and } \\
\text { between precast curbs. }\end{array}$ \\
\hline Nugget Creek Bridge & Canada & 2013 & $\begin{array}{l}\text { Joint fill between adjacent box beams and } \\
\text { between precast curbs. }\end{array}$ \\
\hline Blackwater River Bridge & Canada & 2013 & $\begin{array}{l}\text { Joint fill between adjacent box beams and } \\
\text { between precast curbs. }\end{array}$ \\
\hline Sturgeon River Bridge & Canada & 2013 & $\begin{array}{l}\text { Joint fill between adjacent box beams and } \\
\text { between precast curbs. }\end{array}$ \\
\hline Beaver Creek Bridge & Canada & 2013 & $\begin{array}{l}\text { Joint fill between adjacent box beams and } \\
\text { between precast curbs. }\end{array}$ \\
\hline Bug River Bridge & Canada & 2013 & $\begin{array}{l}\text { Joint fill between adjacent box beams and } \\
\text { between precast curbs. }\end{array}$ \\
\hline Jackpine River Bridge & Canada & 2013 & $\begin{array}{l}\text { Joint fill between adjacent box beams and } \\
\text { between precast curbs. }\end{array}$ \\
\hline Westminster Drive & Canada & 2014 & $\begin{array}{l}\text { Longitudinal joints to connect superstructure } \\
\text { modules. }\end{array}$ \\
\hline
\end{tabular}




\subsection{UHP-FRC Material Constituents}

Special treatment, such as heat curing, pressure and/or extensive vibration, is often required in order to achieve compressive strengths in excess of $150 \mathrm{MPa}$. The development of UHP-FRC without any special treatment and utilizing materials that are commercially available on the market has not been easily achieved [2]. Many variables are involved such as material properties, particle size of constituents, mix design proportions, mixing procedure, and test methods. Achieving compressive strengths exceeding $150 \mathrm{MPa}$ without any special treatment such as heat curing, pressure or extensive vibration is possible through optimizing the mix design [13, 14].

Various types of UHP-FRC can be produced according to its application. Usually, the composite consists of cement, fine sand, silica fume, water, superplasticizer (SP), high-range water-reducing admixture (HRWR), and fibers. In order to improve the homogeneity of the mix, UHP-FRC does not include any coarse aggregates $[16,17]$. However, fine aggregates, as well as chemical admixtures may be used. Ductal which is used in North America to produce UHP-FRC, is a hightech construction material produced by Lafarge Company. Table 2.2 shows a typical composition of Ductal with the specified fiber content.

Table 2.2: Typical composition of Ductal ${ }^{\circledR}[49]$.

\begin{tabular}{|c|c|c|}
\hline Material & $\begin{array}{c}\text { Amount } \\
\left(\mathrm{kg} / \mathrm{m}^{3}\right)\end{array}$ & $\begin{array}{c}\text { Percentage } \\
\text { by Weight } \\
(\%)\end{array}$ \\
\hline Portland Cement & 712 & 28.5 \\
\hline Fine Sand & 1,020 & 40.8 \\
\hline Silica Fume & 231 & 9.3 \\
\hline Ground Quartz & 211 & 8.4 \\
\hline HRWR & 30.7 & 1.2 \\
\hline Accelerator & 30.0 & 1.2 \\
\hline Steel Fibers & 156 & 6.2 \\
\hline Water & 109 & 4.4 \\
\hline
\end{tabular}


Yudenfreund et al. reached a compressive strength of $230 \mathrm{MPa}$ using low porosity cement with a vacuum mixing process [2].

\subsubsection{Mixing and Casting}

Although UHP-FRC can be mixed with conventional mixers, mixing time is greater than that of normal concrete due to more energy consumption. However, over mixing should be avoided. Therefore, it is better to use high-energy mixers or lower the temperature of components. This can be done by using ice instead of water [16]. UHP-FRC possesses more components, as well as more fine particles and the homogeneity of the mix is significant for preventing formation of chunks.

The required shear force for breaking the chunks can be minimized by mixing particles without adding water at the beginning [14]. Therefore, all dry constituents including, silica fume, sand and cement should be mixed for 10 minutes before addition of water. Then, water and superplasticizer should be added slowly for the purpose of flowability [14, 18]. After 5 minutes of addition of water and superplasticizer, UHP-FRC becomes fluid. Finally, fibers are added and mixed for 5 minutes. There is no need for internal vibration. However, limited external vibration can eliminate entrapped air in concrete [16].

\subsubsection{Curing}

In comparison with normal concrete, the importance of curing for UHP-FRC is more. Temperature and moisture are two essential characteristics for UHP-FRC curing. UHP-FRC has a low watercement ratio and cannot loose water [16]. For research purposes, UHP-FRC is usually cured with steam when it has obtained sufficient strength. However, such a controlled environment is not always accessible. Therefore, researchers focus on one of four curing conditions. These conditions are standard steam treatment, a delayed version, steam curing with lower temperature in the initial curing stage, and an untreated regime [19]. In the initial stage, UHP-FRC should maintain appropriate temperature and prevent loss of moisture until setting is done. In the second curing stage, high temperature conditions may apply in a high moisture environment $[16,19]$. 


\subsection{Influence of Mix Parameters on Compressive Strength ( $\left.f^{\prime} \mathbf{c}\right)$}

The effects of mix parameters on compressive strength of UHP-FRC can be divided in the following categories:

\subsubsection{Influence of Water-Cement Ratio (w/c)}

Figure 2.2 shows the effect of water-cement ratio on compressive strength of UHP-FRC. The figure indicates that the compressive strength reduces considerably by increasing w/c. the compressive strength of $115 \mathrm{MPa}$ has been reported for a w/c of 0.265 while for a w/c of 0.22 , the compressive strength is in the range of $150 \mathrm{MPa}$ to $206 \mathrm{MPa}$. Therefore, water-cement ratio is not the only effective parameter influencing compressive strength. Different silica fume-cement ratio (SF/C) from $18 \%$ to $25 \%$ also influence the compressive strength [14].

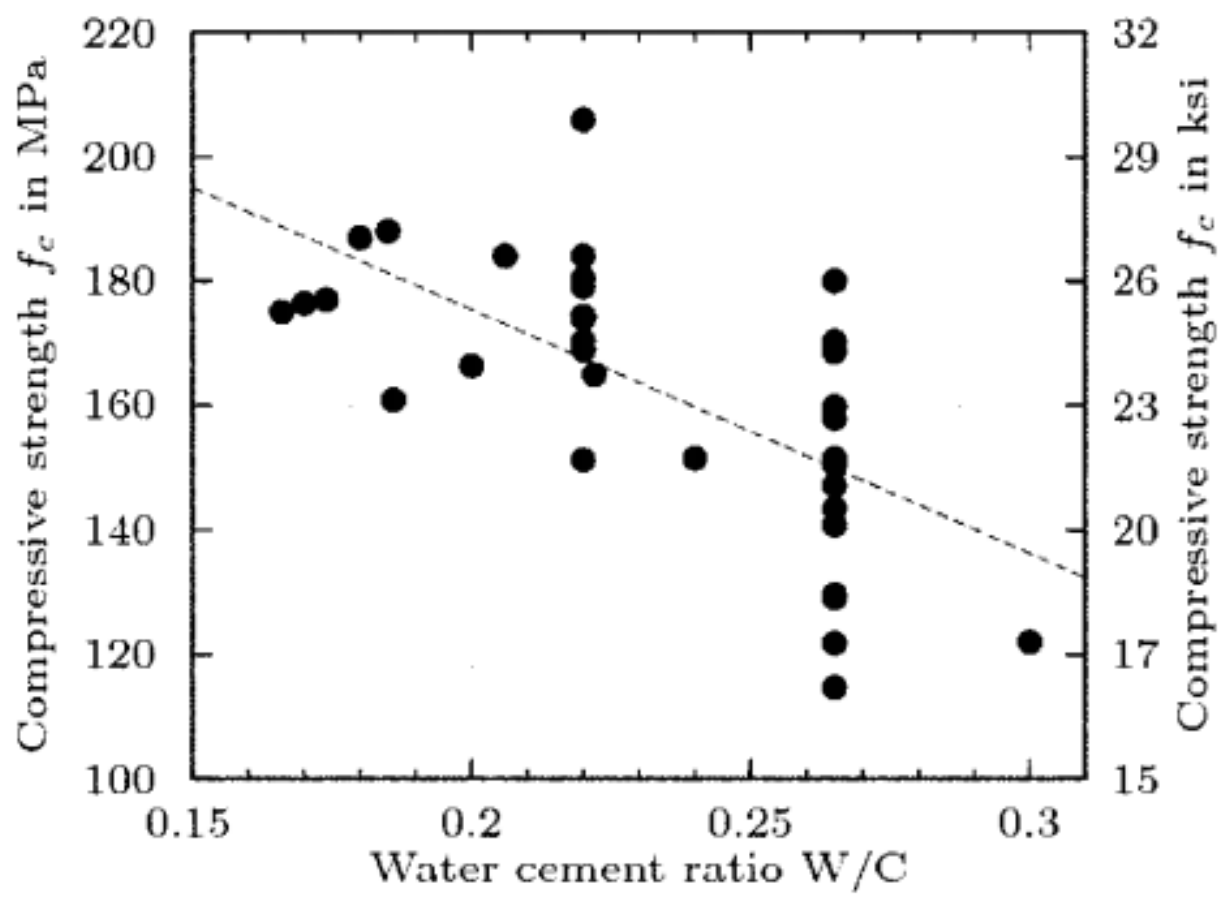

Figure 2.2: Effect of W/C on compressive strength of UHP-FRC [14]. 


\subsubsection{Type of Cement $(C)$}

Four different cements $\left(C_{A}, C_{B}, C_{C}\right.$ and $\left.C_{D}\right)$ were selected by Wille et al. to verify their effects on spread value in the fresh state, as well as compressive strength after 28 days. Cements $C_{A}$ and $C_{B}$ were selected due to their moderate fineness, a low amount of $\mathrm{C}_{3} \mathrm{~A}$ and a high amount of $\mathrm{C}_{3} \mathrm{~S}$ while cements $C_{C}$ and $C_{D}$ were chosen for comparison. Because, the fast hydration process of $C_{3} A$ and the related increase in the surface area of the particles, as well as the water demand around particle generates higher viscosity, cements with low amount of $\mathrm{C}_{3} \mathrm{~A}$ have been preselected. Designation and properties of cements $C_{A}, C_{B}, C_{C}$ and $C_{D}$ are summarized in Table 2.3.

Table 2.3: Summary of cement designation and properties [14].

\begin{tabular}{|c|c|c|c|c|c|}
\hline Type of Cement & $\mathbf{C}_{\mathbf{3}} \mathbf{S}(\boldsymbol{\%})$ & $\mathbf{C}_{\mathbf{2}} \mathbf{S}(\boldsymbol{\%})$ & $\mathbf{C}_{\mathbf{3}} \mathbf{A}(\boldsymbol{\%})$ & $\mathbf{C}_{4} \mathbf{A F}(\boldsymbol{\%})$ & Fineness $_{\left(\mathbf{c m}^{2} / \mathbf{g}\right)}$ \\
\left.\hline${\text { PC Type I* }\left(\mathrm{C}_{\mathrm{A}}\right)}\right)$ & 4.3 & 14.1 & 5.0 & 1.0 & 3930 \\
\hline PC Type II/V ${ }^{*}\left(\mathrm{C}_{\mathrm{B}}\right)$ & 4.0 & 18.0 & 4.0 & 11.0 & 3930 \\
\hline OPC Type I** $\left(\mathrm{C}_{\mathrm{C}}\right)$ & 2.0 & 17.0 & 10.0 & 8.0 & 3990 \\
\hline OPC Type III** $\left(\mathrm{C}_{\mathrm{D}}\right)$ & 0.0 & 19.0 & 10.0 & 9.0 & 6440 \\
\hline
\end{tabular}

* Portland Cement (US), ** Ordinary Portland Cement, local supplier.

Test results revealed that appropriate cements for UHP-FRC in US market are Type I Portland cements having a low amount of $\mathrm{C}_{3} \mathrm{~A}$ and a low-to-moderate fine particles having a surface of $4000 \mathrm{~cm}^{2} / \mathrm{g}$. Also, type II/V Portland cements demonstrated good properties in terms of compressive strength, as well as spread value, but they may not be accessible through all parts of the US. The best results were obtained from a cement type with a high amount of $\mathrm{C}_{3} \mathrm{~S}$ with $\mathrm{C}_{2} \mathrm{~S}$, a value of $\mathrm{C} 3 \mathrm{~A}$ of $5 \%$, and particles of moderate fineness.

\subsubsection{Type of Silica Fume (SF)}

Considering an average particle size of $10 \mu \mathrm{m}$ for cement particles, silica fume particles having an average particle size of about $0.5 \mu \mathrm{m}$, are around 20 times smaller than cement particles. The specific surface area of usual cement is $0.4 \mathrm{~m}^{2} / \mathrm{g}$ while that of silica fume differs from $12 \mathrm{~m}^{2} / \mathrm{g}$ to $25 \mathrm{~m}^{2} / \mathrm{g}$. Such fine particles enhance the packing density of the concrete matrix in both, physical and chemical ways. Wille et al. showed that by reducing fineness and carbon content, the water demand lowers and the flowability enhances. They also demonstrated that the influence of the silica fume type on compressive strength was negligible [14]. 


\subsubsection{Powder Proportion}

In order to improve the packing density of the matrix, in addition to silica fume, very fine glass powder (GP) called silica powder or sand powder, was also used by Wille et al. The silica powder used contained over $99 \%$ silicon dioxide $\left(\mathrm{SiO}_{2}\right)$ having an average particle size of $1.7 \mu \mathrm{m}$. This is much smaller than that of silica powder used for UHPC (5 to $10 \mu \mathrm{m}$ ) [14].

\subsubsection{Influence of Type and Amount of HRWR}

Type of HRWR and its interaction with the cement particles vastly affect the fresh properties of the mix. The interaction can be between very fine particles as well. The most appropriate HRWRs on the market for using in UHP-FRC are based on polycarboxylate ether having different side chain length. The required HRWR is reduced by enhancing the packing density of fine sand. With maximum optimization of the mix, sufficient flowability can be obtained with minimum HRWR. Iminimizing HRWR increases both flowability and compressive strength. The optimum range found to be from 1.4 to $2.4 \%$ of cement by weight [14].

\subsubsection{Fiber Content}

Addition of up to $2.5 \%$ (by volume fraction) straight high strength steel fibers with $13 \mathrm{~mm}$ long, and $0.2 \mathrm{~mm}$ diameter and a tensile strength of $2600 \mathrm{MPa}$, enhanced the mechanical properties of UHP-FRC especially in respect with tensile strength and ductility. Even with addition of $2.5 \%$ steel fiber (by volume fraction), mixture maintained high workability. At a strain of $0.25 \%$, the maximum direct tensile strength of $14 \mathrm{MPa}$, as well as equivalent bending strength of $30 \mathrm{MPa}$ was obtained.

\subsection{Static Properties of UHP-FRC}

UHP-FRC has superior mechanical properties including high durability and ductility, high compressive strength, and very low permeability [20, 21]. ]. Ductal ${ }^{\circledR}$ is a UHP-FRC technology that offers a unique combination of characteristics including but, not limited to ductility, strength and durability with compressive strengths, and equivalent flexural strengths up to 200 and $40 \mathrm{MPa}$, respectively. Due to superior characteristics of UHP-FRC, many researches have worked to 
enhance the static mechanical properties [22, 23], as well as the impact resistance capacity [24, 25] of UHP-FRC.

Curing method also influences on the mechanical properties of UHP-FRC including compressive and tensile strength, and modulus of elasticity. Curing under heat, pressure, and extended vibration is done in laboratories. However, in practice these methods are not functional and economic. Other factors that may affect the mechanical properties of UHP-FRC include fiber orientation, mix proportion, and casting method $[16,20]$. Table 2.4 shows a range of mechanical properties of UHP-FRC to be considered in structural design.

Table 2.4: Range of UHP-FRC material properties [16].

\begin{tabular}{|c|c|}
\hline Property & Range \\
\hline Compressive strength & 150 to $200 \mathrm{MPa}$ \\
\hline Direct tensile strength & 8 to $15 \mathrm{MPa}$ \\
\hline Flexural strength & 30 to $45 \mathrm{MPa}$ \\
\hline Modulus of elasticity & 45 to $55 \mathrm{GPa}$ \\
\hline Poisson's ratio & 0.2 \\
\hline Density & 2400 to $2550 \mathrm{~kg} / \mathrm{m}^{3}$ \\
\hline
\end{tabular}

\subsubsection{Compressive Strength}

Compressive strength is a significant characteristic and parameter for designing concrete structures. As table 2.4 shows, compressive strength of UHP-FRC ranges from 150 to $200 \mathrm{MPa}$. In figure 2.3, UHP-FRC shows a linear elastic behavior during the ascending branch (region I) of the stress-strain curve. Region II is due to multiple micro-cracking and region III corresponds to the single failure crack opening and is generally under the control of fiber pulling out stage [26]. 


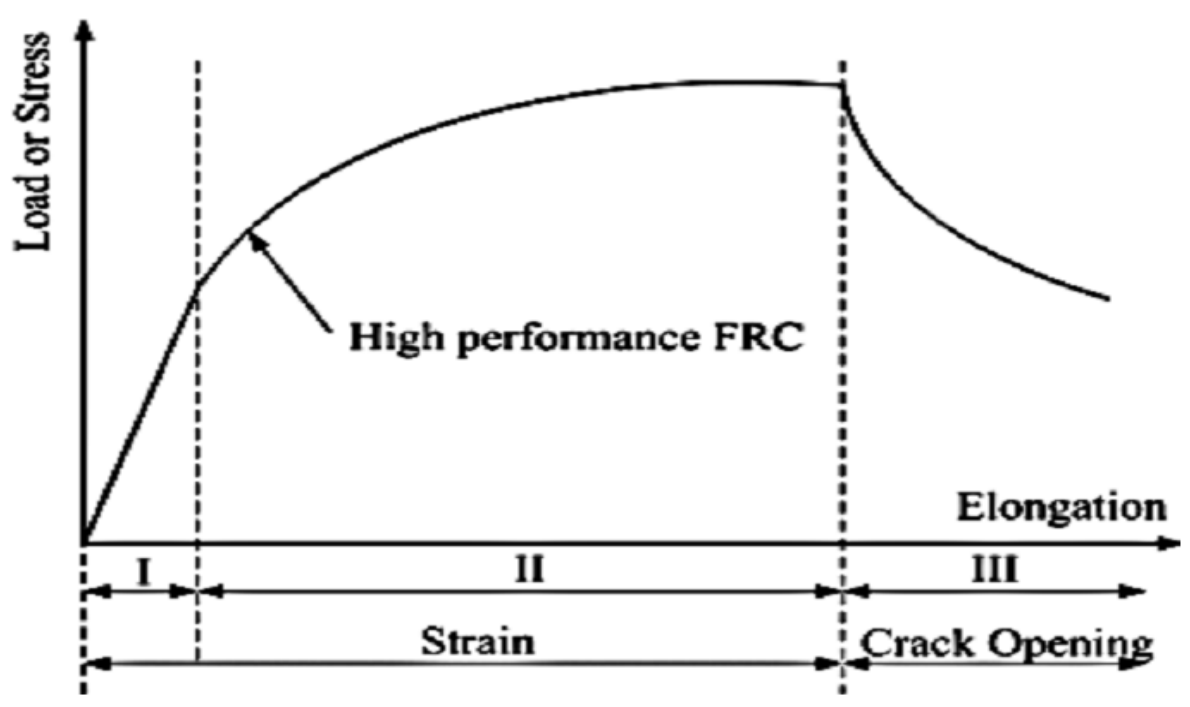

Figure 2.3: Stress-strain curve for UHP-FRC [26].

Despite UHPC, UHP-FRC has a ductile behavior at failure and a descending branch is generated due to the influence of fibers. Although fibers do not have much effect on compressive strength of UHP-FRC, researchers indicated the enhancement of compressive strength up to $15 \%$ for various fiber contents [27, 28].

\subsubsection{Compressive Strength Test}

Compressive strength test for UHP-FRC can be conducted through one of the following methods:

- ASTM C39 on concrete cylinders

- ASTM C109 on concrete cubes

Since the compressive strength of UHP-FRC is very high, the modified version of ASTM C39 test contains a load rate of $1 \mathrm{MPa} / \mathrm{s}$ [16]. Graybeal et al. reported that $102 \mathrm{~mm}$ diameter cylinders, 76 $\mathrm{mm}$ diameter cylinders, and $100 \mathrm{~mm}$ cubes are acceptable and interchangeable [29]. Furthermore, Graybeal showed that if loading rates range from 0.24 to $1.7 \mathrm{MPa} / \mathrm{s}$ no major effect on mechanical properties of UHP-FRC can be detected [19]. 


\subsubsection{Indirect Tensile Strength Test (Splitting Test or Brazilian Test)}

The tensile strength of UHPC is between 7 and $15 \mathrm{MPa}$ [27]. Due to the presence of fibers in UHPFRC, tensile strength is higher than that of UHPC. Also, as previously mentioned, UHP-FRC is more ductile and tensile strength can be continued after cracking. However, researchers normally report the strength at first crack (see Figure 2.4) [16, 27].
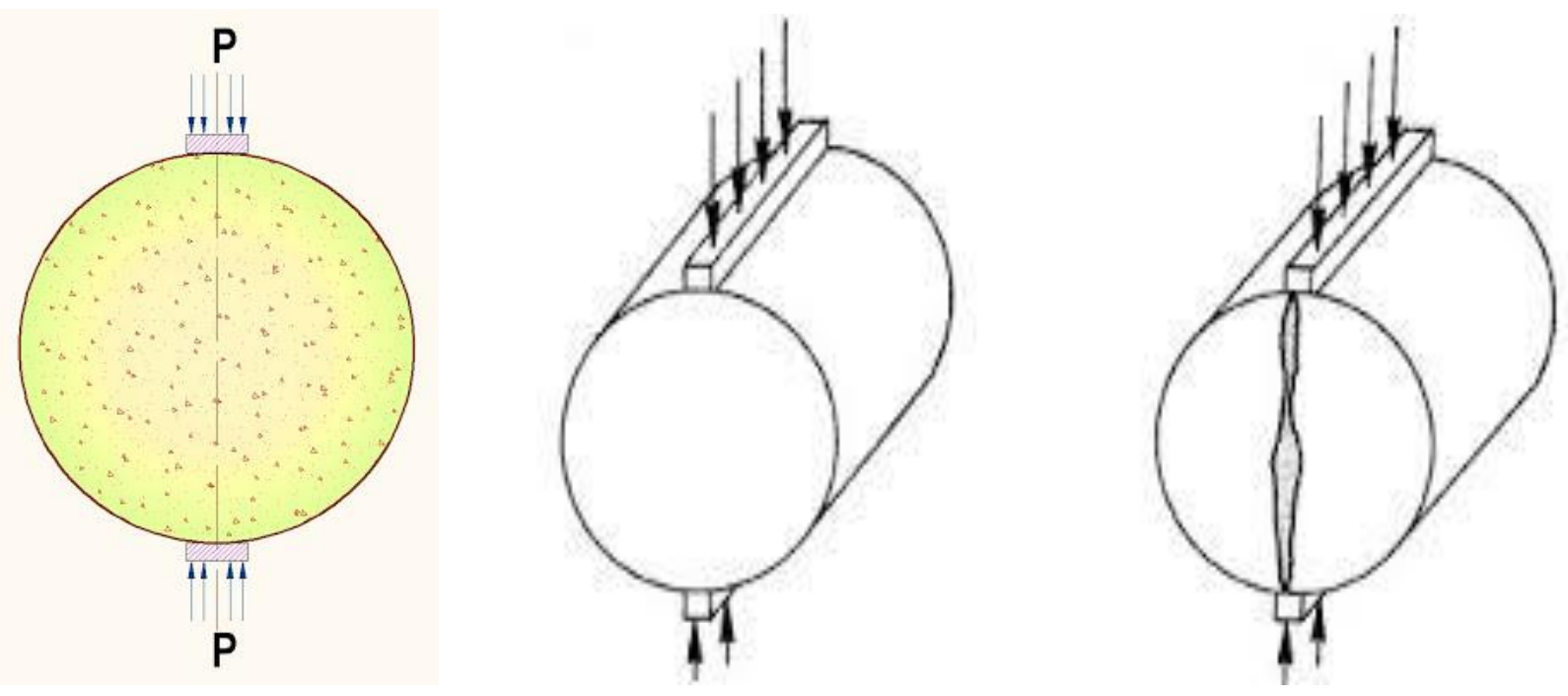

Figure 2.4: Indirect tensile test (Brazilian test or splitting test) [31, 32].

\subsubsection{Modulus of Rupture ( $\left.f_{r}\right)$ Test}

Standard test method for flexural strength of concrete using simple beam with center point loading (ASTM C293) and standard test method for splitting tensile strength of cylindrical concrete specimens (ASTM C496) may be used to assess the first cracking strength of UHP-FRC. However, due to the presence of the strain hardening stage in UHP-FRC, they may not be suitable for evaluating the post cracking phase and overestimate the tensile strength $[16,19]$. Through the modification of ASTM C496 testing method, the splitting tensile strength can be obtained from the first crack load [30]. Although there are various methods for measuring tensile strength of UHP-FRC, only flexural prisms and split cylinders were conducted here. However, direct tension test has been done previously. 


\subsubsection{Modulus of Elasticity $\left(\mathbf{E}_{c}\right)$}

UHP-FRC has a modulus of elasticity higher than that of NC or HSC. This is due to particle packing in UHP-FRC that causes a denser structural material [27]. There is no need for any modification to ASTM C496 testing method in order to obtain static modulus of elasticity [16].

\subsection{Dynamic Properties of UHP-FRC}

The influence of strain rate on UHP-FRC subjected to both, compressive and tensile forces is discussed in this section. The discussion here is focused on the effect of strain rate on mechanical properties of UHP-FRC considering the related experimental technique.

\subsubsection{Strain Rate Response of Concrete}

The dynamic behavior of concrete materials is strain-rate dependent [37]. Concrete exhibits higher strength, higher strain and higher fracture energy when subjected to higher loading rates [38]. Concrete structures that resist high dynamic and impact loading such as, nuclear power plants could be influenced by high strain rates generated by various sources [36]. Different strain rates related to different loading conditions are shown in Figure 2.5.

Generally, researchers study the influences of various loading rates on mechanical properties of UHP-FRC under compressive, tensile, and flexural loading conditions [36]. In this study, the effects of different strain rates on the strength of UHP-FRC $\left(3 \times 10^{-5}\right.$ and $3 \times 10^{-4} \mathrm{~s}^{-1}$ as quasi-static strain rates for compressive strength test, and $3 \times 10^{-3}, 1 \times 10^{-2}, 3 \times 10^{-2}$, and $1 \times 10^{-1} \mathrm{~s}^{-1}$ as dynamic strain rates for compressive strength test, and $1 \times 10^{-6} \mathrm{~s}^{-1}$ as quasi-static strain rate for flexural strength test, and $1 \times 10^{-5}$ and $1 \times 10^{-4} \mathrm{~s}^{-1}$ as low speed strain rates for flexural strength test), as well as the available experimental tests for determining the strengths are described. 
Blasts

Earthquake and induced shocks

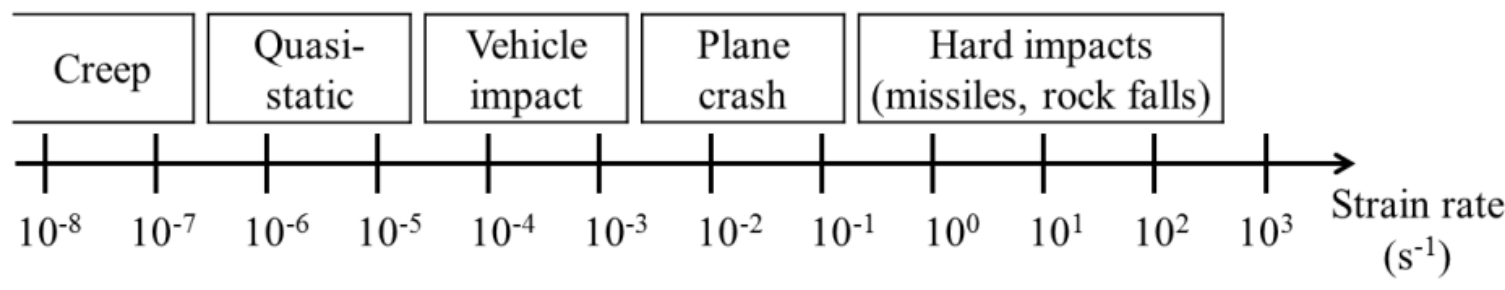

Figure 2.5: Strain rates regime [36].

\subsubsection{Strain Rate Effects on the Strength of Concrete}

Dynamics of structures is necessary to fully understand concrete behavior under different ranges of strain rates, in order to properly design the concrete structures especially those that are subjected to loadings that generate high or very high strain rates. The strain rate effects on the strength of concrete is shown below.

\subsubsection{Dynamic Increase Factor (DIF)}

Dynamic Increase Factor (DIF) describes the relative strength improvement. Generally, the influence of strain rate on the compressive and tensile strengths of concrete is reported as DIF. In other words, DIF is the ratio of dynamic-to-static strength versus strain rate on a semi-log or log$\log$ scale.

$\mathrm{DIF}=\mathrm{f}_{\mathrm{cd}}{ }^{\prime} / \mathrm{f}_{\mathrm{cs}}{ }^{\prime}$

Usually, DIFs for compressive and tensile strengths subjected to high rates of loading are reported by the Comité Euro-International du Béton (CEB) Model Code in accordance with test results and analytical models. This model is the most comprehensive model for strain rate enhancement of concrete in compression and tension [39]. 
In compression, DIF of the compressive strength is shown as:

$\mathrm{DIF}=\mathrm{f}_{\mathrm{cd}} / \mathrm{f}_{\mathrm{cs}}=\left(\dot{\varepsilon} / \dot{\varepsilon}_{\mathrm{s}}\right)^{1.026 \alpha} \quad$ for $\dot{\varepsilon} \leq 30 \mathrm{~s}^{-1}$

$\mathrm{DIF}=\mathrm{f}_{\mathrm{cd}} / \mathrm{f}_{\mathrm{cs}}=\gamma\left(\dot{\varepsilon} / \dot{\varepsilon}_{\mathrm{s}}\right)^{1 / 3} \quad$ for $\dot{\varepsilon} \geq 30 \mathrm{~s}^{-1}$

Where,

$\mathrm{f}_{\mathrm{cd}}=$ dynamic compressive strength at $\dot{\varepsilon}$

$\mathrm{f}_{\mathrm{cs}} \quad=$ static compressive strength at $\dot{\varepsilon}_{\mathrm{s}}$

$\mathrm{f}_{\mathrm{cd}} / \mathrm{f}_{\mathrm{cs}}=$ compressive strength dynamic increase factor

$\dot{\varepsilon}=$ strain rate in the range of $3 \times 10^{-6}$ to $300 \mathrm{~s}^{-1}$

$\dot{\varepsilon}_{\mathrm{s}}=3 \times 10^{-6} \mathrm{~s}^{-1}$ (static strain rate)

$\log \gamma=6.156 \alpha-2$

$\alpha \quad=1 /\left(5+9 \mathrm{f}_{\mathrm{cs}} / \mathrm{f}^{\prime}{ }_{\mathrm{co}}\right)$

$\mathrm{f}^{\prime}{ }^{\prime}$ o $=10 \mathrm{MPa}$

In tension, DIF of the tensile strength is shown as:

$\mathrm{f}_{\mathrm{t}} / \mathrm{f}_{\mathrm{ts}}=\left(\dot{\varepsilon} / \dot{\varepsilon}_{\mathrm{s}}\right)^{1.016 \delta} \quad$ for $\dot{\varepsilon} \leq 30 \mathrm{~s}^{-1}$

$\dot{\varepsilon}_{\mathrm{s}}=\beta\left(\dot{\varepsilon} / \dot{\varepsilon}_{\mathrm{s}}\right)^{1 / 3} \quad$ for $\dot{\varepsilon} \geq 30 \mathrm{~s}^{-1}$

Where,

$\mathrm{f}_{\mathrm{t}}=$ dynamic tensile strength at $\dot{\varepsilon}$

$\mathrm{f}_{\mathrm{ts}} \quad=$ static tensile strength at $\dot{\varepsilon}_{\mathrm{s}}$

$\mathrm{f}_{\mathrm{t}} / \mathrm{f}_{\mathrm{ts}}=$ tensile strength dynamic increase factor

$\dot{\varepsilon}=$ strain rate in the range of $3 \times 10^{-6}$ to $300 \mathrm{~s} \mathrm{~s}^{-1}$

$\dot{\varepsilon}_{\mathrm{s}}=3 \times 10^{-6} \mathrm{~s}^{-1}$ (static strain rate)

$\log \beta=7.11 \delta-2.33$

$\delta=1 /\left(10+6 \mathrm{f}_{\mathrm{c}}{ }^{\prime} / \mathrm{f}^{\prime}{ }_{\mathrm{co}}\right)$

$\mathrm{f}^{\prime}{ }_{\text {co }}=10 \mathrm{MPa}$ 
The CEB expression is valid up to $300 \mathrm{~s}^{-1}$, where the DIF is 3.9 for $30 \mathrm{MPa}$ concrete which is much higher than the compression DIF at the same strain rate.

\subsubsection{Strain Rate Properties of Concrete in Compression}

Research on the dynamic behavior of concrete in compression have been performed by many researchers. These studies have demonstrated that the measured dynamic compressive strength is a function of strain rate $[40,41]$. Generally, hydraulic testing machines are used to conduct static loading of concrete in compression at a strain rate close to $10^{-5} \mathrm{~s}^{-1}$. These machines may also be used to conduct loading at high strain rate about $10^{-1} \mathrm{~s}^{-1}$. When using hydraulic testing machines at high strain rates, displacement control is suggested to achieve a stable failure [42].

Furthermore, particular attention should be drawn to the existing conditions during applying the dynamic loads. These may include characteristics of the machine, influence of stress-wave propagation, consistency of stress and strain over the specimen length, specimen geometry, strain-rate variation, and frequency response of the system. Moreover, the poorer the concrete, the larger increase in compressive strength under high strain rate loading [42].

\subsubsection{Strain Rate Properties of Concrete in Tension}

Although many researchers have studied the dynamic compression behavior of concrete, there are few studies on tensile behavior of concrete. This is due to the difficulties of conducting tests for measuring the dynamic response of concrete in tension. Test results have shown that here also the tensile strength of concrete increases with the increase in strain rate $[43,44,45]$.

The CEB model express that the log DIF versus log $\dot{\varepsilon}$ relation is bilinear with a slope change about

$30 \mathrm{~s}^{-1}$. However, Leppanen reported the turning point to be at $1 \mathrm{~s}^{-1}$ [45]. Some researchers have reported that the turning point is caused by the inertial effects $[46,47]$.

\subsubsection{Comparison of the Strain Rate Responses of Concrete in Compression and Tension}

Figure 2.6 shows the comparison of the results of concrete in vast range of compressive and tensile strain rates. The rate effect is considerably lower in compression than in tension. For strain rates below $10^{-1} \mathrm{~s}^{-1}$ no major differences are observed in the behavior of concrete under tension and 
compression. The significant increase in concrete strength initiates at lower strain rates in tension rather than in compression. In compression, strain rate is about $10^{3} \mathrm{~s}^{-1}$ with (DIF) $\max =3.5$ and in tension for strain rate of $2 \times 10^{2} \mathrm{~s}^{-1} \mathrm{DIF}$ reaches 13.0.

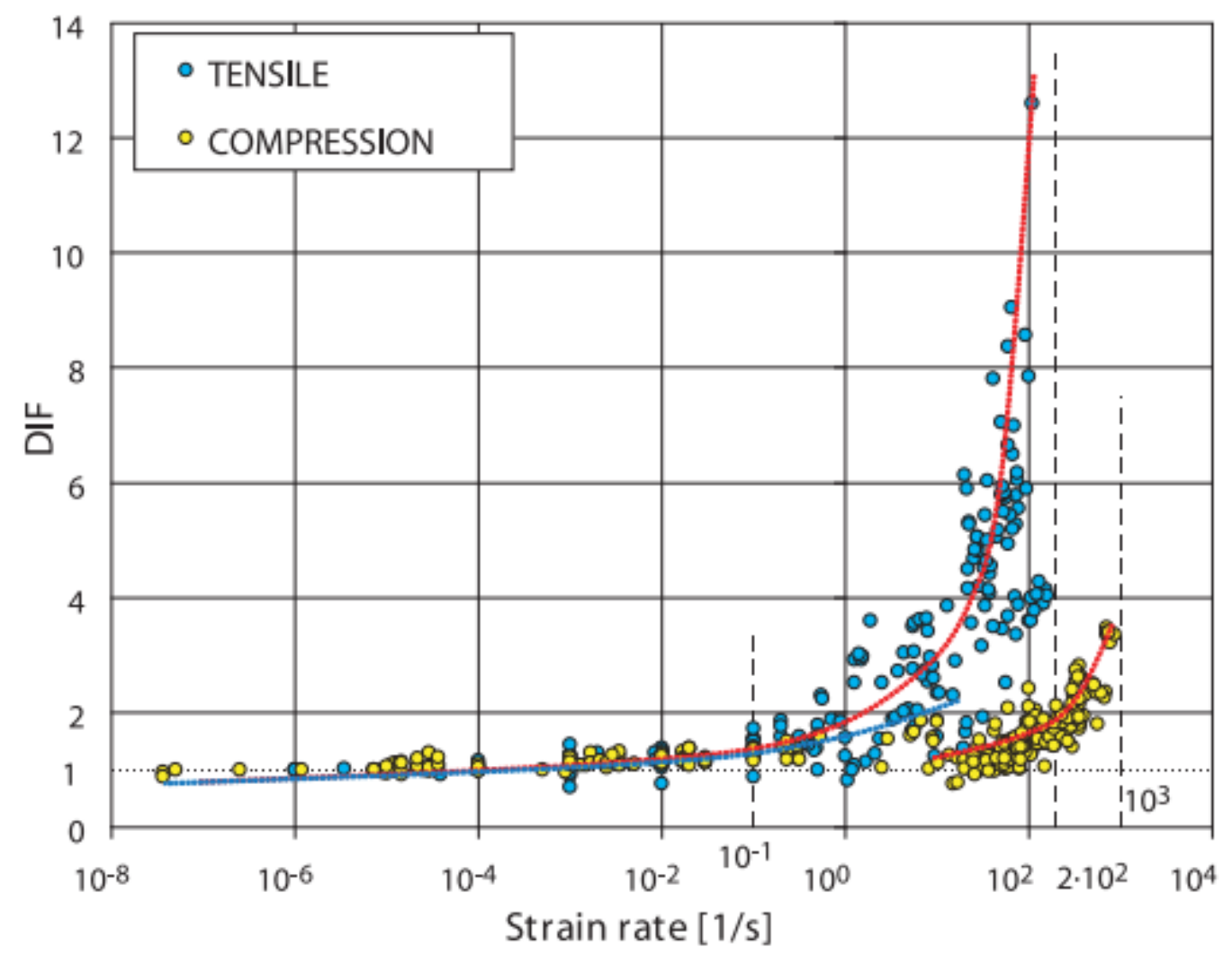

Figure 2.6: Comparison of strain rate effect on tensile and compressive strengths [36].

\subsubsection{Strain Rate Response of UHP-FRC}

The tensile behavior of UHP-FRC made of Ductal premix subjected to various strain rates from $10^{-6}$ to $0.5 / \mathrm{sec}$. has been researched by Fujikake et al [34]. According to the extracted stresselongation relationships in uniaxial tension, they proposed a rate dependent law to express the relation between tensile stress and crack opening. Wille et al. worked and reported on the strain rate dependent tensile behavior of UHP-FRC with three various fiber contents at strain rates from $10^{-4}$ to $10^{-1} \mathrm{~s}^{-1}$. They showed that for a given strain rate, increase in fiber contents led to the increase in both, strength and energy absorption capacity. Very few studies has been conducted on high strain rate behavior of UHP-FRC. Flexural and shear high-speed loading tests of UHP-FRC 
have been conducted by Millard et al. using a drop-hammer testing instrument. They showed that the DIF of the flexural tensile strength increases at the strain rate of $1 \mathrm{~s}^{-1}$ with a slope of $1 / 3$ on a $\log$ (strain rate) versus log (DIF) scale [48].

A series of drop weight tests have been conducted by Habel et al. on UHP-FRC plates subjected to analyze the dynamic behavior of three point bend loading. They showed that strength and fracture energy of UHP-FRC plate under dynamic loading compared to static or quasi static loading were highly increased. Also, the strength of UHP-FRC was increased with increase in strain rate [18]. The impact response of UHP-FRC having a fiber content of $0.75 \%$ and $6 \%$ was studied by Bindiganavile et al. they showed that UHP-FRC with $6 \%$ of steel fibers by volume fraction under quasi static load appeared two to three times stronger in flexure and had three times greater energy absorption compared to those with $0.75 \%$ fiber by volume fraction [9].

Researchers conducted a series of Impact test using Split Hopkinson Pressure Bar (SHPB) in order to verify the behavior of UHP-FRC under very high loading rates such as blast. The results then have been compared to high strength concrete (HSC) and normal strength concrete (NSC). They showed that the strength of UHP-FRC is increased at high strain rates and UHP-FRC has less sensitivity to strain rate compared to HSC and NSC [50].

\subsection{Testing Methods for Concrete under Variable Strain Rates}

Various experimental tests on concrete subjected to quasi-static loading, as well as high strain rate loading have previously been conducted. The most popular methods are discussed here.

\subsubsection{Testing Methods for Concrete in Tension under Quasi-Static Loading}

There are two testing methods for concrete in tension which is subjected to quasi-static loading:

- Direct tension test

- Indirect tensile strength test (splitting test or Brazilian test)

\subsubsection{Direct Tension Test}

Despite bending or compression test, no standard can be found for direct tensile test on concrete, 
even under quasi-static loading. This is due to the difficulties of controlling the applied stress in the case of direct uniaxial tension test [51]. To overcome the issue, various tests were conducted by different researchers on concrete with different specimen shapes and various boundary conditions subjected to tension. Table 2.5 shows the different setups for direct tension test. Each setup may have advantages or disadvantages. A standard specimen and test setup is necessary for comparing the tensile responses of concrete subjected to static or dynamic loads at different strain rates. In this study, direct tension test has not been conducted.

Table 2.5: Direct tension test setups [52].

\begin{tabular}{|c|c|c|c|c|c|c|c|c|}
\hline \multirow{2}{*}{$\begin{array}{c}\text { Shape } \\
\text { dogbone / dumbbell }\end{array}$} & \multirow{2}{*}{$\begin{array}{c}\text { Material } \\
\text { - }\end{array}$} & \multirow{2}{*}{$\begin{array}{c}\text { Level } \\
-\end{array}$} & \multicolumn{3}{|c|}{$\begin{array}{c}\text { Constant Area } \\
\text { (Total Specimen) }\end{array}$} & \multirow[t]{2}{*}{$\begin{array}{l}\text { Diff. } \\
\text { Area }\end{array}$} & \multirow[t]{2}{*}{ Grip } & \multirow[t]{2}{*}{$\begin{array}{l}\text { DOF } \\
\text { top- } \\
\text { bottom }\end{array}$} \\
\hline & & & $\mathrm{L}$ & W & D & & & \\
\hline & UHP-FRC & 4 & $\begin{array}{c}80 \\
(330)\end{array}$ & $\begin{array}{c}30 \\
(60)\end{array}$ & $\begin{array}{c}13 \\
(13)\end{array}$ & $50 \%$ & fixed & $0-0$ \\
\hline & HPFRCC & 4 & $\begin{array}{c}152 \\
(457)\end{array}$ & $\begin{array}{c}38 \\
(76)\end{array}$ & $\begin{array}{c}76 \\
(76)\end{array}$ & $50 \%$ & $\begin{array}{c}\text { self- } \\
\text { clamping } \\
\text { friction grip }\end{array}$ & $1-1$ \\
\hline & HPFRCC & 3 & $\begin{array}{l}150 \\
(200)\end{array}$ & $\begin{array}{c}25 \\
(40)\end{array}$ & $\begin{array}{c}25 \\
(25)\end{array}$ & $63 \%$ & $\begin{array}{c}\text { anchored/ } \\
\text { pinned }\end{array}$ & $1-1$ \\
\hline & HPFRCC & 3 & $\begin{array}{l}200 \\
(525)\end{array}$ & $\begin{array}{c}50 \\
(125)\end{array}$ & $\begin{array}{c}13 \\
(13)\end{array}$ & $40 \%$ & $\begin{array}{c}\text { anchored/ } \\
\text { pinned }\end{array}$ & $1-1$ \\
\hline & UHP-FRC & $3-4$ & $\begin{array}{c}178 \\
(525)\end{array}$ & $\begin{array}{c}51 \\
(125)\end{array}$ & $\begin{array}{l}25 \\
(25)\end{array}$ & $41 \%$ & $\begin{array}{l}\text { anchored/ } \\
\text { pinned }\end{array}$ & $1-1$ \\
\hline & UHP-FRC & $3-4$ & $\begin{array}{c}200 \\
(750)\end{array}$ & $\begin{array}{c}100 \\
(300)\end{array}$ & $\begin{array}{c}50 \\
(50)\end{array}$ & $33 \%$ & $\begin{array}{l}\text { top glued/ } \\
\text { anchored }\end{array}$ & $0-0$ \\
\hline & UHP-FRC & 3 & $\begin{array}{c}250 \\
(740)\end{array}$ & $\begin{array}{l}100 \\
(200)\end{array}$ & $\begin{array}{l}35 \\
(35)\end{array}$ & $50 \%$ & $\begin{array}{l}\text { side glued/ } \\
\text { pinned }\end{array}$ & $1-1$ \\
\hline & UHP-FRC & 3 & $\begin{array}{c}200 \\
(700)\end{array}$ & $\begin{array}{l}160 \\
(200)\end{array}$ & $\begin{array}{c}45 \\
(45)\end{array}$ & $80 \%$ & $\begin{array}{l}\text { side glued + } \\
\text { anchored } \\
\text { (greased) }\end{array}$ & $0-0$ \\
\hline & HPFRCC & $3-4$ & $\begin{array}{c}80 \\
(330)\end{array}$ & $\begin{array}{l}30 \\
(60)\end{array}$ & $\begin{array}{c}13 / 30 \\
(13 / 30)\end{array}$ & $50 \%$ & $\begin{array}{l}\text { clamped/ } \\
\text { fixed/pinned }\end{array}$ & $0 / 2-0 / 2$ \\
\hline & $\begin{array}{l}\text { Plain } \\
\text { Concrete }\end{array}$ & 0 & $\begin{array}{l}200 \\
(400)\end{array}$ & $\begin{array}{c}60 \\
(100)\end{array}$ & $\begin{array}{l}100 \\
(100)\end{array}$ & $60 \%$ & top glued & $0-0$ \\
\hline & $\begin{array}{l}\text { Plain } \\
\text { Concrete }\end{array}$ & 0 & $\begin{array}{c}0^{\mathrm{b}} \\
(150)^{\mathrm{b}}\end{array}$ & $\begin{array}{c}60 \\
(100)\end{array}$ & $\begin{array}{l}100 \\
(100)\end{array}$ & $60 \%$ & $\begin{array}{l}\text { top glued / } \\
\text { pinned }\end{array}$ & $2-2$ \\
\hline & $\begin{array}{c}\text { Plain } \\
\text { Lightweight } \\
\text { Concrete }\end{array}$ & 0 & $\begin{array}{c}0 \\
(270)\end{array}$ & $\begin{array}{c}80 \\
(100)\end{array}$ & - & $64 \%$ & top glued & $0-0$ \\
\hline
\end{tabular}




\subsubsection{Indirect Tensile Strength Test (Splitting Test or Brazilian Test)}

The Brazilian test or the indirect tension test is a common method of specifying the tensile strength of concrete. This is because the cylinder is a regularly fabricated specimen. Furthermore, the testing procedure is very simple, and has been characterized in standards including, ASTM C496 [53], RILEM CPC6 [54], and UNE 83-806-85 [55]. Usually, a cylinder or disc is subjected to compressive loading over a diagonal plane. The load is applied using strips of cardboard or wood with $15-25 \mathrm{~mm}$ width between the specimen and the instrument, under load control. The test ends at the maximum load. The pick load is used to compute the maximum tensile stress, considering line loads and a uniform distribution of tensile stresses.

The strength resulted from the Brazilian test depends on the diameter of the specimen [56, 57]. However, with the use of a standard diameter as in compression tests, the obtained strength is not a material property but, it is reliable for comparison and design purposes. The traditional indirect tension test is not very appropriate for UHP-FRC. The extended increase in the contact area between the cylinder and the instrument will occur as a result of crushing due to the concentrated loads, as well as the large deformations across the crack [58].

\subsubsection{Testing Methods for High Strain Rate Loading}

Various experimental tests on concrete subjected to high strain rate loading have previously been conducted. The most popular methods are discussed below.

\subsubsection{Split Hopkinson Pressure Bar (SHPB)}

The SHPB is considered as the gold standard for testing materials under dynamic loads. Recent alternatives according to immediate release of strain energy have been introduced. Such methods are explained in this project as well. The SHPB system has been broadly used to determine the dynamic behavior of materials in tension and compression [59, 60, 62, 63]. Figure 2.7 shows a simple configuration of the SHPB system for compression test.

The traditional SHPB poses two restrictions to adopt the system for testing concrete specimens different from other composite materials. First, using specimens with thoroughly different geometry from the ones used in pseudo static testing increases the potential risk of influencing on 
direct comparisons between static and dynamic results by specimen geometry and size. This makes complexity in obtaining the conclusions regarding the effects of high strain rate on concrete response. Second, for conducting a successful testing of concrete in a SHPB under high strain rate, a specific minimum size identified by the size of concrete components is necessary [61].

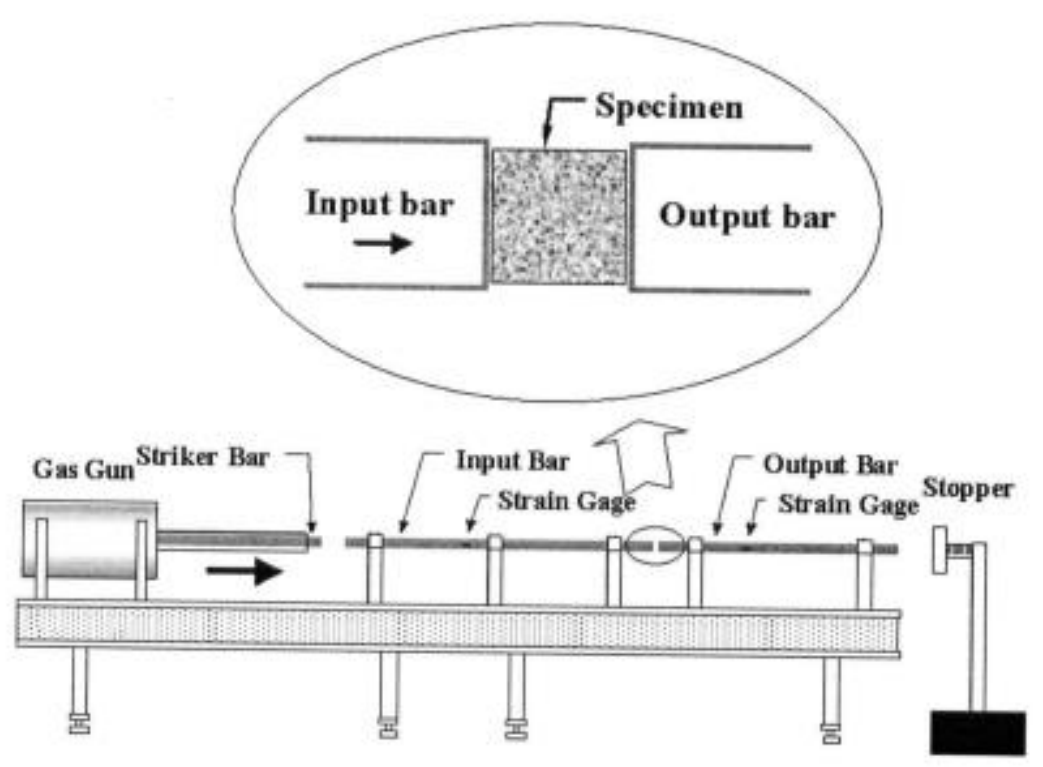

Figure 2.7: Schematic view of the Split Hopkinson Pressure Bar (SHPB) [37].

The restricting component in normal concrete is the aggregate, while for UHP-FRC and cementitious composites, fiber length must also be taken into account. Furthermore, the specimen size must be bigger than the minimum required size to prevent the results from adversely affected by the size effect [64].

Moreover, incident bar, as well as transmitter bar must be at least 20 times longer than the specimen length to prevent signal interference inside the bars. As a result, testing concrete specimens using SHPB, generally requires relatively large specimens. Hence, the SHPB is 
relatively long and the bigger the SHPB, the more expensive it becomes. Figure 2.8 shows a SHPB with $100 \mathrm{~mm}$ diameter for testing concrete specimens under compression.

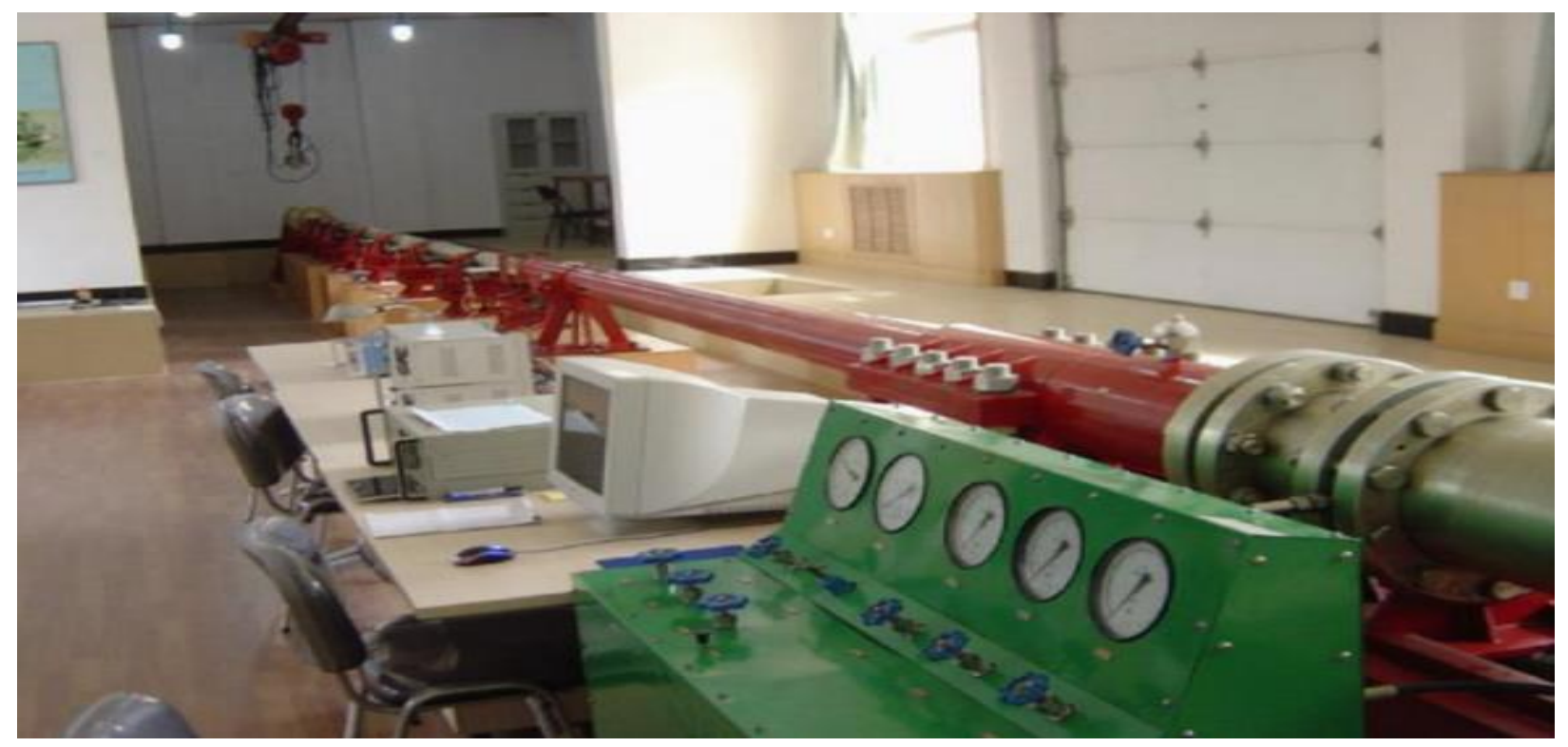

Figure 2.8: SHPB setup for testing concrete specimens under compression [66].

\subsubsection{Tension Testing Using SHPB}

Researchers have tried to modify SHPB setups to typify tensile behavior of different materials under high strain rate loading. These were include, using a weigh bar tube to strike a yoke at the end of the input bar by Harding and Welsh (see Figure 2.9) [63], using a clamp to discharge a stored tensile load by Staab and Gilat [64], using a gas gun chamber connected to the incident bar by Owens and Tippur to generate a tensile wave [67]. Other researchers include, Lindholm and Yeakley [61], Nicholas [62], Li et al. [68], Li and Xu [66], and Song et al [65].

A modified SHPB has been used by Ross to accommodate direct tension test of concrete at high strain rate by employing a hollow cylindrical striker bar sliding on the incident bar [69]. Ross et al. performed dynamic Brazilian test in order to specify failure strength of concrete using the SHPB by entering a cylindrical specimen between the bars with its axis normal to the bars [70].

Brara et al. developed a spalling version of the SHPB for concrete in order to specify the tensile strength at high strain rates up to $120 \mathrm{~s}^{-1}$ [71]. Cadoni et al. carried out dynamic tension tests on concrete by means of a SHPB Bundle with 100 m-long strain energy storing steel cables for a large 
concrete specimen having a square cross section of $200 \times 200 \mathrm{~mm}^{2}$ [72]. They reached a strain rate of $10 \mathrm{~s}^{-1}$.

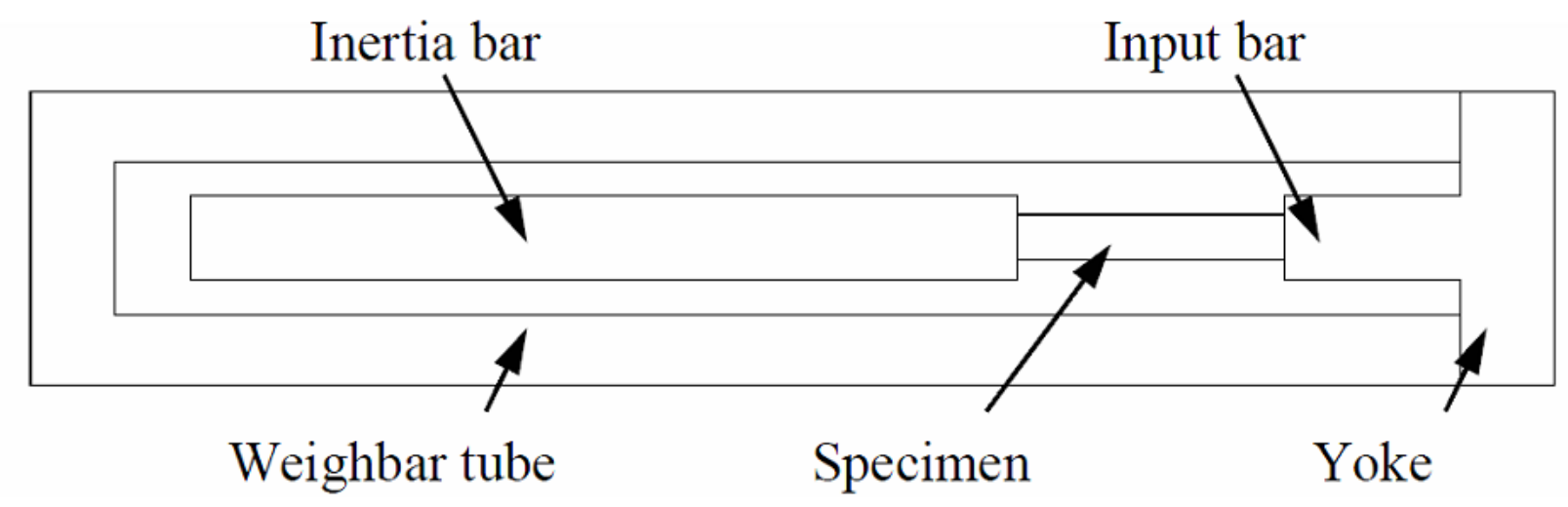

Figure 2.9: Tension setup for SHPB [63].

\subsubsection{Drop Hammer Impact Test}

Impact loadings caused by crashing vehicles, ships, airplanes, falling rocks, avalanches, floating and flying objects due to Tsunami and Tornado are identified by their high intensity and high loading rates and represent severe loading conditions for RC structures. Impact loadings may result in very serious consequences therefore, it is significant that enhance the impact resistance of RC structures.

No standard test is available for verifying the DIF of UHP-FRC under flexural loading. One of the most generally used techniques for testing concrete specimens under high strain rate is drop hammer impact test. A drop hammer impact test is performed to investigate the effect of drop height of the hammer on the impact response of the UHP-FRC beam. The impact test reveals that UHP-FRC beams have excellent impact resistance compared to conventional RC beams $[9,18$, $48,50]$. Various drop hammer setups used at different universities. Some of these techniques are discussed here.

\subsection{RU Drop Hammer Impact Test}

For the investigation of the impact response of UHP-FRC specimens, a drop hammer impact test system developed at Ryerson University in 2014. The test system included, a concrete platform, a 
steel frame, a drop hammer of $38 \mathrm{~kg}$ weight, a circular electric lifting magnet, a crane, two load cells, two accelerometers, and a data acquisition system with a computer.

The 2 meter high steel frame had a load carrying capacity of $500 \mathrm{~kg}$. Two steel HSS sections were attached to the top of the frame to hold the drop hammer weight. The drop hammer was absorbed by a circular electric lifting magnet and a crane lifted the magnet to the desired height. Then, the drop hammer was dropped by releasing the electric lifting magnet. A schematic view of the drop hammer impact test system used at Ryerson University in 2014 is shown in Figure 2.10.

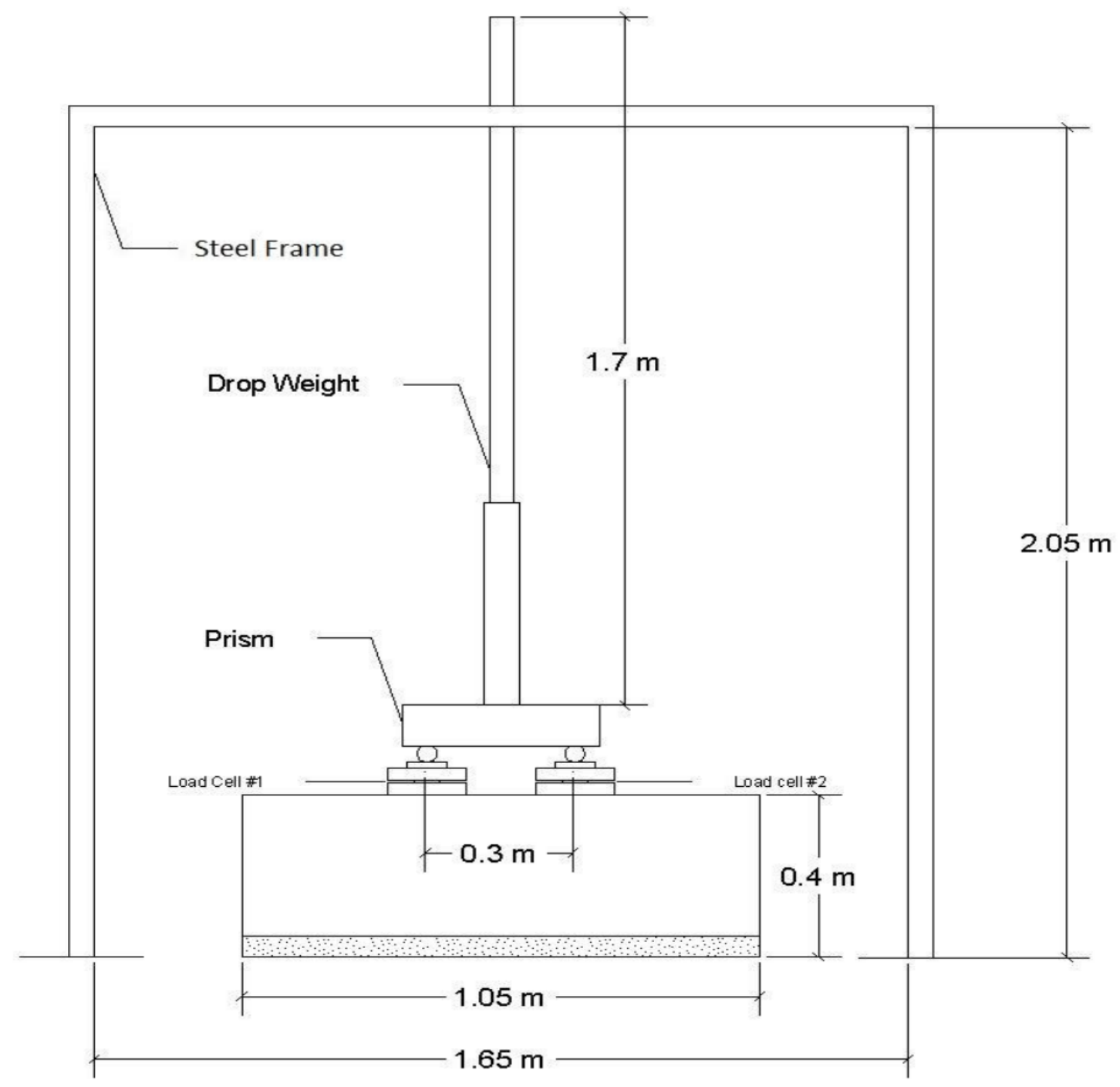

Figure 2.10: Schematic view of the drop hammer impact test system used at Ryerson University in 2014 [75]. 


\subsection{U of T Drop Hammer Impact Test}

A drop hammer impact test has been used by Habel et al. at university of Toronto to investigate the impact response of UHP-FRC [18]. Two drop weights of 10.2 and $20.6 \mathrm{~kg}$ with a fixed drop height of $1050 \mathrm{~mm}$ are used for the purpose of the test. A $20 \mathrm{~mm}$ long plywood with $19 \mathrm{~mm}$ thickness was used as a damper between the weight and the specimen. Several drops were done to achieve the desired fracture. The speed of the drop weight at the moment of impact was calculated using a high speed camera operating at 1000 frames per second. The speed at impact was estimated as $4.2 \mathrm{~m} / \mathrm{s}$ for the $10.3 \mathrm{~kg}$ weight and $4.3 \mathrm{~m} / \mathrm{s}$ for the $20.6 \mathrm{~kg}$ weight. Two accelerometers were attached to the drop weight for specifying the impact force. In addition, two load cells were located underneath the steel rollers for measuring the support reactions. The deflection was evaluated with potentiometers.

Researchers conducted thirteen tests to specify the dynamic behavior of UHPFRC. The maximum strain rate observed in this test was $2 \mathrm{~s}-1$, which was confirmed by data obtained from the strain gauge. peak deflections for the plates impacted with $10.3 \mathrm{~kg}$ weight was between 4.1 and $5.7 \mathrm{~mm}$ and for $20.6 \mathrm{~kg}$ weight was greater than $6.5 \mathrm{~mm} \mathrm{[18].}$

\subsection{RMIT Drop Hammer Impact Test}

Millard et al. used a drop hammer to investigate the dynamic enhancement of impact resistant UHP-FRC. Figure 2.11 shows a basic configuration of the drop hammer at RMIT University. The instrument was made of a $30.1 \mathrm{~kg}$ cylindrical steel hammer with $2 \mathrm{~m}$ long and $51 \mathrm{~mm}$ diameter. The lower end of the hammer was hemispherical. The hammer is led by four bolts and the transmission bar located centrally on top of the specimen to transfer the impact force from hammer. The length of the transmission bar was $500 \mathrm{~mm}$ with $51 \mathrm{~mm}$ diameter.

A $15 \mathrm{~mm}$ fiberboard used on top of the transmission bar in order to damp the force exerted by the drop hammer. Two strain gauges were connected to the bar on the opposite sides in order to measure the strain rates. $25 \mathrm{~mm}$ diameter steel rollers were used as supports for the specimen. Load cells were placed under each support to obtain a set of data from impact test. A $200 \mathrm{~mm}$ thick concrete slab was located on a $30 \mathrm{~mm}$ sand bed to reduce noise at the supports and 
transmission bar. An accelerometer was connected to the concrete slab to record an insight operation of the rig [48].

Drop weight hammer was used for the verification of the flexural strength of UHP-FRC subjected to impact loads. $280 \times 70 \times 70 \mathrm{~mm}$ prisms having a span of $210 \mathrm{~mm}$ were used for flexural test. Three various drop heights of 400, 600 and $1600 \mathrm{~mm}$ were tested. The peak strain rate recorded in the test was $4.01 \mathrm{~s}^{-1}$ for a drop height of $1600 \mathrm{~mm}$ and a DIF of 2.53 [48]. RMIT drop hammer impact test apparatus not only eliminates the need for high speed camera, but also requires a simple setup. These reduce the cost and provide open opportunities for further research in future. The drop hammer impact test apparatus used for this project was extracted from the basic configuration of RMIT drop hammer impact test instrument.

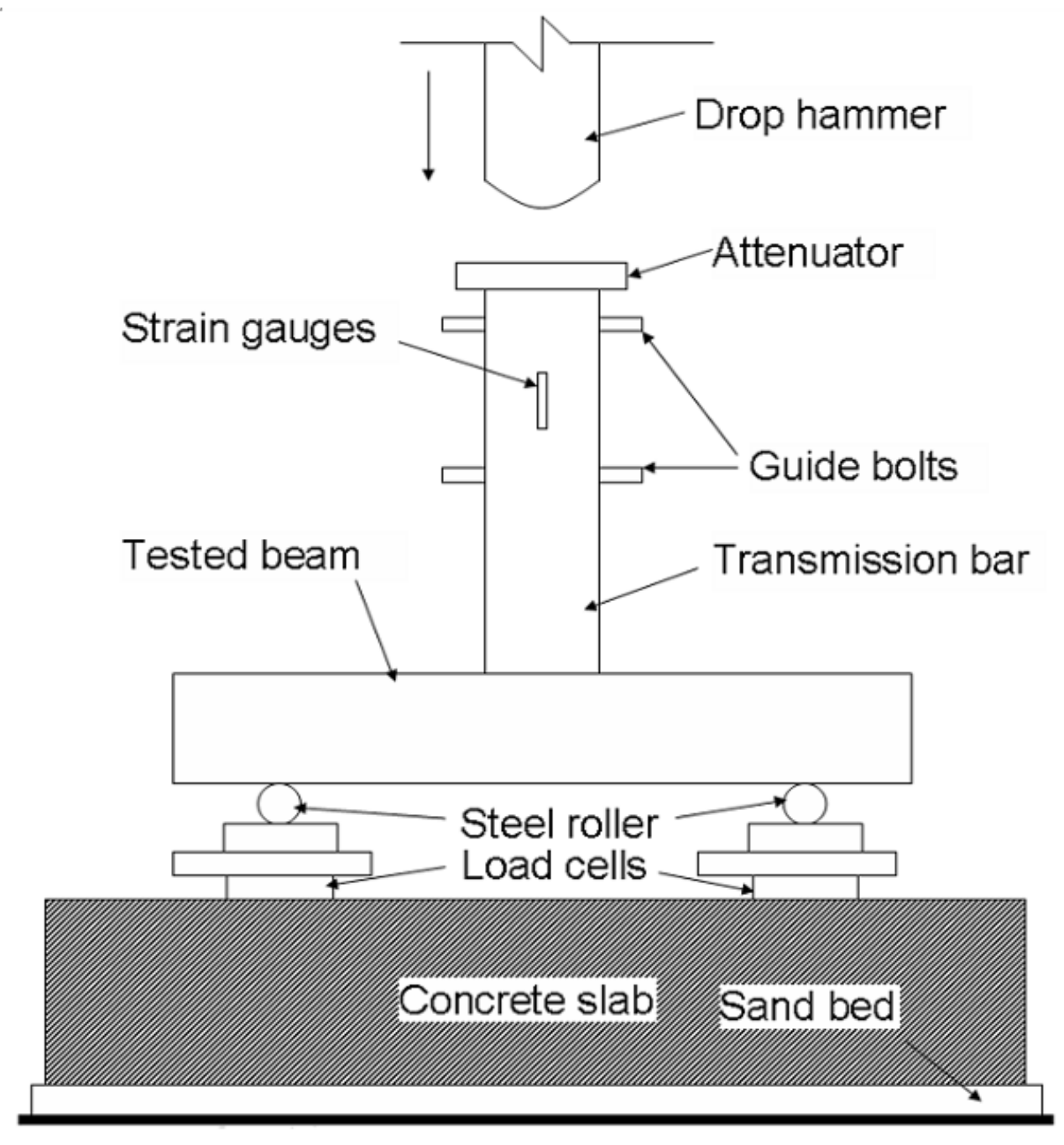

Figure 2.11: Drop hammer impact test apparatus at RMIT University [48]. 


\subsection{The 1kJ Drop Hammer Impact Test}

A drop hammer impact testing machine has been designed and built at University of British Columbia (UBC) [9]. This machine is floor mounted with a RC base. The hoist chain controls the hammer by means of electromagnetic field. The apparatus is capable of dropping a $60 \mathrm{~kg}$ mass from a height of $2.5 \mathrm{~m}$ above the specimen which leads to a maximum possible impact energy of $1 \mathrm{~kJ}$. Bindiganvile et al. conducted impact test with this machine for determining the impact response of UHS-FRCC with up to $6 \%$ steel fiber contents by volume fraction [9]. In this study, researchers tested four drop-heights of 200, 500, 750, and $1000 \mathrm{~mm}$ to verify the impact resistance of materials under a wide range of stress rates. They reported the increase of the maximum loads, as well as the flexural strengths with an increase in the drop height. Also, all specimens showed stiffer response at higher drop heights which indicates an increase in the elastic modulus of the material with an increase in the applied stress rate (see Figures 2.12 and 2.13) [9].

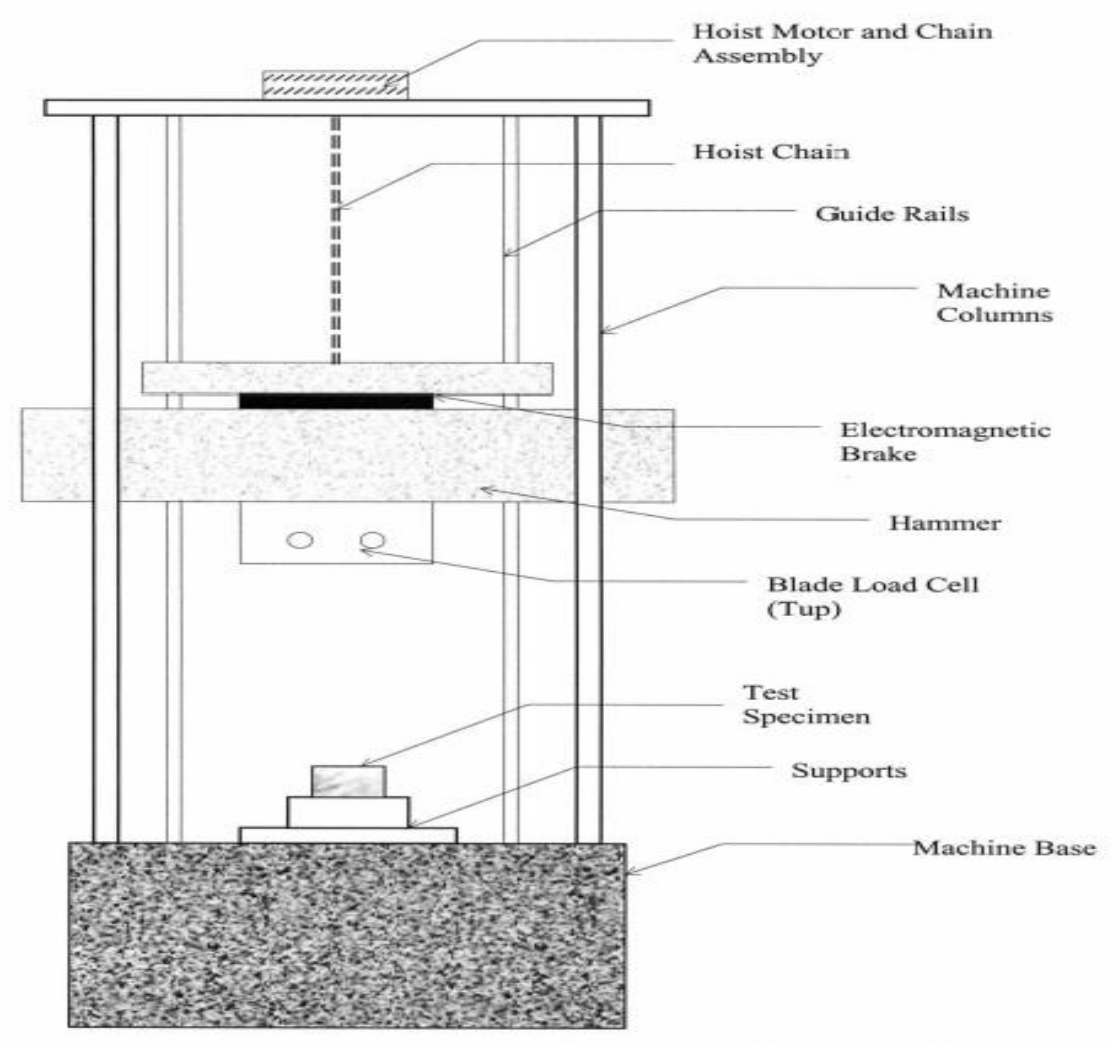

Figure 2.12: Schematic view of the medium impact machine (1,000 J capacity) at UBC [73]. 


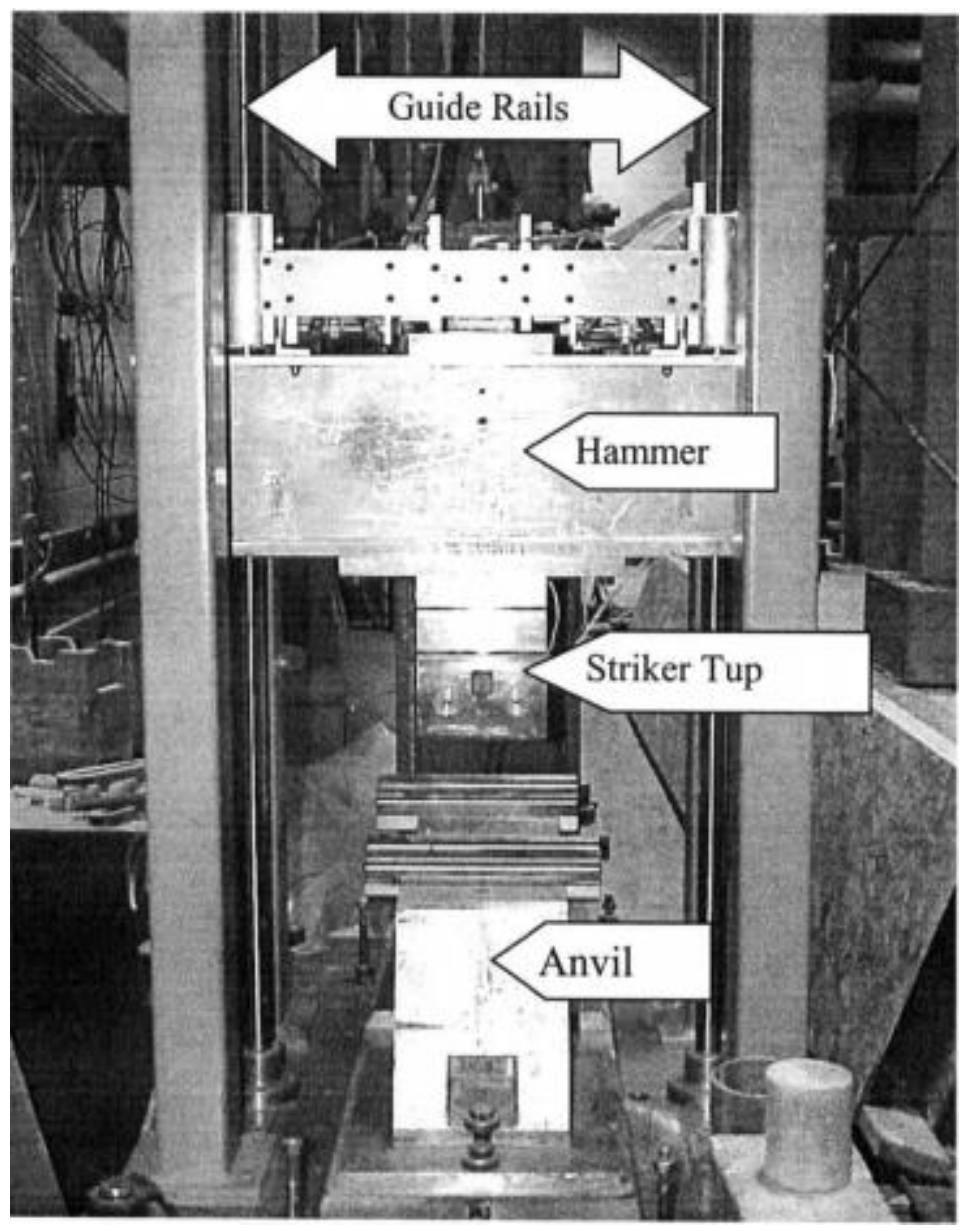

Figure 2.13: Drop-weight impact machine with 1,000 J capacity at UBC [73].

\subsection{Liverpool Drop Hammer Impact Test}

The principles of Liverpool drop hammer and RMIT drop hammer tests are very similar. A lighter $23.3 \mathrm{~kg}$ hammer was used here, which required the maximum drop height of $2 \mathrm{~m}$ to ensure entire failure of each specimen. Also, for Liverpool drop hammer test, the applied impact force was not measured using a transmission bar above the specimen, instead a Laser Doppler Anemometer (LDA) was used. Moreover, a high speed camera was used in this test to assess the specimen displacement against time (see Figure 2.14). 


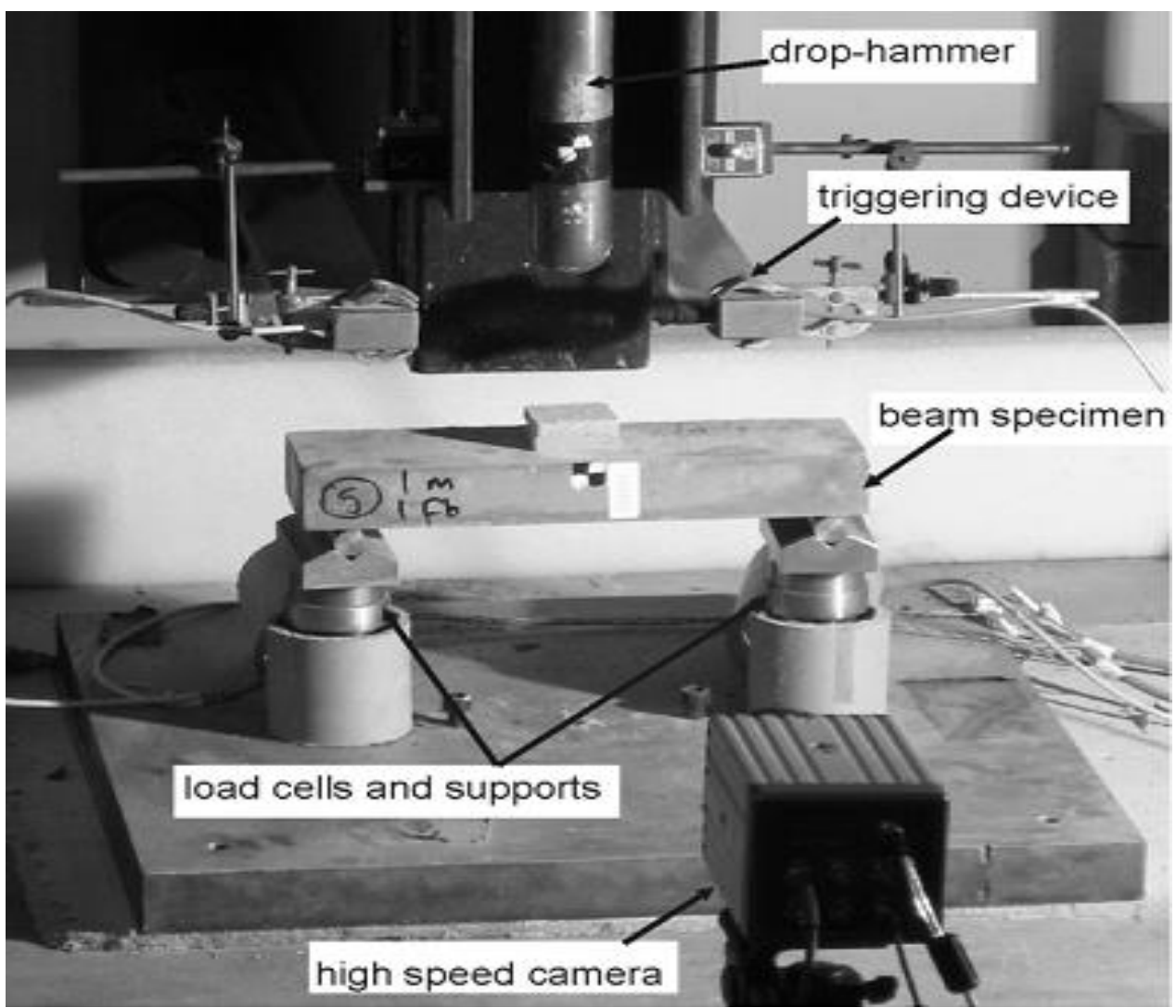

Figure 2.14: Drop hammer impact test machine at University of Liverpool [48].

For the results of this test, strain rate could be obtained either from an applied load along with a measured elastic modulus, or from the measured deflection. The load used to compute the strain rate was the load resulted from the load cells. A maximum flexural tensile strength between 54 and $68 \mathrm{MPa}$ was obtained using $6 \%$ steel fibers by volume fraction. Also, the Maximum strain rate of $1.66 \mathrm{~s}^{-1}$ was achieved [48]. 


\section{Chapter 3}

\section{EXPERIMENTAL PROGRAM}

"Look deep into nature, and then you will understand everything better."

Albert Einstein (1879-1955)

The main purpose of the experimental program for this project is to investigate and enhance the understanding of different strain rate effects on UHP-FRC with different fiber contents. This includes, the response of UHP-FRC to static and dynamic loadings, dynamic properties of UHPFRC, material property characterization of UHP-FRC, development of the mechanical properties of UHP-FRC, and effects of strain rate on compressive and tensile behaviors of UHP-FRC using indirect tension test or Brazilian test, flexural test, and impact test. This chapter covers explanations about mixture proportions, mixing procedure, casting and curing, compressive strength test, indirect tensile test (splitting test or Brazilian test), and flexural strength test. Finally, the development of drop hammer impact testing is thoroughly discussed.

\subsection{Mixture Proportions}

UHP-FRC with three different fiber contents $(1 \%, 2 \%$, and $3 \%$ by volume fraction) has been investigated in this project. Mix proportions for each type of UHP-FRC are discussed in this section.

\subsubsection{UHP-FRC with Steel Fibers at $1 \%$ by Volume fraction}

A sample of the steel fibers used in UHP-FRC has been shown in Figure 3.1. The type of fiber used in this stage was brass coated straight micro steel fiber with a density of $7850 \mathrm{~kg} / \mathrm{m}^{3}$, a length of $14 \mathrm{~mm}$, a diameter of $0.20 \mathrm{~mm}$, and an aspect ratio (L/D) of 70. The cross section of the fiber was circular. The quantity of fiber in the concrete mixture was $1 \%$ of the mixture volume. All dry material was blended first in the mixing machine except for the steel fiber, and then the steel fibers were gradually added to ensure a maximum dispersion. 

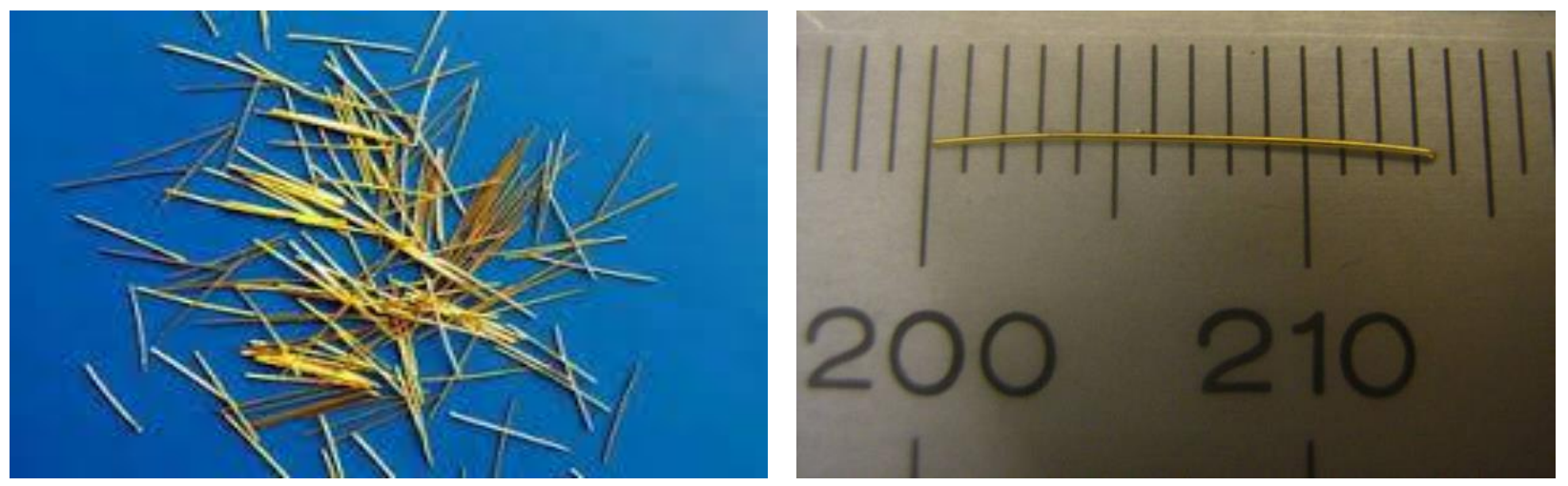

Figure 3.1: Straight micro steel fiber (unit: $\mathrm{mm}$ ).

\subsubsection{UHP-FRC with Steel Fibers at $2 \%$ by Volume fraction}

The fiber used in this stage was brass coated straight micro steel fiber with a density of $7850 \mathrm{~kg} / \mathrm{m}^{3}$, a length of $14 \mathrm{~mm}$, a diameter of $0.20 \mathrm{~mm}$, and an aspect ratio (L/D) of 70. The cross section of the fiber was circular (see Figure 3.1). The quantity of fiber in the concrete mixture was $2 \%$ of the mixture volume. All dry material was blended first in the mixing machine except for the steel fiber, and then the steel fibers were gradually added to ensure a maximum dispersion.

\subsubsection{UHP-FRC with Steel Fibers at $3 \%$ by Volume fraction}

The fiber used in this study was brass coated straight micro steel fiber with a density of 7850 $\mathrm{kg} / \mathrm{m}^{3}$, a length of $14 \mathrm{~mm}$, a diameter of $0.20 \mathrm{~mm}$, and an aspect ratio (L/D) of 70. The cross section of the fiber was circular (see Figure 3.1). The quantity of fiber in the concrete mixture was $3 \%$ of the mixture volume. All dry material was blended first in the mixing machine except for the steel fiber, and then the steel fibers were gradually added to ensure a maximum dispersion. 


\subsection{Mixing Procedure}

Mixing time for UHP-FRC is usually longer than conventional concrete. Since UHP-FRC has more components and finer particles compared to normal strength concrete, all particles should uniformly be distributed within the mixture in order to prevent forming chunk by very fine particles. Therefore, it is suggested that all dry components including cement, silica fume, and sand should be blended before adding water, HRWR, and superplasticizer [14, 16]. Before mixing, constituents were carefully weighted using an accurate digital scale. In this study, Ductal premix was first put into the mixer. After 1 minute, half of the amount of the measured water was added and then half of the amount of superplasticizer was added after water. Fibers were gradually added during the following 5 minutes. Afterward, the second half of the amount of the measured water was added. The rest of the superplasticizer was added after the water and mixing was continued for another 5 minutes. The entire mixing time from adding water was 15 minutes. The Ductal premix used for this study did not include any coarse aggregates. Figure 3.2 shows a UHP-FRC mixer machine.
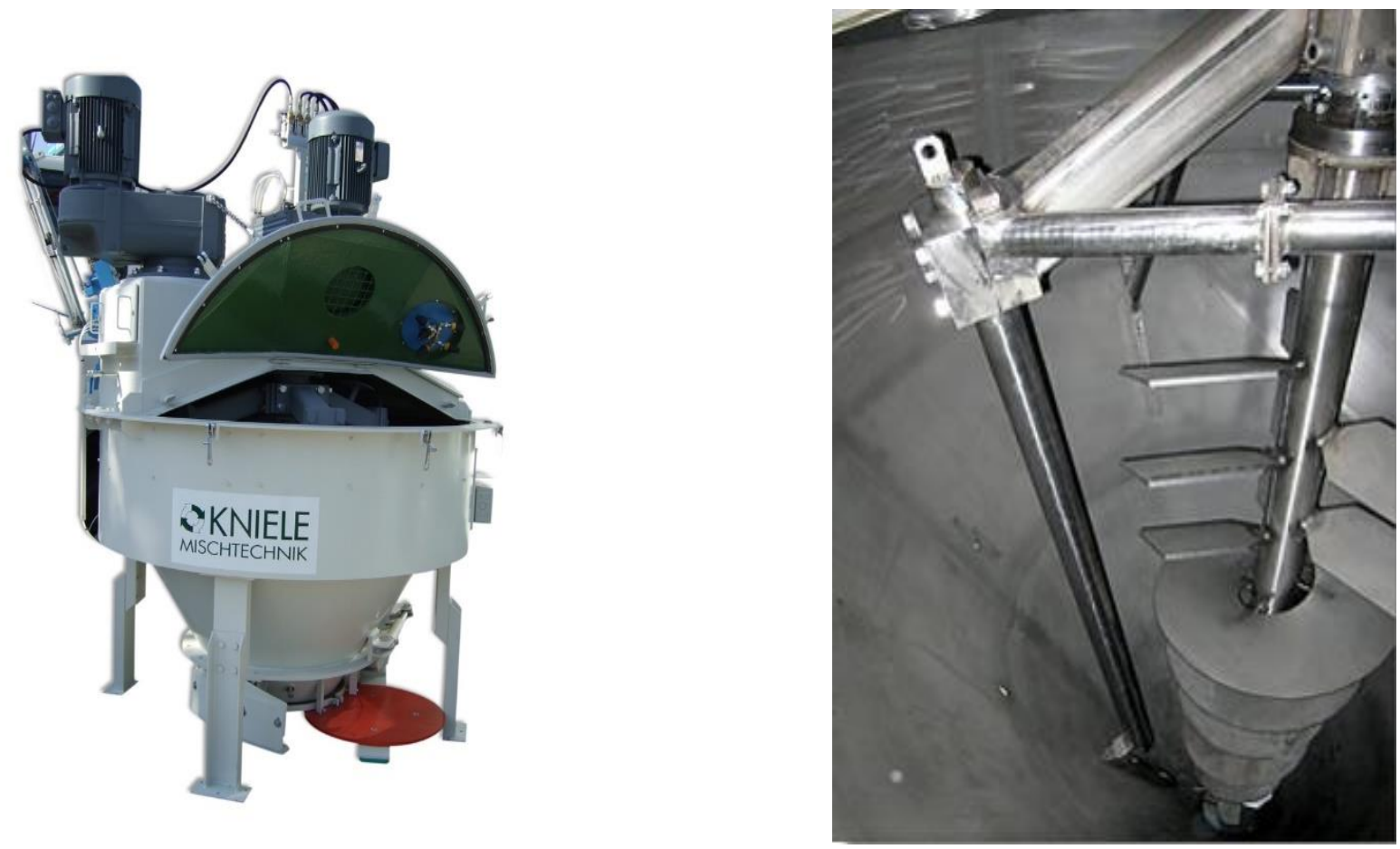

Figure 3.2: UHP-FRC mixer [74]. 
The mixing procedure for this investigation can be summarized as follows:

1. The entire premix was put into the mixing machine and mixed for 1 minute before adding water, HRWR, and superplasticizer.

2. $50 \%$ of the measured water was added to the mix.

3. $50 \%$ of the measured superplasticizer was added to the mix.

4. Straight micro steel fibers were added to the mix during 5 minutes.

5. The rest of the water was added to the mix.

6. The rest of the superplasticizer was added to the mix.

7. Mixing was continued for another 5 minutes.

After 15 minutes from step 2 when the mix became homogenous, a concrete sample was taken from the mix and was tested for flowability. The test was completed immediately after mixing to assess consistency between mixes and appropriateness for casting. The flow test showed the flowability of about $253 \mathrm{~mm}$. Figure 3.3 shows the flow test conducted on UHP-FRC.
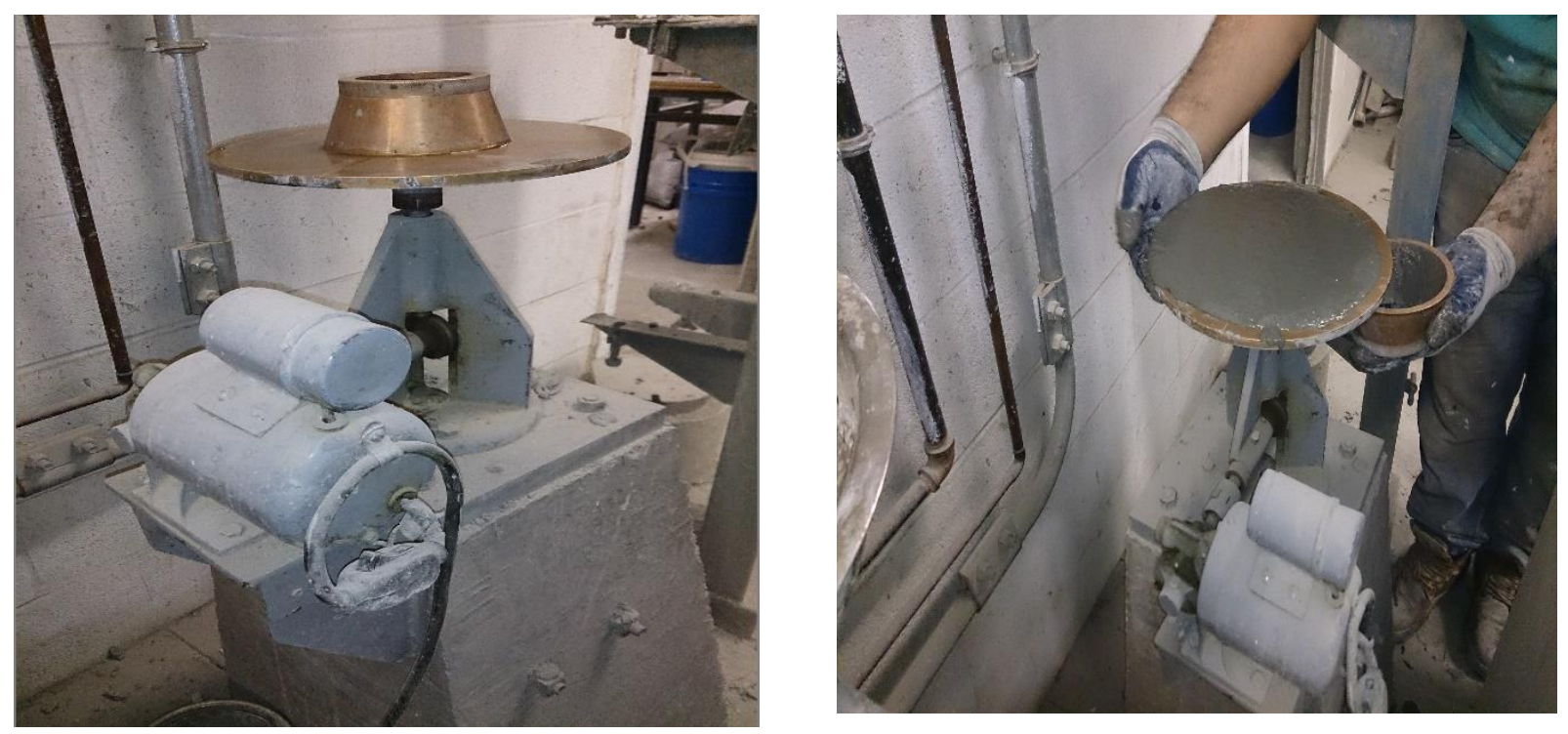

Figure 3.3: Flow test.

\subsection{Casting and Curing}

For prism specimens, wooden molds of $400 \times 100 \times 100 \mathrm{~mm}$ made from plywood have been provided. Plastic molds for cylindrical specimens had $200 \mathrm{~mm}$ length and $100 \mathrm{~mm}$ diameter. For 
the ease of separation, a little bit of lubricant was applied to the internal surface of the molds before casting. Figure 3.4 shows the provided molds before casting.
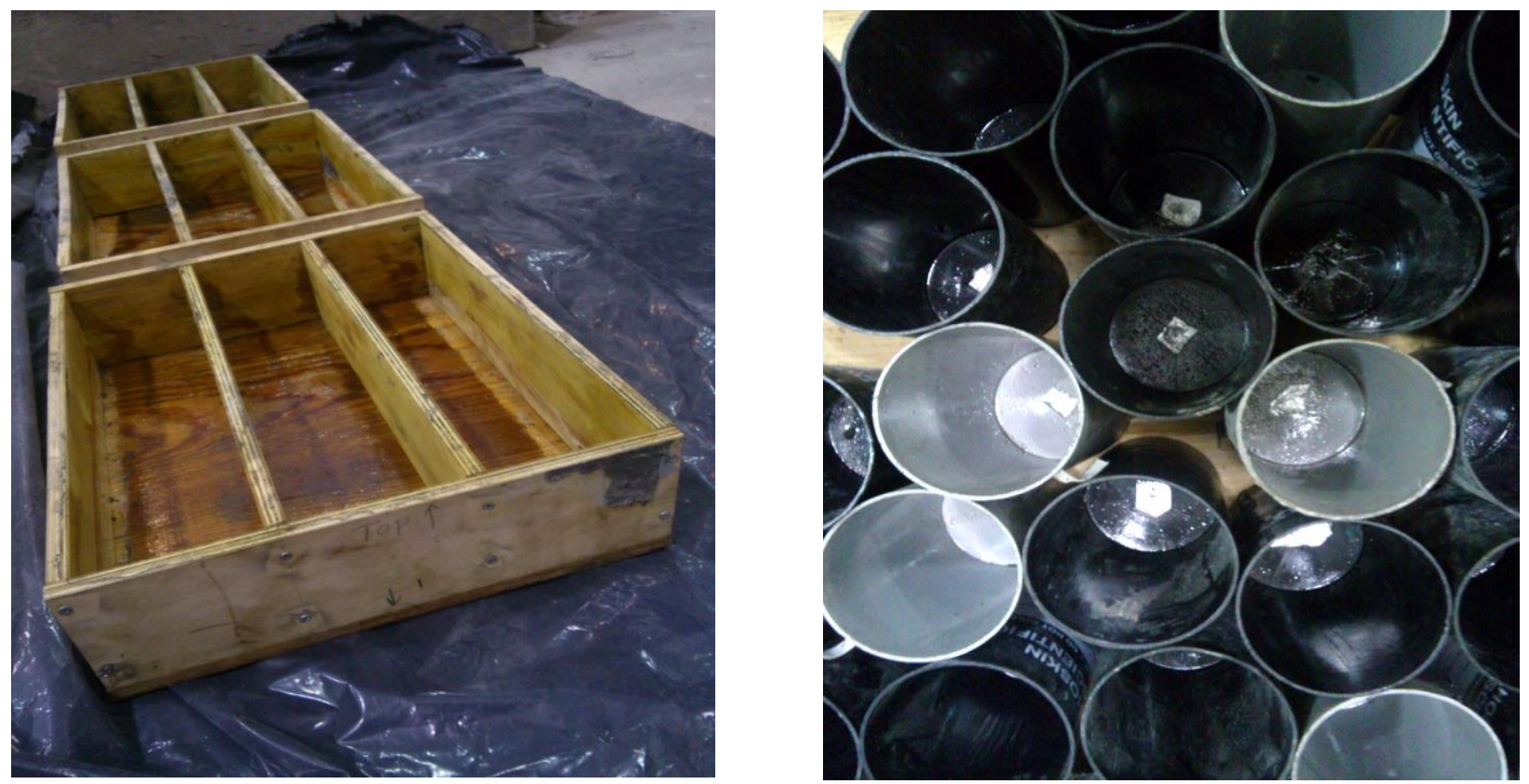

Figure 3.4: Prism and cylinder molds before casting.

Limited vibration was applied by compacting bar to release the entrapped air. During the first three days the specimens were covered with damp burlap and kept wet. The specimens were demolded 72 hours after casting and were grinded at both ends and transferred to the curing room. The specimens were taken out 24 hours before testing. Figure 3.5 shows the specimens in the curing room.
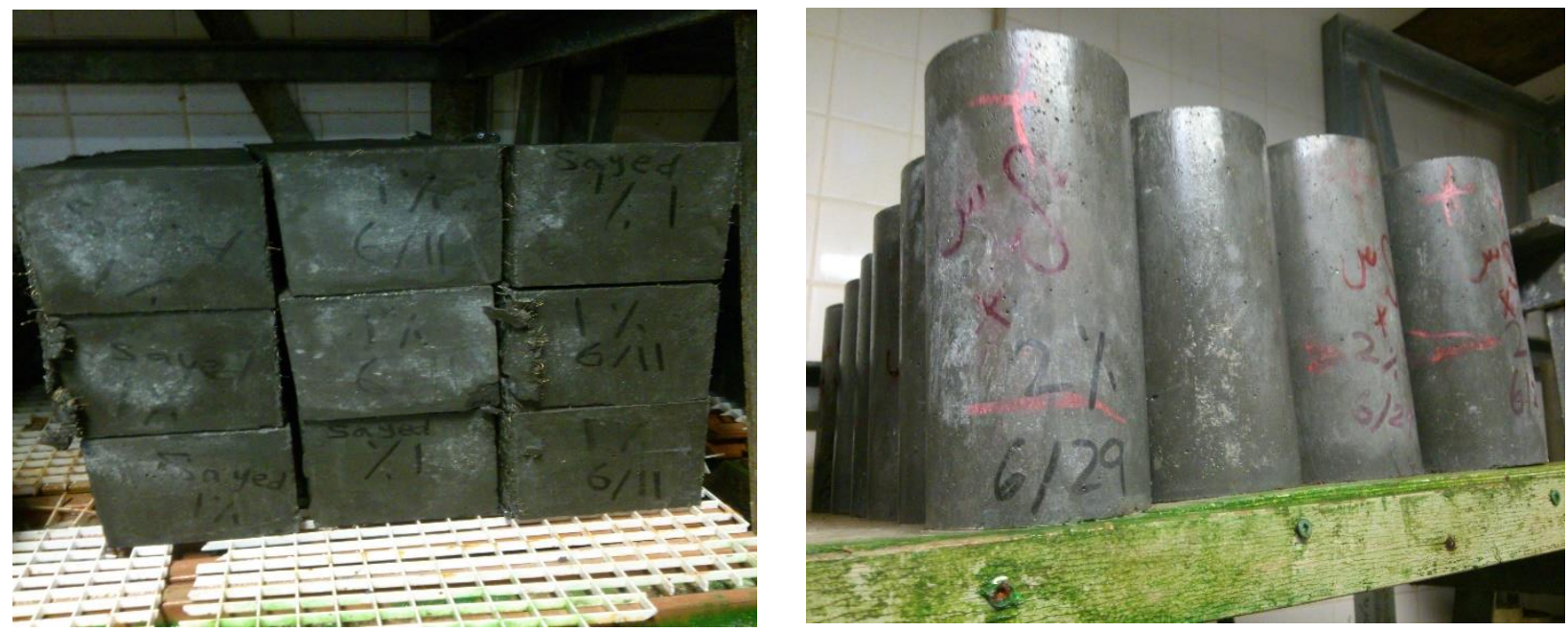

Figure 3.5: Prisms and cylinders in the curing room. 


\subsection{Compressive Strength Test}

The compressive test for UHP-FRC was completed in accordance to the ASTM C39 standard test method for cylinders. Cylindrical specimens had $100 \mathrm{~mm}$ diameter and $200 \mathrm{~mm}$ height and were provided for testing using a concrete cylinder end grinding machine. Figure 3.6 shows the cylindrical specimens in the grinding machine.

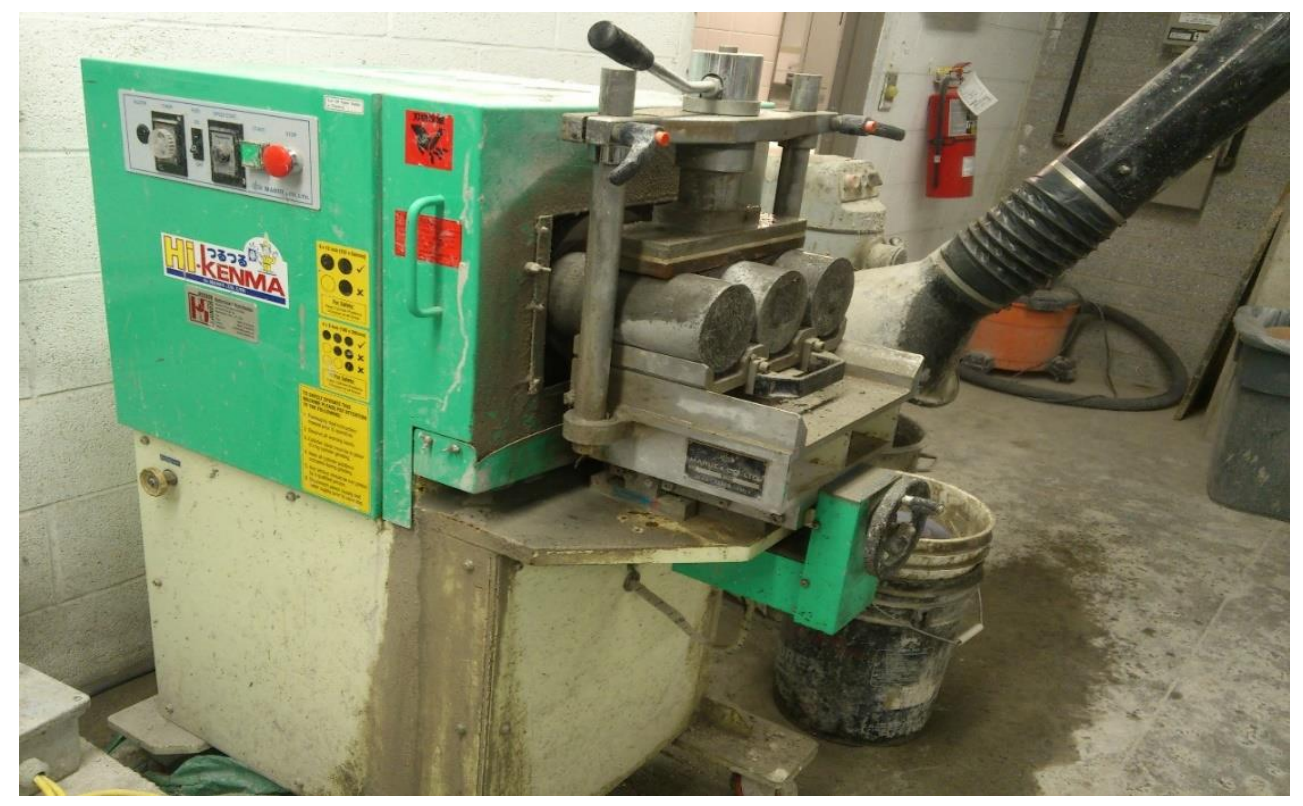

Figure 3.6: Concrete cylinder end grinding machine.

Figure 3.7 shows the cylindrical specimens after grinding.

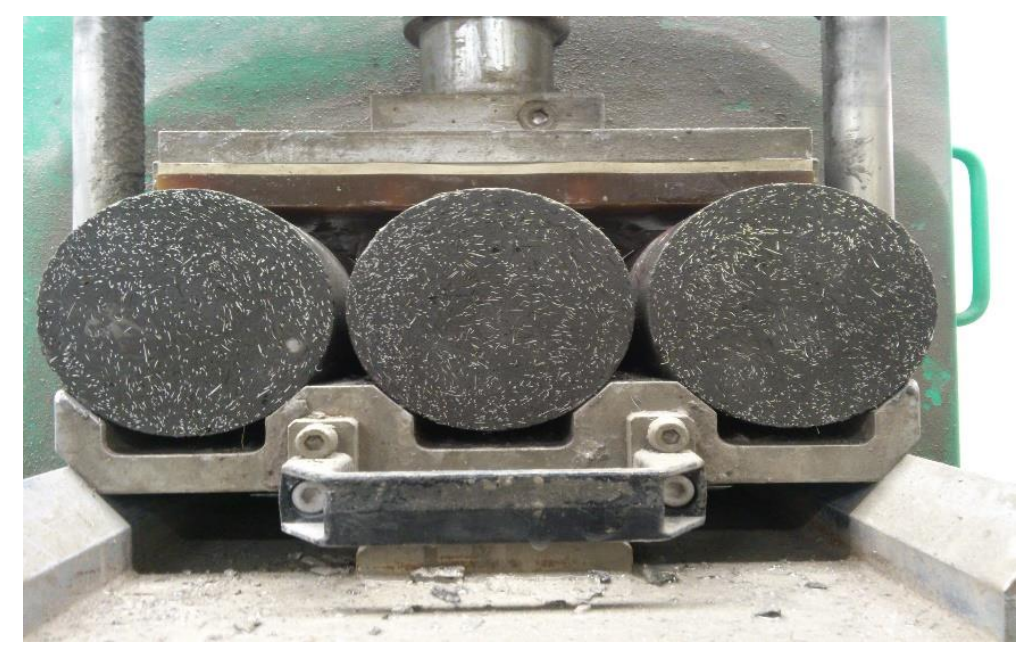

Figure 3.7: Cylinder specimens after grinding. 
The compressive strength of each specimen was recorded after 28 days from casting. The average reading of tested cylindrical specimens with identical fiber content was taken as the compressive strength of UHP-FRC with specific fiber content. The compressive strength test was carried out in MTS 815 Test System. The maximum load was recorded when the specimen could not bear any more loads. Then, compressive strength was calculated using equation (6).

$\mathrm{f}^{\prime}{ }_{\mathrm{c}}=\frac{\operatorname{Load}(P)}{\text { Cross Sectional Area }(A)}$

\subsubsection{Compressive Strength Test under Quasi Static and Dynamic Loading}

Concrete cylinders with $100 \mathrm{~mm}$ diameter and $200 \mathrm{~mm}$ height were used to conduct compressive strength test. Both low and high strain rates were applied to the machine. Compressive strength test was done by MTS 815 testing system. Figure 3.8 shows the MTS 815 test system used for conducting compressive strength test.
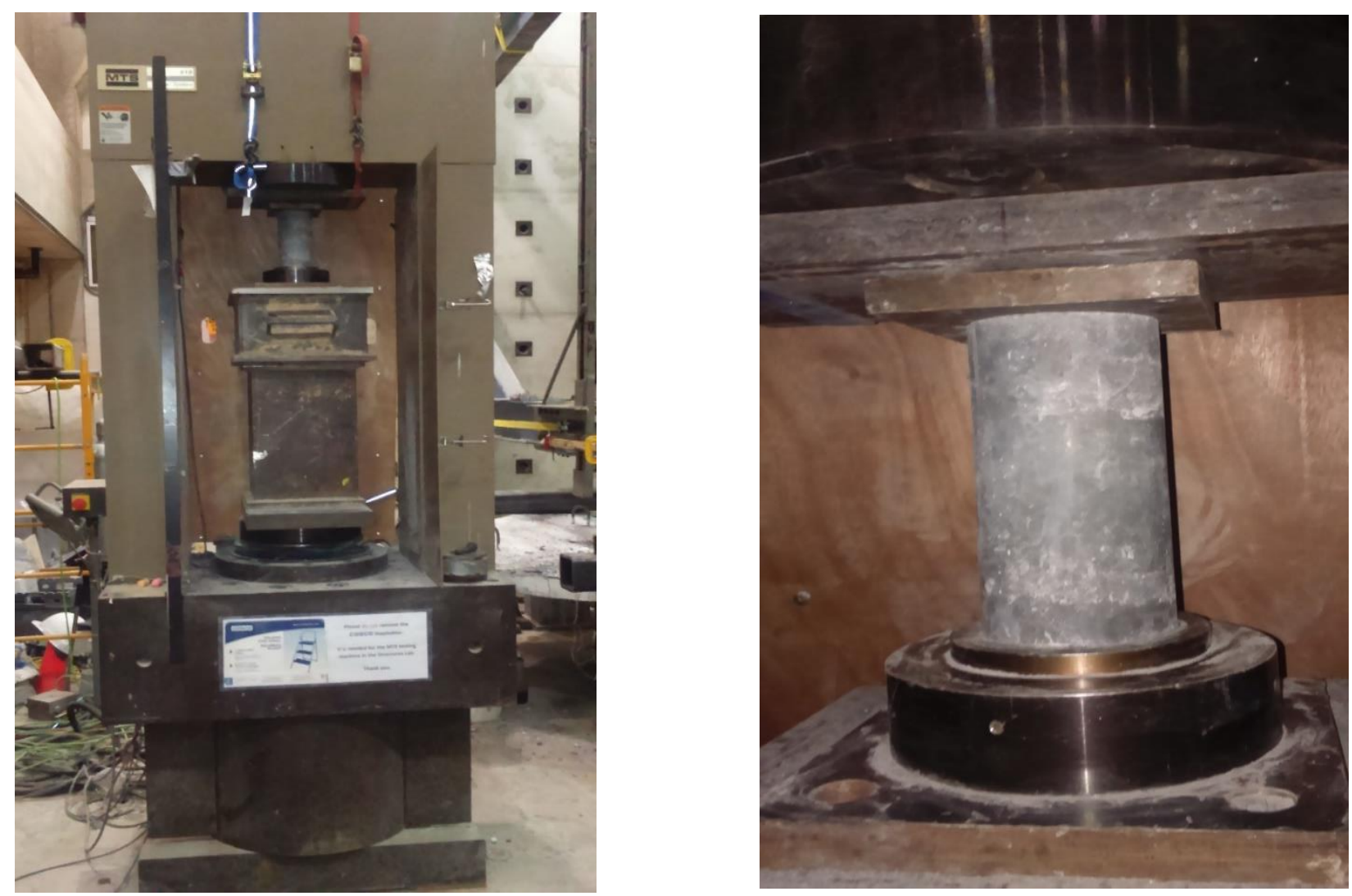

Figure 3.8: MTS 815 test system - Compressive strength test. 
Strain rates were converted to displacement rates using equation (7).

$\Delta \mathrm{L}^{\cdot}=\varepsilon^{\cdot} \times \mathrm{L}_{0}$

Where,

$\Delta \mathrm{L}^{\cdot}=$ Displacement rate $(\mathrm{mm} / \mathrm{sec})$

$\varepsilon^{\cdot}=$ Strain rate $\left(\mathrm{s}^{-1}\right)$

$\mathrm{L}_{0}=$ Original length of specimen $(\mathrm{mm})$

The displacement rates were in the range of $0.36 \mathrm{~mm} / \mathrm{min}$ (quasi-static) to $1200 \mathrm{~mm} / \mathrm{min}$ (dynamic). The calculated displacement rates along with the corresponding strain rates have been tabulated in Tables 3.1 and 3.2.

Table 3.1: Quasi-static strain and displacement rates for compressive strength test.

\begin{tabular}{|c|c|c|c|c|}
\hline \multicolumn{5}{|c|}{ Compressive Strength Test under Quasi-Static Loading } \\
\hline \multicolumn{3}{|c|}{ Number of Specimens } & \multirow{2}{*}{$\begin{array}{c}\text { Strain Rate } \\
\left(\mathrm{S}^{-1}\right)\end{array}$} & \multirow{2}{*}{$\begin{array}{l}\text { Displacement Rate } \\
(\mathrm{mm} / \mathrm{min})\end{array}$} \\
\hline $1 \%$ Fiber & $2 \%$ Fiber & $3 \%$ Fiber & & \\
\hline 2 & 3 & 1 & $3 \times 10^{-5}$ & 0.36 \\
\hline 2 & 3 & 1 & $3 \times 10^{-4}$ & 3.60 \\
\hline
\end{tabular}

Table 3.2: Dynamic strain and displacement rates for compressive strength test.

\begin{tabular}{|c|c|c|c|c|}
\hline \multicolumn{5}{|c|}{ Compressive Strength Test under Dynamic Loading } \\
\hline \multicolumn{3}{|c|}{ Number of Specimens } & $\begin{array}{c}\text { Strain Rate } \\
\left(\mathrm{S}^{-1}\right)\end{array}$ & $\begin{array}{c}\text { Displacement Rate } \\
(\mathrm{mm} / \mathrm{min})\end{array}$ \\
\hline $1 \%$ Fiber & $2 \%$ Fiber & $3 \%$ Fiber & $3 \times 10^{-3}$ & 36 \\
\hline 1 & 3 & 1 & $1 \times 10^{-2}$ & 120 \\
\hline 1 & 3 & 1 & $3 \times 10^{-2}$ & 360 \\
\hline 1 & 3 & 1 & $1 \times 10^{-1}$ & 1200 \\
\hline
\end{tabular}


The cylindrical specimens after conducting compressive strength test are shown in Figure 3.9.
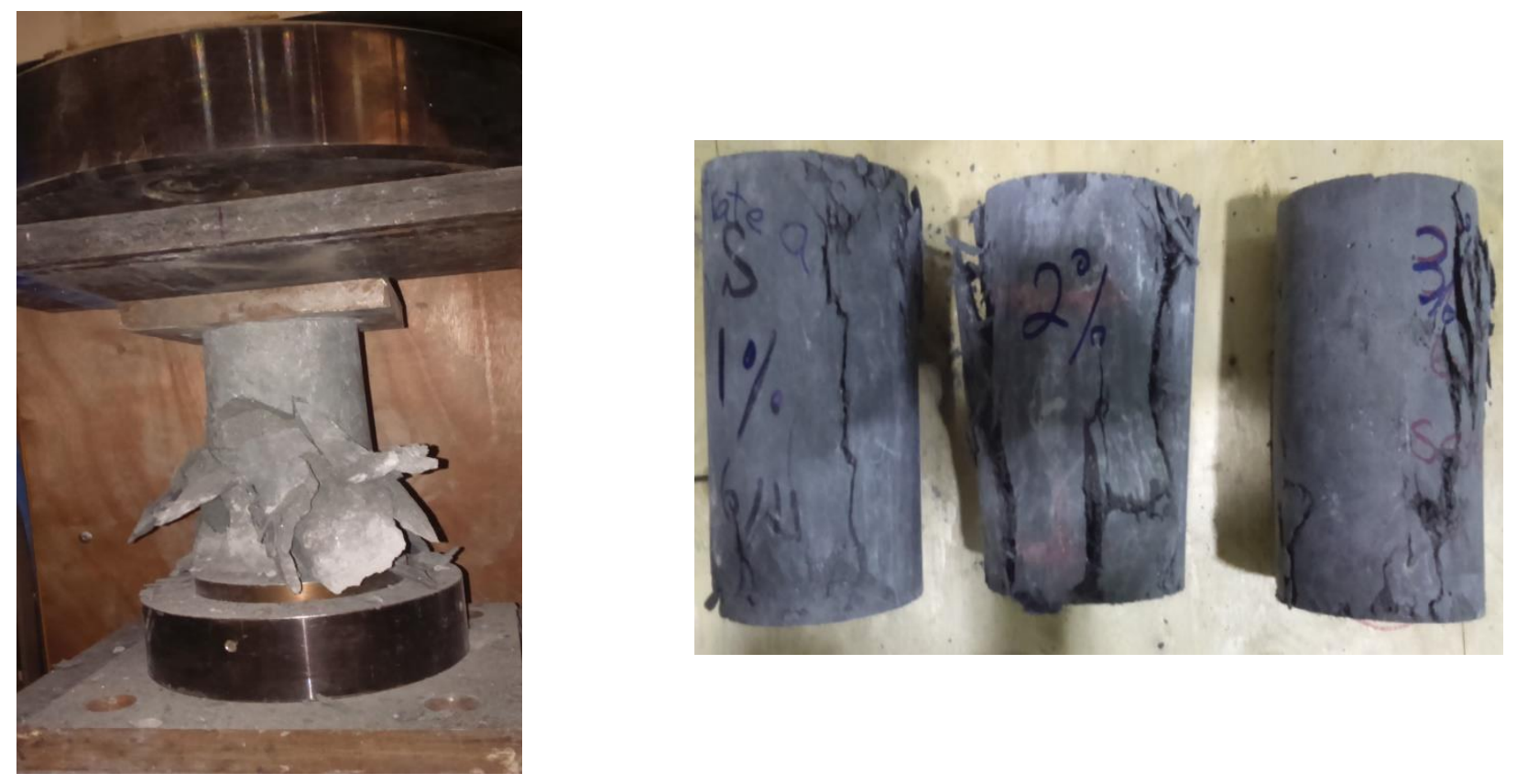

Figure 3.9: Cylindrical specimens after compressive strength test.

After conducting the compressive strength test for all specimens, Dynamic Increase Factor (DIF) was calculated for each specimen using equation (8).

$\mathrm{DIF}=\mathrm{f}_{\mathrm{cd}}^{\prime} / \mathrm{f}_{\mathrm{cs}}^{\prime}$

Where,

$\mathrm{f}_{\mathrm{cd}}^{\prime}=$ Dynamic peak stress $(\mathrm{MPa})$

$\mathrm{f}_{\mathrm{cs}}^{\prime}=$ Static compressive strength $(\mathrm{MPa})$

$\mathrm{f}_{\mathrm{cs}}^{\prime}$ was calculated by taking the average of the values of the tested specimens at the reference strain rate $\left(30 \times 10^{-6}\right)$. Also, $\mathrm{f}_{\mathrm{cd}}^{\prime}$ was calculated from the average value of the tested specimens at strain rates other than the reference one. 


\subsection{Indirect Tensile Strength Test}

The most common method of determination of the tensile strength of concrete is Brazilian test or indirect tension test or splitting tension test on cylindrical specimens. Usually, in this test a cylinder is subjected to compressive loading along its diametrical plane. The load is applied through 15 to $25 \mathrm{~mm}$ wide strips between the specimen and the platens. The test ends at the peak load, which is recorded to compute the maximum tensile stress considering line loads and uniformly distributed stresses. Figure 3.10 shows geometry and loading of the specimen for Brazilian test.
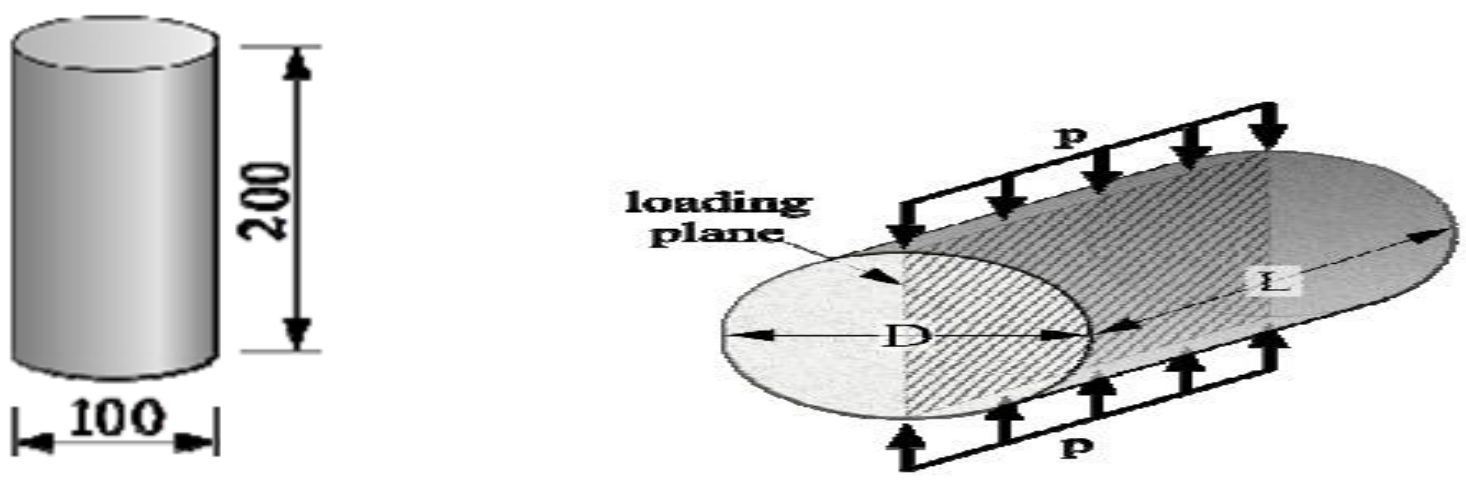

Figure 3.10: Geometry and loading of the specimen for splitting tension test.

The splitting tensile strength $\left(\mathrm{f}_{\mathrm{t}}\right)$ can be computed from equation (9), which was extracted from the theory of elasticity.

$\mathrm{f}_{\mathrm{t}}=\frac{2 P}{\pi \cdot D \cdot L}$

Where,

$\mathrm{f}_{\mathrm{t}}=$ Splitting tensile strength $(\mathrm{MPa})$

$\mathrm{P}=$ Measured peak load $(\mathrm{N})$

$\mathrm{D}=$ Diameter of specimen $(\mathrm{mm})$

$\mathrm{L}=$ Length of specimen (mm) 
As in other fracture tests, the most critical deformation of the specimen subjected to splitting is the crack opening. The strength obtained from the splitting tension test depends on the diameter of the specimen. However, the result is not reliable to be used for comparison and design.

\subsubsection{Indirect Tensile Strength Test under Quasi Static and Dynamic Loading}

Concrete cylinders with $100 \mathrm{~mm}$ diameter and $200 \mathrm{~mm}$ length were used to conduct indirect tensile strength test. Splitting tensile strength test was done by MTS 815 testing system with the capacity of $4600 \mathrm{kN}$ in compression and $2300 \mathrm{kN}$ in tension. Both low and high strain rates were applied to the machine. Figure 3.11 shows the MTS 815 test system for conducting Brazilian test.
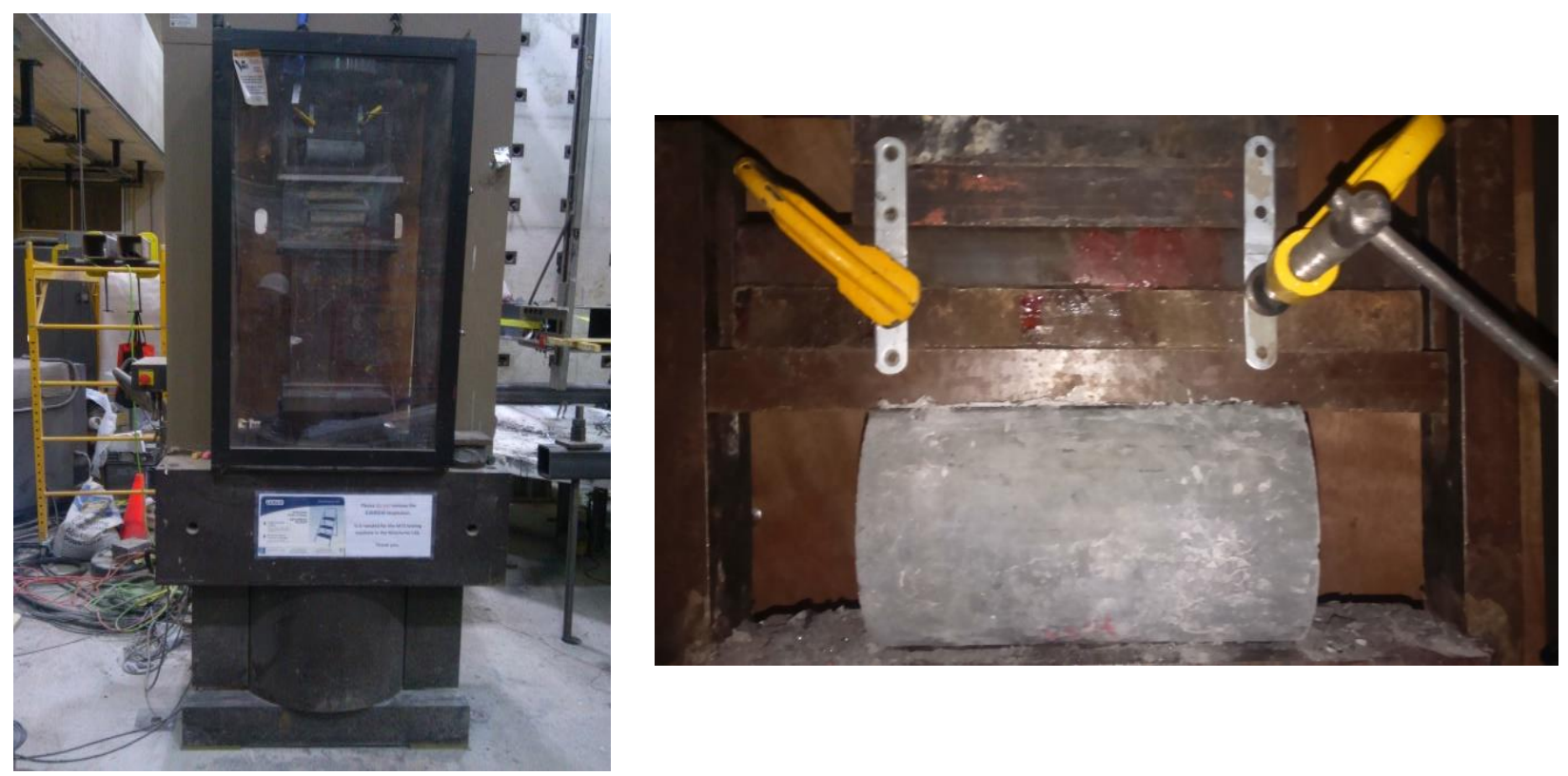

Figure 3.11: MTS 815 test system - Indirect tensile strength test.

Strain rates were converted to displacement rates using equation (7). The displacement rates were in the range of $0.006 \mathrm{~mm} / \mathrm{min}$ to $6 \mathrm{~mm} / \mathrm{min}$. The displacement rates along with the loading rates and sample rates have been tabulated in Table 3.3. 
Table 3.3: Displacement and loading rates for Brazilian test.

\begin{tabular}{|c|c|c|c|c|c|}
\hline \multicolumn{7}{|c|}{ Indirect Tensile Strength Test } \\
\hline \multicolumn{2}{|c|}{ No. of Specimens } & $\begin{array}{c}\text { Sample Rate } \\
(\mathrm{Hz})\end{array}$ & $\begin{array}{c}\text { Loading } \\
\text { Rate }(\mathrm{kN} / \mathrm{s})\end{array}$ & $\begin{array}{c}\text { Displacement } \\
\text { Rate }(\mathrm{mm} / \mathrm{min})\end{array}$ \\
\hline $1 \%$ Fiber & $2 \%$ Fiber & $3 \%$ Fiber & 1 & 0.2 & $6 \times 10^{-3}$ \\
\hline 3 & 3 & 2 & 2 & 2.0 & $6 \times 10^{-2}$ \\
\hline 2 & 2 & 1 & 2 & 20 & $6 \times 10^{-1}$ \\
\hline 2 & 2 & 1 & 3 & 200 & 6 \\
\hline 2 & 2 & 1 & & &
\end{tabular}

The cylindrical specimens after conducting indirect tensile strength test are shown in Figure 3.12.
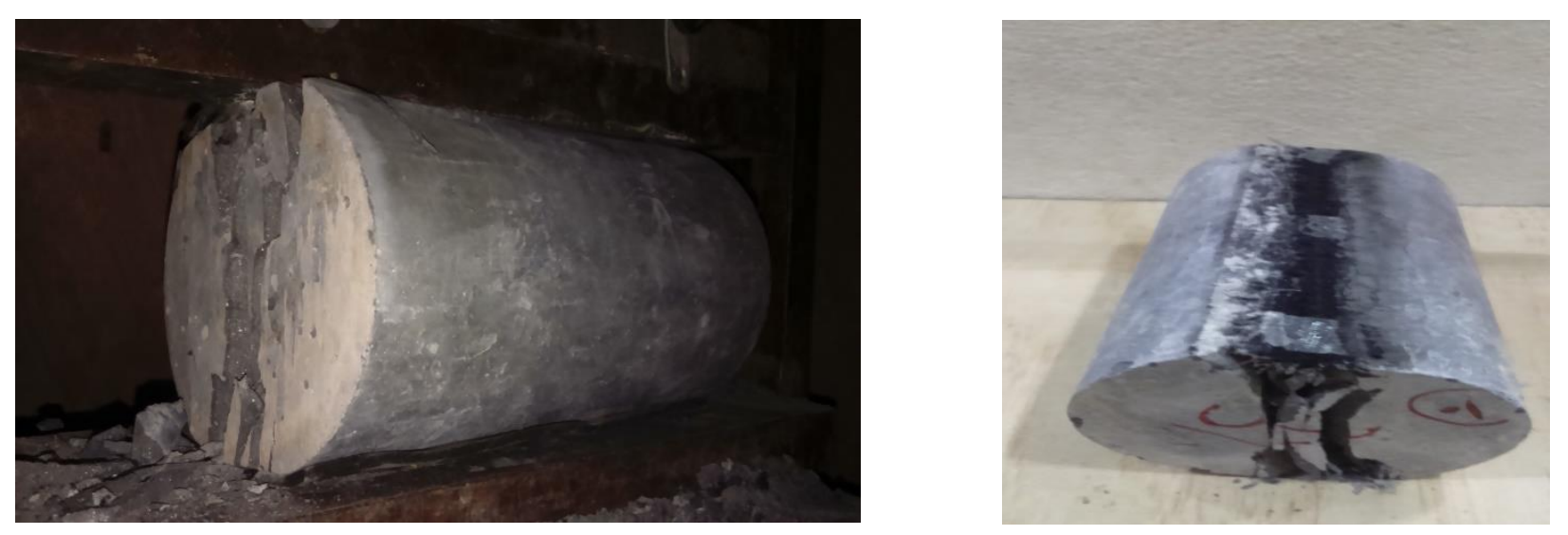

Figure 3.12: Cylindrical specimens after indirect tensile strength test.

\subsection{Flexural Strength Test}

Flexural strength test for UHP-FRC prisms was completed according to the ASTM C1609-12 standard test method for flexural performance of FRC (using beam with third-point loading). For conducting this test, prisms of $400 \times 100 \times 100 \mathrm{~mm}$ were tested at three strain rates and flexural stress (modulus of rupture) was computed from equation (10).

$\mathrm{f}_{\mathrm{r}}=1.5 \mathrm{PL} / \mathrm{bd}^{2}$

Where, 
$\mathrm{f}_{\mathrm{r}}=$ Flexural stress $(\mathrm{MPa})$

$\mathrm{P}=$ Peak load at the fracture point $(\mathrm{N})$

$\mathrm{L}=$ Clear span $(\mathrm{mm})$

$\mathrm{b}=$ Width of the prism $(\mathrm{mm})$

$\mathrm{d}=$ Depth of the prism $(\mathrm{mm})$

\subsubsection{Flexural Strength Test under Quasi static and Low Speed Loading Rates}

Concrete prisms $(400 \times 100 \times 100 \mathrm{~mm})$ were used for flexural strength test under quasi-static loading using MTS 793 test system. The specimens were tested under three point bending flexural test and modulus of rupture for UHP-FRC specimens of different fiber content was calculated. The test was conducted on prism specimens using MTS 793 test system with $100 \mathrm{kN}$ capacity in flexure. The MTS 793 test system is shown in Figure 3.13.
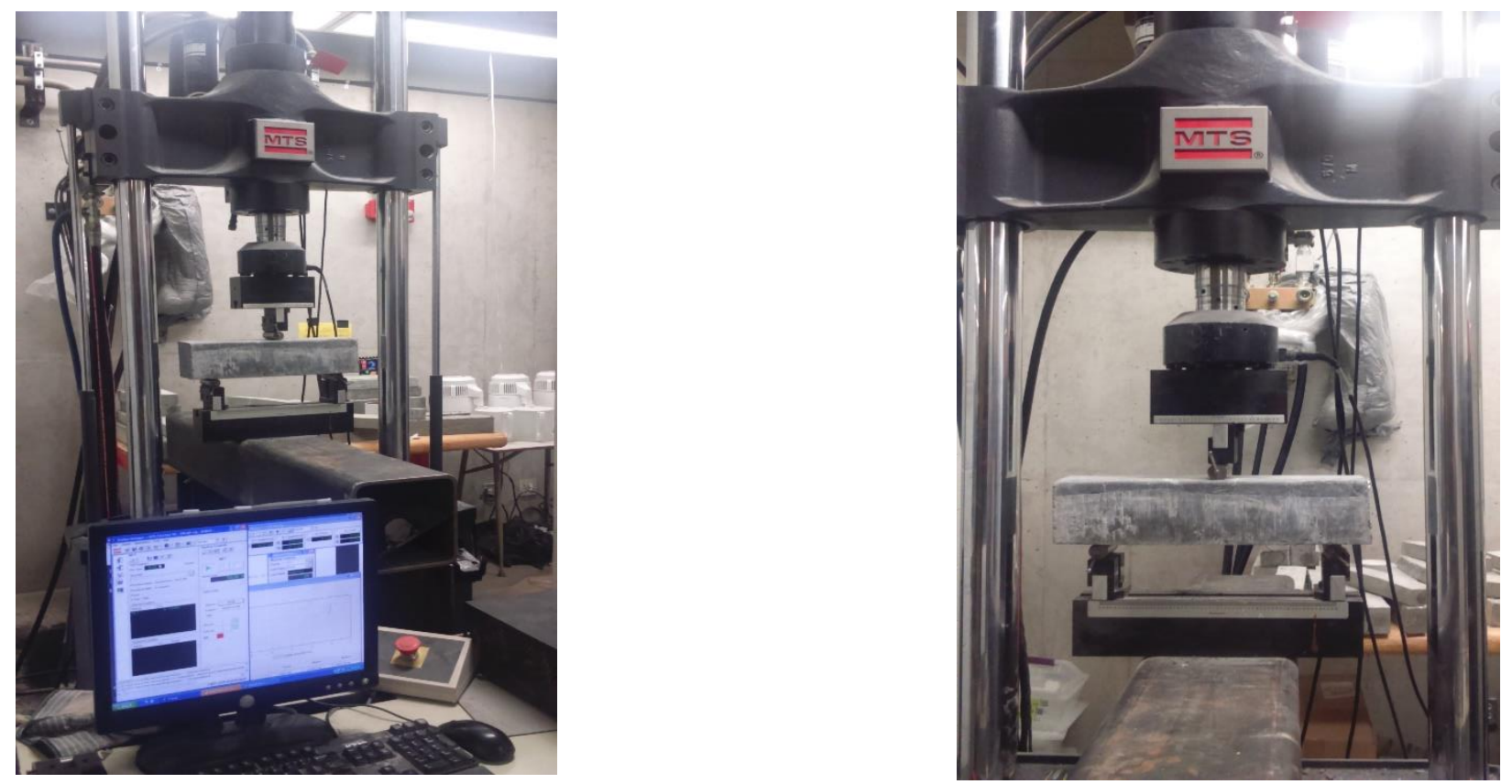

Figure 3.13: MTS 793 test system - Flexural strength test.

The clear span of the prism was $300 \mathrm{~mm}$ and the load was applied on the smooth side of the prism. Because of the enough clearance under the prism, it can deform freely (see Figure 3.13). 
The specimens were tested at three strain rates. Similar to the compressive strength test, the strain rates were converted to the corresponding displacement rates using equation (7). The displacement rates were in the range of $0.018 \mathrm{~mm} / \mathrm{min}$ to $1.80 \mathrm{~mm} / \mathrm{min}$. The calculated displacement rates along with the corresponding strain rates have been tabulated in Table 3.4.

Table 3.4: Strain and displacement rates for flexural strength test.

\begin{tabular}{|c|c|c|c|c|c|}
\hline \multicolumn{6}{|c|}{ Flexural Strength Test under Quasi static and Low Speed Loading Rates } \\
\hline \multicolumn{3}{|c|}{ Number of Specimens } & \multirow{2}{*}{ Range } & \multirow{2}{*}{$\begin{array}{c}\text { Strain Rate } \\
\left(\mathrm{S}^{-1}\right)\end{array}$} & \multirow{2}{*}{$\begin{array}{l}\text { Displacement Rate } \\
\qquad(\mathrm{mm} / \mathrm{min})\end{array}$} \\
\hline $1 \%$ Fiber & $2 \%$ Fiber & $3 \%$ Fiber & & & \\
\hline 2 & 3 & 2 & Quasi-Static & $1 \times 10^{-6}$ & 0.018 \\
\hline 1 & 2 & 1 & \multirow{2}{*}{ Low Speed } & $1 \times 10^{-5}$ & 0.180 \\
\hline 1 & 2 & 1 & & $1 \times 10^{-4}$ & 1.80 \\
\hline
\end{tabular}

The prism specimens after conducting flexural strength test are shown in Figure 3.14.
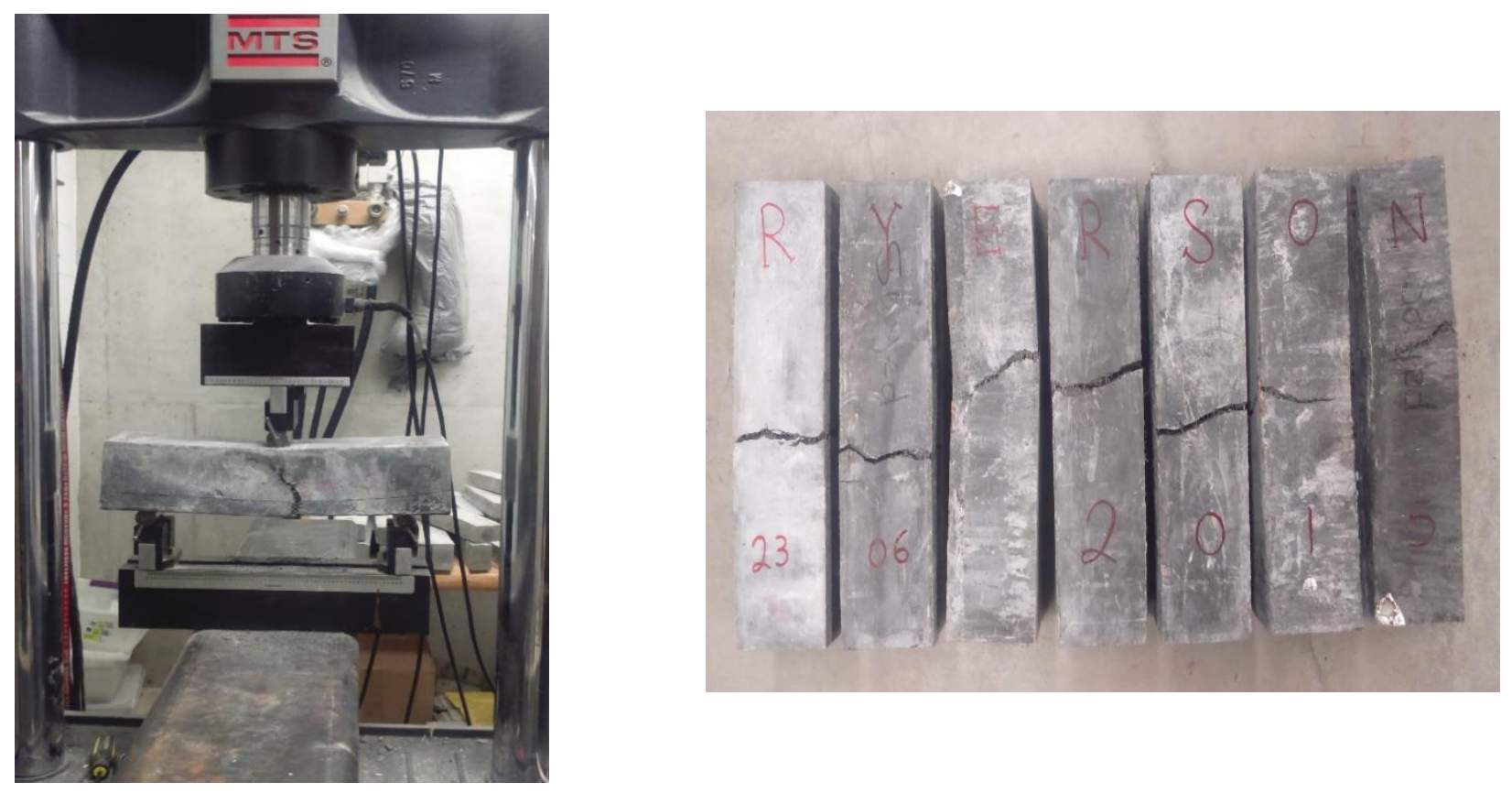

Figure 3.14: Prism specimens after flexural strength test. 


\subsubsection{Flexural Strength Test under Dynamic (Impact) Loading}

Flexural strength test under dynamic (impact) loading was conducted using a $38 \mathrm{~kg}$ drop weight rig. Various heights of 600 and $1000 \mathrm{~mm}$ used to achieve different strain rates. The Ryerson University drop hammer impact test system will be discussed thoroughly in Section 3.7. Figure 3.15 shows the drop hammer instrument used for the impact test at Ryerson University.
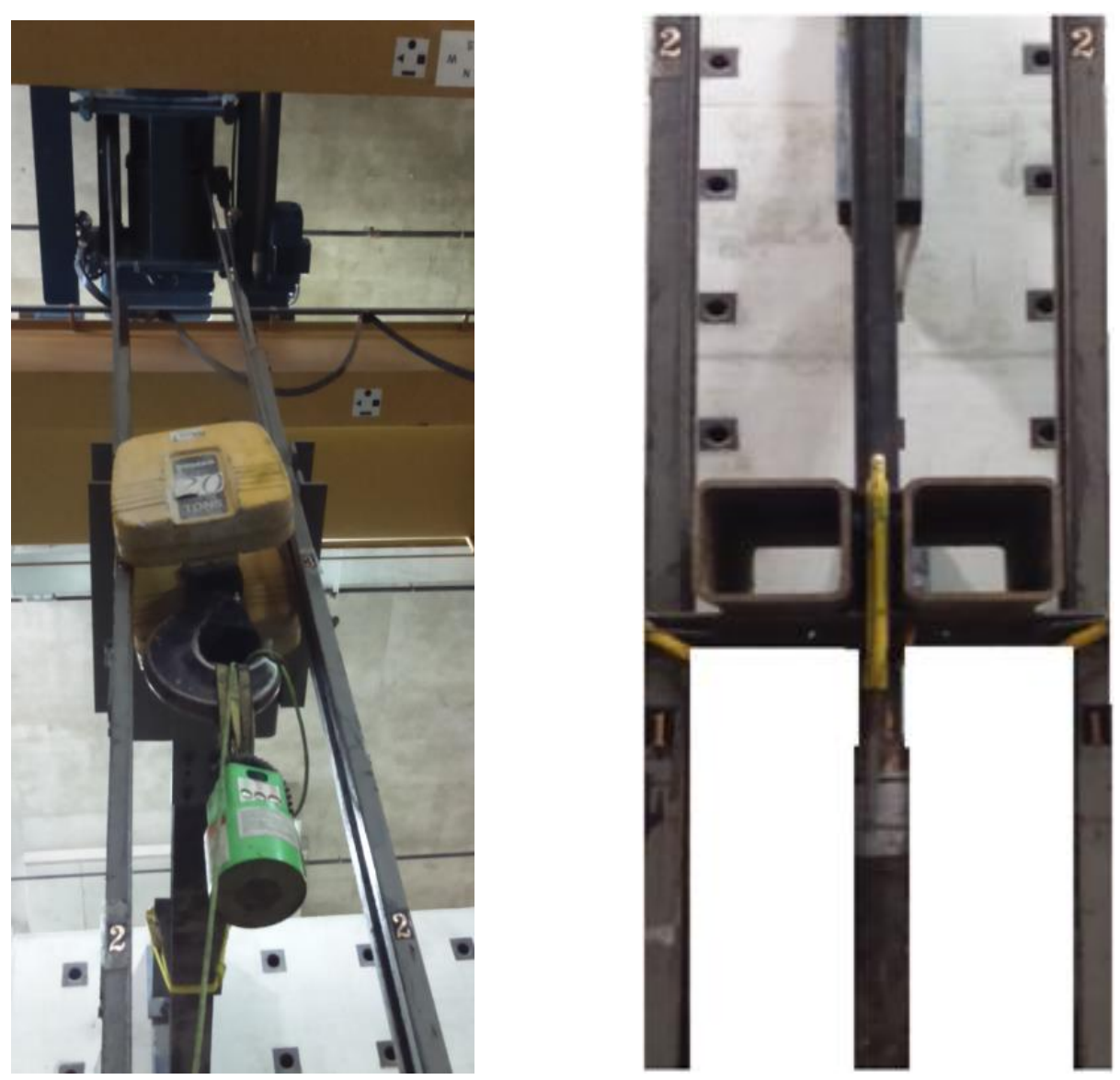

Figure 3.15: Hoist with circular electric lifting magnet (left), and steel drop hammer (right).

The impact force was obtained from the two load cells and the corresponding strain rate was calculated form the loading rates, using equation (11).

Flexural stress can be calculated as:

$\sigma=\mathrm{M} \cdot \mathrm{y} / \mathrm{I}=(\mathrm{PL} / 4)(\mathrm{d} / 2) /\left(\mathrm{bd}^{3} / 12\right)$ 
Stress rate is shown as:

$\sigma^{\cdot}=\varepsilon^{\cdot} \times \mathrm{E}$

After substitution, strain rate can be shown as:

$\varepsilon^{\cdot}=1.5 \mathrm{PL} / \mathrm{Ebd}^{2}$

Where,

$\varepsilon^{\cdot}=$ Strain rate $\left(\mathrm{s}^{-1}\right)$

$\mathrm{P}=$ loading rate $(\mathrm{kN} / \mathrm{s})$

$\mathrm{L}=$ Clear $\operatorname{span}(\mathrm{mm})$

$\mathrm{b}=$ Width of the prism $(\mathrm{mm})$

$\mathrm{d}=$ Depth of the prism (mm)

The number of tested specimens along with the corresponding drop heights are shown in Table 3.5 .

Table 3.5: Number of tested specimens and drop heights.

\begin{tabular}{|c|c|c|c|}
\hline \multicolumn{3}{|c|}{ Number of Specimens } & \multirow{2}{*}{ Drop Height $(\mathrm{mm})$} \\
\hline $1 \%$ Fiber & $2 \%$ Fiber & $3 \%$ Fiber & 600 \\
\hline 2 & 2 & N/A & 1200 \\
\hline 2 & 2 & 1 & 1800 \\
\hline 1 & 2 & 1 & \\
\hline
\end{tabular}

\subsection{RU Drop Hammer Impact Test System}

A drop hammer impact test system was developed at Ryerson University in 2015 to verify the behavior of UHP-FRC prism specimens under dynamic (impact) loading. The test system included a steel frame, a drop hammer of $38 \mathrm{~kg}$ weight, a circular electric lifting magnet, a crane, two load cells, two accelerometers, and a data acquisition system. 
The drop hammer was absorbed by a circular electric lifting magnet and a crane lifted the magnet to the proposed height. Then, the drop hammer was dropped by releasing the electric lifting magnet. The drop hammer, the circular electric lifting magnet, and the crane have been shown in Figure 3.15 .

\subsubsection{Drop Hammer Weight}

The RU drop hammer weight consists of two welded cylindrical steel rods. The upper part of the rig has $1.2 \mathrm{~m}$ length, $19.5 \mathrm{~kg}$ weight, and a diameter of $50 \mathrm{~mm}$. The lower part has a weight of 18.5 $\mathrm{kg}$, a length of $0.53 \mathrm{~m}$, and a diameter of $70 \mathrm{~mm}$. The total weight of the drop hammer is $38 \mathrm{~kg}$ which is effective for conducting the impact test on UHP-FRC prism specimens from a drop height as low as $600 \mathrm{~mm}$.

\subsubsection{Circular Electric Lifting Magnet}

A circular electric lifting magnet (model CER-7 with a capacity of $600 \mathrm{~kg}$ ) manufactured by Walker Magnetics was used to release the drop weight from the desired height by switching off the magnet using the remote control. The maximum rated lift capacity depends on the lifting surface (cleanness, smoothness, flatness, carbon content, plate thickness) and the area of the magnet surface in contact with the load.

\subsubsection{Load Cells}

Load cell or load transducer is a passive transducer or sensor which converts applied force into electrical signals. Two load cells were placed under supports for measuring the reactions resulted from the impact. Each load cell was placed between two bolted steel covers under pre-compression to avoid sliding (see Figure 3.16). Appropriate protection was provided to cables as well. Each prism was placed on two steel rollers of $30 \mathrm{~mm}$ length as prism supports. The steel rollers were welded to the steel plates and were fixed with straps. Figure 3.17 shows the prism specimen before conducting impact test. 

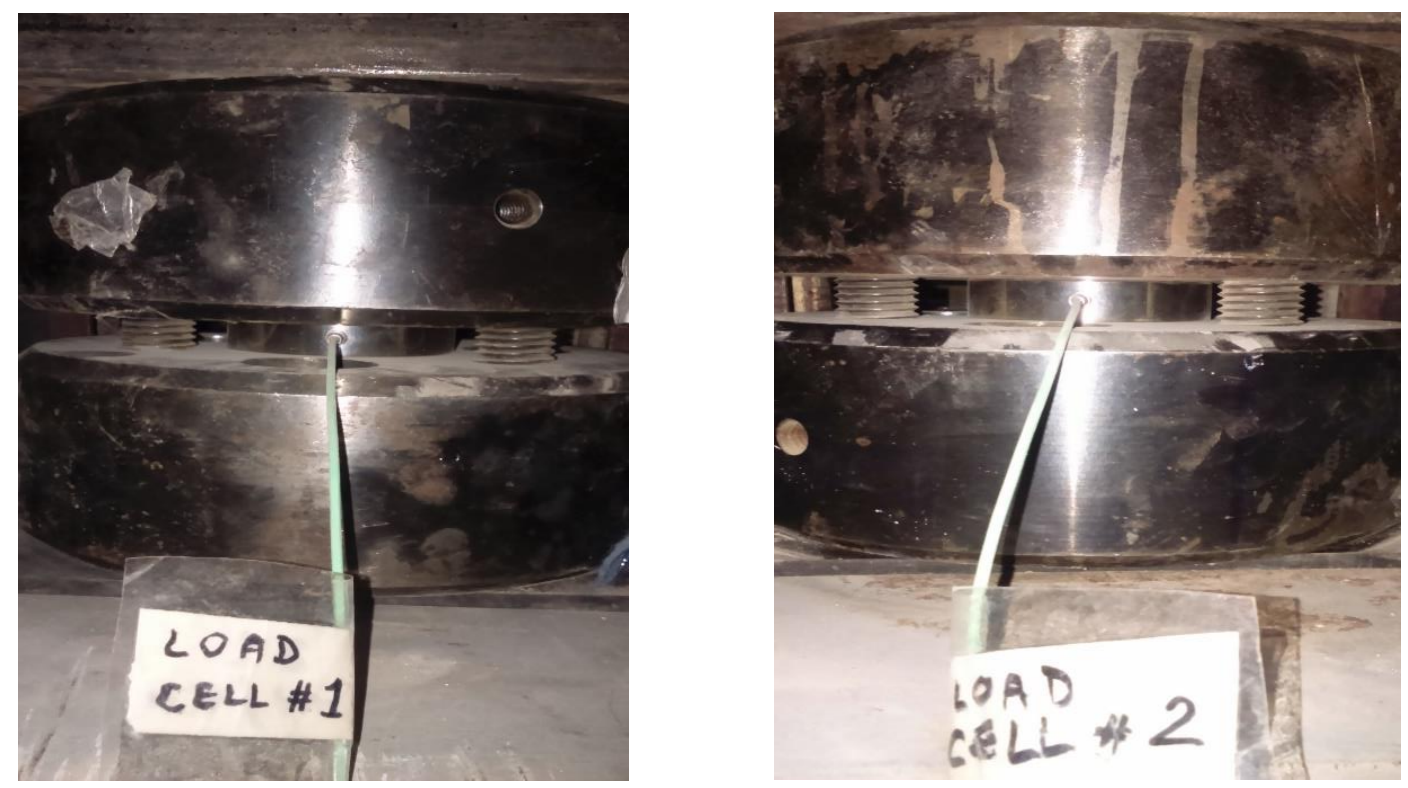

Figure 3.16: Load cells and steel covers.

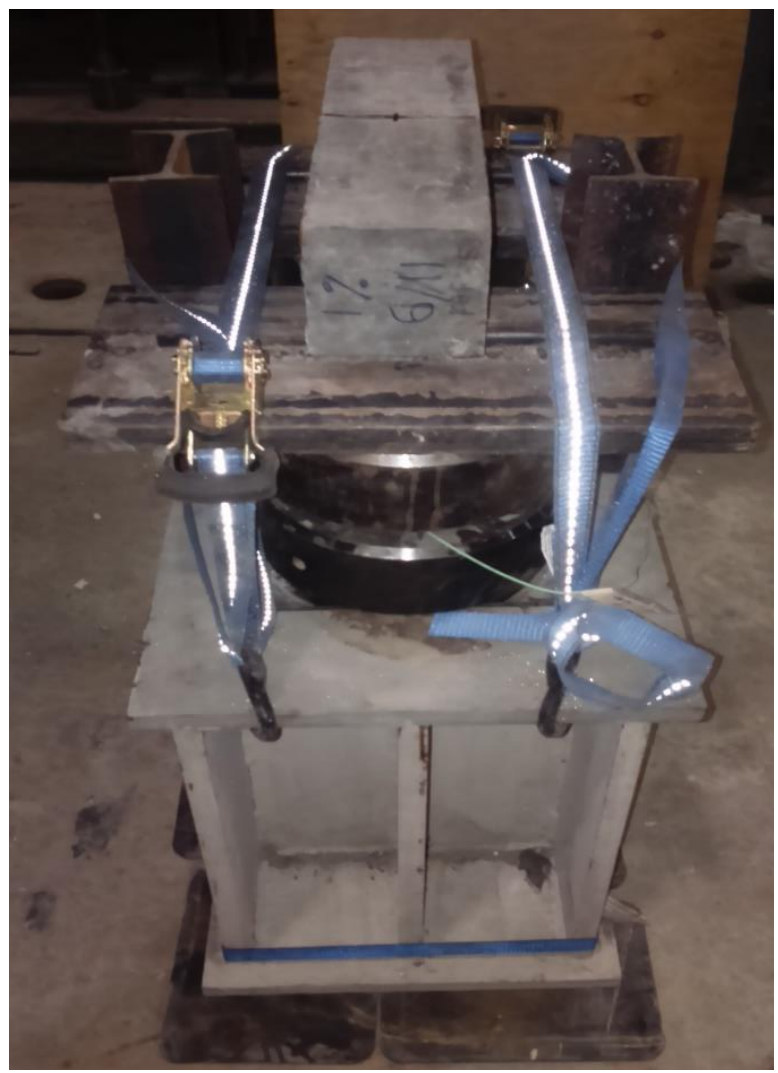

Figure 3.17: Prism specimen before conducting impact test. 


\subsubsection{Accelerometers}

Accelerometers are devices that measure proper acceleration (g-force). Two accelerometers of type 8704B5000 were attached to the drop weight and connected to the data acquisition system as well. The measuring range for each accelerometer was $\pm 5,000 \mathrm{~g}$. Their sensitivity were 0.990 $\mathrm{mV} / \mathrm{g}$ and $1.012 \mathrm{mV} / \mathrm{g}$ as well as their transverse sensitivity were $0.8 \%$ and $1.1 \%$, respectively. Both accelerometers had the resonant frequency of $54.0 \mathrm{kHz}$. Duct tape and rubber were applied on the surface of drop weight to lessen the effects of noise. Figure 3.18 shows the installation of the two accelerometers on the lower part of the drop weight rig.

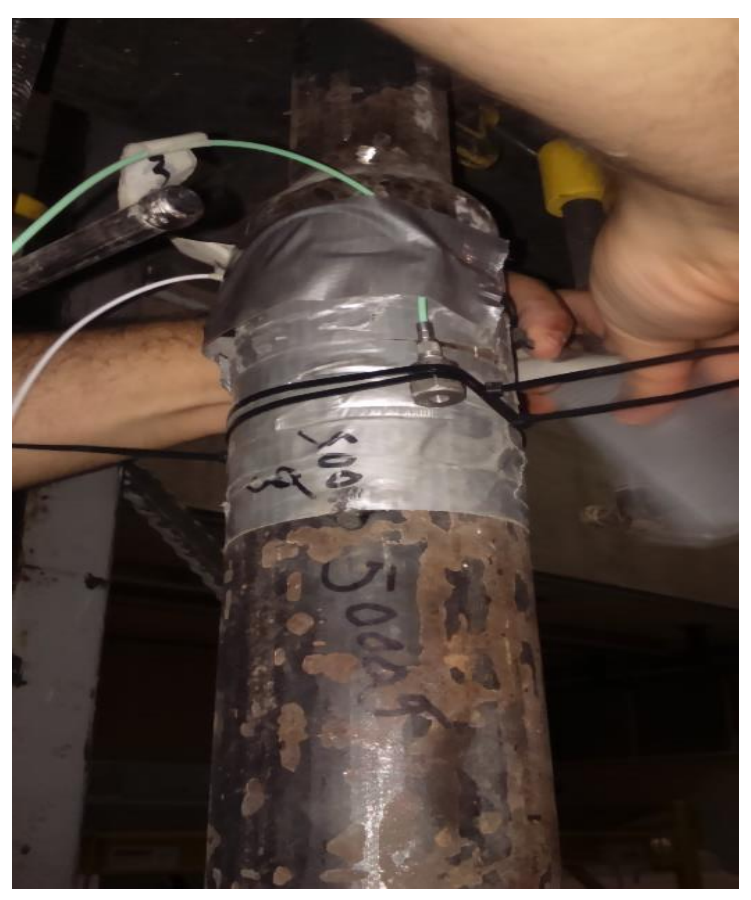

Figure 3.18: installation of the accelerometers on the drop weight.

\subsubsection{Data Acquisition System}

The load cells and the accelerometers were connected to the data acquisition system. The data acquisition system was comprised of ECON MI-7004 hardware, as well as measurement and analysis software with the ability of vibration and noise analysis, enhanced waveform generating, data recording, playback and offline analysis, acoustics analysis, order tracking, modal analysis, 
shock data capture, shaker performance verification, and shock/drop machine performance verification.

The ManuWare software program was used for data acquisition system and for each measuring device one channel was assigned, so that a total of four set of data were obtained after each test. After gathering data, Excel was used for data analysis and graph drawing. The data acquisition system with a computer is shown in Figure 3.19.
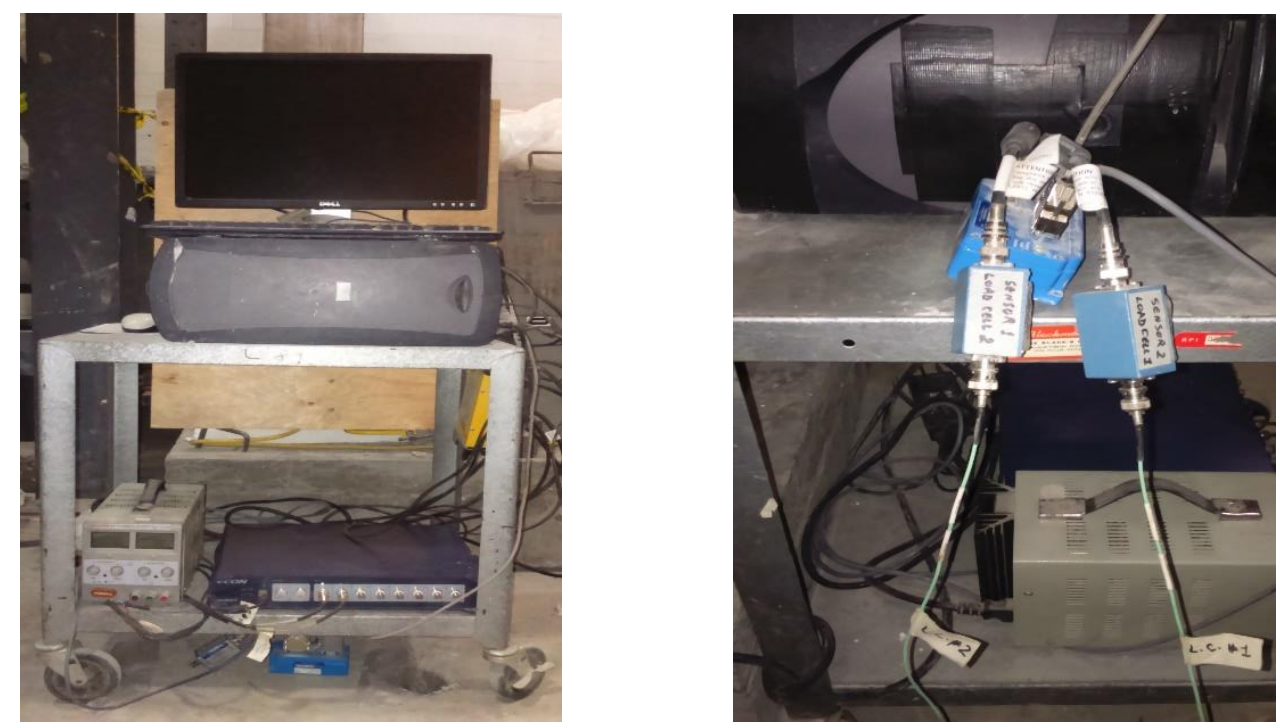

Figure 3.19: Data acquisition system, computer, and connections.

\subsubsection{Steel Frame}

The steel frame has a height of around 5 meters with a high load bearing capacity. The drop hammer weight was supported by the two HSS sections that were attached to the steel frame and leveled (see Figure 3.15).

\subsubsection{Steel Pedestals}

Two steel pedestals were used to provide a stable base for the prism specimens during the impact test. A layer of $6.5 \mathrm{~mm}$ rubber pad (elastomer) was used underneath the pedestals to absorb the impact energy, eliminate vibration, and minimize noise disturbance in output data. Then, both steel pedestals were leveled with a spirit level. Figure 3.20 shows the steel pedestals and rubber pads. 


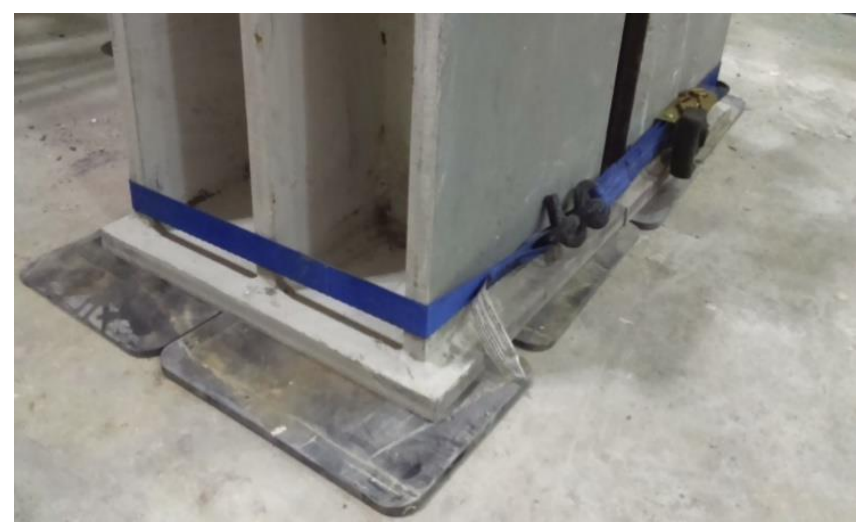

Figure 3.20: Steel pedestals rested on rubber pads.

\subsubsection{Crane}

A crane was used to lift the drop hammer up to the required height. The crane had a maximum capacity of 20 tons and has been shown in Figure 3.15. 


\section{Chapter 4}

\section{RESULTS ANALYSIS AND DISCUSSION}

"If the facts don't fit the theory, change the facts."

Albert Einstein (1879-1955)

\subsection{Introduction}

The results obtained from the experiment for different cases are discussed in this chapter. Flexural strength test, compressive strength test, and indirect tensile strength test were conducted on UHPFRC specimens with different fiber contents at different strain rates. Therefore, Dynamic Increase factor (DIF) can be calculated for each specimen and compared to other specimens. This leads to the evaluation of DIFs in order to identify the sensitivity of the specimens to various strain rates.

\subsection{Compressive Strength Test}

The compressive strength of each specimen was measured at 28 days and the average value of the specimens with identical fiber contents and strain rates was taken as the compressive strength. The maximum load was recorded at the point of fracture when the specimen failed to resist any more increased load.

\subsubsection{Stress-Strain Behavior}

The stress-strain behavior of each cylindrical specimen was recorded as a result of applying uniaxial loading using MTS 815 test system. Various displacement rates were applied to the specimens and test was continued even after reaching the peak load. Cylindrical specimens after compressive strength test have been shown in Figure 3.9.

\subsubsection{Compressive Strength Test under Quasi-Static Loading}

Compressive strength test under quasi-static loading was done on the concrete cylinders with 200 mm length and $100 \mathrm{~mm}$ diameter using MTS 815 test system. Test results based on the various fiber contents and different strain rates are tabulated in Tables 4.1 to 4.3. 
Table 4.1: Compressive strength of UHP-FRC with $1 \%$ fiber, under quasi-static loading.

\begin{tabular}{|c|c|c|c|}
\hline \multicolumn{4}{|c|}{ Quasi Static Loading (1\% Fiber) } \\
\hline Specimen & $\begin{array}{l}\text { Strain Rate } \\
\qquad\left(\mathrm{s}^{-1}\right)\end{array}$ & $\begin{array}{l}\text { Displacement Rate } \\
(\mathrm{mm} / \mathrm{min})\end{array}$ & $\begin{array}{c}\text { Compressive Strength } \\
(\mathrm{MPa})\end{array}$ \\
\hline A & \multirow{3}{*}{$3 \times 10^{-5}$} & \multirow{3}{*}{0.36} & 143.5 \\
\hline $\mathrm{B}$ & & & 140.8 \\
\hline Average & & & 142.2 \\
\hline A & \multirow{3}{*}{$3 \times 10^{-4}$} & \multirow{3}{*}{3.60} & 161.5 \\
\hline B & & & 156.4 \\
\hline Average & & & 159 \\
\hline
\end{tabular}

Table 4.2: Compressive strength of UHP-FRC with $2 \%$ fiber, under quasi-static loading.

\begin{tabular}{|c|c|c|c|}
\hline \multicolumn{4}{|c|}{ Quasi Static Loading (2\% Fiber) } \\
\hline Specimen & $\begin{array}{c}\text { Strain Rate } \\
\left(\mathrm{s}^{-1}\right)\end{array}$ & $\begin{array}{l}\text { Displacement Rate } \\
(\mathrm{mm} / \mathrm{min})\end{array}$ & $\begin{array}{c}\text { Compressive Strength } \\
(\mathrm{MPa})\end{array}$ \\
\hline A & \multirow{4}{*}{$3 \times 10^{-5}$} & \multirow{4}{*}{0.36} & 170.5 \\
\hline B & & & 166.2 \\
\hline $\mathrm{C}$ & & & 165.4 \\
\hline Average & & & 167.4 \\
\hline A & \multirow{4}{*}{$3 \times 10^{-4}$} & \multirow{4}{*}{3.60} & 170.9 \\
\hline B & & & 181.3 \\
\hline $\mathrm{C}$ & & & 170.1 \\
\hline Average & & & 174.1 \\
\hline
\end{tabular}

Table 4.3: Compressive strength of UHP-FRC with 3\% fiber, under quasi-static loading.

\begin{tabular}{|c|c|c|c|}
\hline \multicolumn{4}{|c|}{ Quasi Static Loading (3\% Fiber) } \\
\hline Specimen & $\begin{array}{c}\text { Strain Rate } \\
\left(\mathrm{s}^{-1}\right)\end{array}$ & $\begin{array}{c}\text { Displacement Rate } \\
(\mathrm{mm} / \mathrm{min})\end{array}$ & $\begin{array}{c}\text { Compressive Strength } \\
(\mathrm{MPa})\end{array}$ \\
\hline $\mathrm{A}$ & $3 \times 10^{-5}$ & 0.36 & 151.9 \\
\hline $\mathrm{A}$ & $3 \times 10^{-4}$ & 3.60 & 164.1 \\
\hline
\end{tabular}




\subsubsection{Compressive Strength Test under Dynamic Loading}

Compressive strength test under dynamic loading was done on the concrete cylinders with 200 $\mathrm{mm}$ length and $100 \mathrm{~mm}$ diameter using MTS 815 test system. The test results based on the various fiber contents and different strain rates are tabulated in Tables 4.4 to 4.6.

Table 4.4: Compressive strength of UHP-FRC with $1 \%$ fiber, under dynamic loading.

\begin{tabular}{|c|c|c|c|}
\hline \multicolumn{4}{|c|}{ Dynamic Loading (1\% Fiber) } \\
\hline Specimen & $\begin{array}{c}\text { Strain Rate } \\
\left(\mathrm{s}^{-1}\right)\end{array}$ & $\begin{array}{c}\text { Displacement Rate } \\
(\mathrm{mm} / \mathrm{min})\end{array}$ & $\begin{array}{c}\text { Compressive Strength } \\
(\mathrm{MPa})\end{array}$ \\
\hline A & $3 \times 10^{-3}$ & 36 & 167.8 \\
\hline A & $1 \times 10^{-2}$ & 120 & 173.4 \\
\hline A & $3 \times 10^{-2}$ & 360 & 179.9 \\
\hline A & $1 \times 10^{-1}$ & 1200 & 183.4 \\
\hline
\end{tabular}

Table 4.5: Compressive strength of UHP-FRC with $2 \%$ fiber, under dynamic loading.

\begin{tabular}{|c|c|c|c|}
\hline \multicolumn{4}{|c|}{ Dynamic Loading (2\% Fiber) } \\
\hline Specimen & $\begin{array}{c}\text { Strain Rate } \\
\left(\mathrm{s}^{-1}\right)\end{array}$ & $\begin{array}{l}\text { Displacement Rate } \\
(\mathrm{mm} / \mathrm{min})\end{array}$ & $\begin{array}{c}\text { Compressive Strength } \\
\text { (MPa) }\end{array}$ \\
\hline A & \multirow{4}{*}{$3 \times 10^{-3}$} & \multirow[t]{4}{*}{ 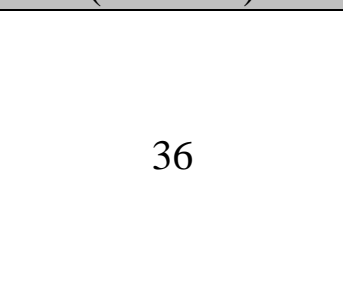 } & 189 \\
\hline B & & & 183.5 \\
\hline $\mathrm{C}$ & & & 187.8 \\
\hline Average & & & 186.8 \\
\hline A & \multirow{4}{*}{$1 \times 10^{-2}$} & \multirow{4}{*}{120} & 191.3 \\
\hline $\mathrm{B}$ & & & 186.1 \\
\hline $\mathrm{C}$ & & & 188.8 \\
\hline Average & & & 188.7 \\
\hline A & \multirow{4}{*}{$3 \times 10^{-2}$} & \multirow{4}{*}{360} & 193.9 \\
\hline B & & & 192.7 \\
\hline $\mathrm{C}$ & & & 189.1 \\
\hline Average & & & 191.9 \\
\hline
\end{tabular}


Table 4.5: Compressive strength of UHP-FRC with 2\% fiber, under dynamic loading (continued).

\begin{tabular}{|c|c|c|c|}
\hline \multicolumn{4}{|c|}{ Dynamic Loading (2\% Fiber) } \\
\hline Specimen & $\begin{array}{c}\text { Strain Rate } \\
\left(\mathrm{s}^{-1}\right)\end{array}$ & $\begin{array}{l}\text { Displacement Rate } \\
(\mathrm{mm} / \mathrm{min})\end{array}$ & $\begin{array}{c}\text { Compressive Strength } \\
(\mathrm{MPa})\end{array}$ \\
\hline $\mathrm{A}$ & \multirow{4}{*}{$1 \times 10^{-1}$} & \multirow{4}{*}{1200} & 198.5 \\
\hline B & & & 196.1 \\
\hline $\mathrm{C}$ & & & 197.9 \\
\hline Average & & & 197.5 \\
\hline
\end{tabular}

Table 4.6: Compressive strength of UHP-FRC with 3\% fiber, under dynamic loading.

\begin{tabular}{|c|c|c|c|}
\hline \multicolumn{4}{|c|}{ Dynamic Loading (3\% Fiber) } \\
\hline Specimen & $\begin{array}{c}\text { Strain Rate } \\
\left(\mathrm{s}^{-1}\right)\end{array}$ & $\begin{array}{c}\text { Displacement Rate } \\
(\mathrm{mm} / \mathrm{min})\end{array}$ & $\begin{array}{c}\text { Compressive Strength } \\
(\mathrm{MPa})\end{array}$ \\
\hline $\mathrm{A}$ & $3 \times 10^{-3}$ & 36 & 174.7 \\
\hline $\mathrm{A}$ & $1 \times 10^{-2}$ & 120 & 179.2 \\
\hline $\mathrm{A}$ & $3 \times 10^{-2}$ & 360 & 183.8 \\
\hline $\mathrm{A}$ & $1 \times 10^{-1}$ & 1200 & 188.4 \\
\hline
\end{tabular}

\subsubsection{Dynamic Increase Factor (DIF)}

Dynamic Increase Factor (DIF) was computed by dividing dynamic peak stress by static compressive strength under the quasi-static reference strain rate $\left(3 \times 10^{-5} \mathrm{~s}^{-1}\right)$. DIF for each specimen is shown in Tables 4.7 to 4.9. 
Table 4.7: DIF for specimens with $1 \%$ fiber.

\begin{tabular}{|c|c|c|}
\hline \multicolumn{3}{|c|}{ UHP-FRC (1\% Fiber) } \\
\hline $\begin{array}{c}\text { Strain Rate } \\
\left(\mathbf{s}^{-1}\right)\end{array}$ & $\begin{array}{c}\text { Compressive Strength } \\
(\mathbf{M P a})\end{array}$ & DIF \\
\hline $3 \times 10^{-5}$ & 142.2 & 1.00 \\
\hline $3 \times 10^{-4}$ & 159.0 & 1.12 \\
\hline $3 \times 10^{-3}$ & 167.8 & 1.18 \\
\hline $1 \times 10^{-2}$ & 173.4 & 1.22 \\
\hline $3 \times 10^{-2}$ & 179.9 & 1.26 \\
\hline $1 \times 10^{-1}$ & 183.4 & 1.29 \\
\hline
\end{tabular}

Table 4.8: DIF for specimens with $2 \%$ fiber.

\begin{tabular}{|c|c|c|}
\hline \multicolumn{3}{|c|}{ UHP-FRC (2\% Fiber) } \\
\hline $\begin{array}{c}\text { Strain Rate } \\
\left(\mathbf{s}^{\mathbf{- 1}}\right)\end{array}$ & $\begin{array}{c}\text { Compressive Strength } \\
(\mathbf{M P a})\end{array}$ & DIF \\
\hline $3 \times 10^{-5}$ & 167.4 & 1.00 \\
\hline $3 \times 10^{-4}$ & 174.1 & 1.04 \\
\hline $3 \times 10^{-3}$ & 186.8 & 1.12 \\
\hline $1 \times 10^{-2}$ & 188.7 & 1.13 \\
\hline $3 \times 10^{-2}$ & 191.9 & 1.15 \\
\hline $1 \times 10^{-1}$ & 197.5 & 1.18 \\
\hline
\end{tabular}


Table 4.9: DIF for specimens with $3 \%$ fiber.

\begin{tabular}{|c|c|c|}
\hline \multicolumn{3}{|c|}{ UHP-FRC (3\% Fiber) } \\
\hline $\begin{array}{c}\text { Strain Rate } \\
\left(\mathbf{s}^{-\mathbf{1}}\right)\end{array}$ & $\begin{array}{c}\text { Compressive Strength } \\
(\mathrm{MPa})\end{array}$ & DIF \\
\hline $3 \times 10^{-5}$ & 151.9 & 1.00 \\
\hline $3 \times 10^{-4}$ & 164.1 & 1.08 \\
\hline $3 \times 10^{-3}$ & 174.7 & 1.15 \\
\hline $1 \times 10^{-2}$ & 179.2 & 1.18 \\
\hline $3 \times 10^{-2}$ & 183.8 & 1.21 \\
\hline $1 \times 10^{-1}$ & 188.4 & 1.24 \\
\hline
\end{tabular}

Figure 4.1 shows DIF-strain rate graph (fitted lines) for compressive strength of each UHP-FRC specimen.

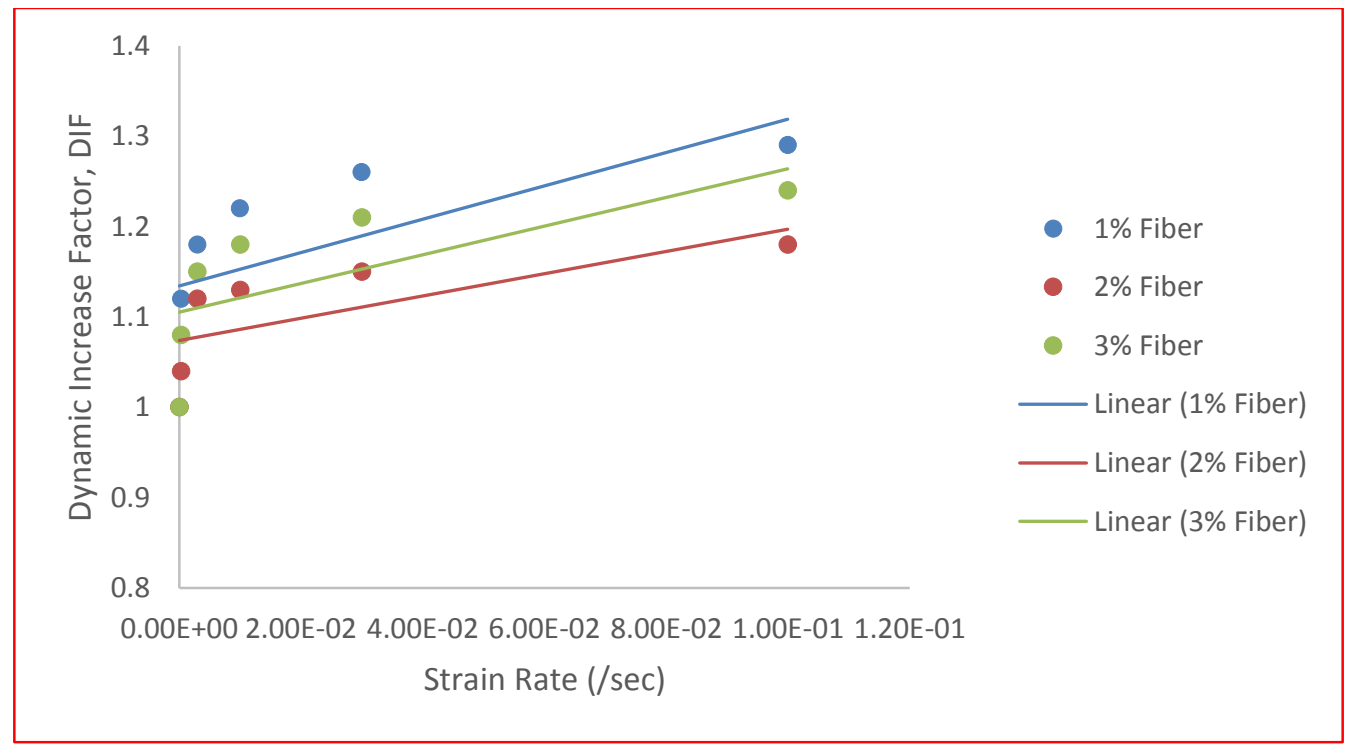

Figure 4.1: Experimental DIF-strain rate fitted lines for compressive strength of UHP-FRC. 


\subsection{Indirect Tensile Strength Test}

The tensile strength of each specimen was measured at 28 days and the average value of the specimens with identical fiber contents and strain rates was taken as the tensile strength. The maximum load was recorded at the point of fracture when the specimen failed to resist any more increased load.

\subsubsection{Indirect Tensile Strength Test under Quasi-Static and Low Speed Loading Rates}

The splitting tensile strength test results for UHP-FRC specimens with different fiber contents at various strain rates under quasi-static and low speed loading rates are tabulated in Tables 4.10 to 4.12 .

Table 4.10: Tensile strength of UHP-FRC with $1 \%$ fiber.

\begin{tabular}{|c|c|c|c|c|c|}
\hline \multicolumn{6}{|c|}{ Quasi-Static and Low Speed Loading Rates (1\% Fiber) } \\
\hline Specimen & $\begin{array}{l}\text { Sample } \\
\text { Rate } \\
\text { (Hz) }\end{array}$ & $\begin{array}{c}\text { Loading } \\
\text { Rate } \\
(\mathrm{kN} / \mathrm{s})\end{array}$ & $\begin{array}{c}\text { Displacement } \\
\text { Rate } \\
(\mathrm{mm} / \mathrm{min})\end{array}$ & $\begin{array}{c}\text { Maximum } \\
\text { Load } \\
(\mathrm{kN})\end{array}$ & $\begin{array}{c}\text { Tensile } \\
\text { Strength } \\
\text { (MPa) }\end{array}$ \\
\hline A & \multirow{4}{*}{1} & \multirow{4}{*}{0.2} & \multirow{4}{*}{$6 \times 10^{-3}$} & 417.8 & 13.3 \\
\hline B & & & & 414.7 & 13.2 \\
\hline $\mathrm{C}$ & & & & 402.1 & 12.8 \\
\hline Average & & & & 411.5 & 13.1 \\
\hline A & \multirow{3}{*}{2} & \multirow{3}{*}{2} & \multirow{3}{*}{$6 \times 10^{-2}$} & 430.4 & 13.7 \\
\hline B & & & & 417.8 & 13.3 \\
\hline Average & & & & 424.1 & 13.5 \\
\hline A & \multirow{3}{*}{2} & \multirow{3}{*}{20} & \multirow{3}{*}{$6 \times 10^{-1}$} & 424.1 & 13.5 \\
\hline B & & & & 436.7 & 13.9 \\
\hline Average & & & & 430.4 & 13.7 \\
\hline A & \multirow{3}{*}{3} & \multirow{3}{*}{200} & \multirow{3}{*}{6} & 436.7 & $13 . .9$ \\
\hline B & & & & 443.0 & 14.1 \\
\hline Average & & & & 439.8 & 14.0 \\
\hline
\end{tabular}


Table 4.11: Tensile strength of UHP-FRC with $2 \%$ fiber.

\begin{tabular}{|c|c|c|c|c|c|}
\hline \multicolumn{6}{|c|}{ Quasi-Static and Low Speed Loading Rates (2\% Fiber) } \\
\hline Specimen & $\begin{array}{c}\text { Sample } \\
\text { Rate } \\
(\mathrm{Hz})\end{array}$ & $\begin{array}{c}\text { Loading } \\
\text { Rate } \\
(\mathrm{kN} / \mathrm{s})\end{array}$ & $\begin{array}{c}\text { Displacement } \\
\text { Rate } \\
(\mathrm{mm} / \mathrm{min})\end{array}$ & $\begin{array}{c}\text { Maximum } \\
\text { Load } \\
(\mathrm{kN})\end{array}$ & $\begin{array}{c}\text { Tensile } \\
\text { Strength } \\
(\mathrm{MPa})\end{array}$ \\
\hline A & \multirow{4}{*}{1} & \multirow{4}{*}{0.2} & \multirow{4}{*}{$6 \times 10^{-3}$} & 468.1 & 14.9 \\
\hline B & & & & 439.8 & 14.0 \\
\hline $\mathrm{C}$ & & & & 458.7 & 14.6 \\
\hline Average & & & & 455.5 & 14.5 \\
\hline A & \multirow{3}{*}{2} & \multirow{3}{*}{2} & \multirow{3}{*}{$6 \times 10^{-2}$} & 449.2 & 14.3 \\
\hline B & & & & 468.1 & 14.9 \\
\hline Average & & & & 458.7 & 14.6 \\
\hline A & \multirow{3}{*}{2} & \multirow{3}{*}{20} & \multirow{3}{*}{$6 \times 10^{-1}$} & 458.7 & 14.6 \\
\hline B & & & & 471.2 & 15.0 \\
\hline Average & & & & 464.9 & 14.8 \\
\hline A & \multirow{3}{*}{3} & \multirow{3}{*}{200} & \multirow{3}{*}{6} & 480.7 & 15.3 \\
\hline B & & & & 468.1 & 14.9 \\
\hline Average & & & & 474.4 & 15.1 \\
\hline
\end{tabular}

Table 4.12: Tensile strength of UHP-FRC with $3 \%$ fiber.

\begin{tabular}{|c|c|c|c|c|c|}
\hline \multicolumn{6}{|c|}{ Quasi-Static and Low Speed Loading Rates (3\% Fiber) } \\
\hline Specimen & $\begin{array}{c}\text { Sample } \\
\text { Rate } \\
(\mathrm{Hz})\end{array}$ & $\begin{array}{c}\text { Loading } \\
\text { Rate } \\
(\mathrm{kN} / \mathrm{s})\end{array}$ & $\begin{array}{c}\text { Displacement } \\
\text { Rate } \\
(\mathrm{mm} / \mathrm{min})\end{array}$ & $\begin{array}{l}\text { Maximum } \\
\text { Load } \\
(\mathrm{kN})\end{array}$ & $\begin{array}{l}\text { Tensile } \\
\text { Strength } \\
(\mathrm{MPa})\end{array}$ \\
\hline A & \multirow{3}{*}{1} & \multirow{3}{*}{0.2} & \multirow{3}{*}{$6 \times 10^{-3}$} & 512.1 & 16.3 \\
\hline B & & & & 493.2 & 15.7 \\
\hline Average & & & & 502.6 & 16.0 \\
\hline $\mathrm{A}$ & 2 & 2 & $6 \times 10^{-2}$ & 502.6 & 16.0 \\
\hline A & 2 & 20 & $6 \times 10^{-1}$ & 515.2 & 16.4 \\
\hline A & 3 & 200 & 6 & 593.8 & 18.9 \\
\hline
\end{tabular}




\subsection{Flexural Strength Test}

Flexural strength test was conducted under quasi-static loading using MTS 793 test system and in accordance with ASTM C1609 / C1609M - 12 standard test method for flexural performance of fiber reinforced concrete (using beam with third-point loading).

\subsubsection{Flexural Strength Test under Quasi-Static and Low Speed Loading Rates}

The flexural strength test results for UHP-FRC specimens with different fiber contents at various strain rates under quasi-static and low speed loading rates are tabulated in Tables 4.13 to 4.15.

Table 4.13: Flexural strength of UHP-FRC with $1 \%$ fiber.

\begin{tabular}{|c|c|c|c|c|}
\hline \multicolumn{5}{|c|}{ Quasi-Static and Low Speed Loadings (1\% Fiber) } \\
\hline Specimen & $\begin{array}{c}\text { Strain Rate } \\
\left(\mathrm{s}^{-1}\right)\end{array}$ & $\begin{array}{l}\text { Displacement Rate } \\
(\mathrm{mm} / \mathrm{min})\end{array}$ & $\begin{array}{l}\text { Maximum Load } \\
(\mathrm{kN})\end{array}$ & $\begin{array}{c}\text { Flexural Strength } \\
(\mathrm{MPa})\end{array}$ \\
\hline A & \multirow{3}{*}{$1 \times 10^{-6}$} & \multirow{3}{*}{0.018} & 22.4 & 10.1 \\
\hline B & & & 24.4 & 11.0 \\
\hline Average & & & 23.4 & 10.5 \\
\hline $\mathrm{A}$ & $1 \times 10^{-5}$ & 0.18 & 29.8 & 13.4 \\
\hline A & $1 \times 10^{-4}$ & 1.80 & 24.7 & 11.1 \\
\hline
\end{tabular}

Table 4.14: Flexural strength of UHP-FRC with $2 \%$ fiber.

\begin{tabular}{|c|c|c|c|c|}
\hline \multicolumn{5}{|c|}{ Quasi-Static and Low Speed Loadings (2\% Fiber) } \\
\hline Specimen & $\begin{array}{c}\text { Strain Rate } \\
\left(\mathrm{s}^{-1}\right)\end{array}$ & $\begin{array}{l}\text { Displacement Rate } \\
(\mathrm{mm} / \mathrm{min})\end{array}$ & $\begin{array}{l}\text { Maximum Load } \\
(\mathrm{kN})\end{array}$ & $\begin{array}{l}\text { Flexural Strength } \\
\text { (MPa) }\end{array}$ \\
\hline A & \multirow{4}{*}{$1 \times 10^{-6}$} & \multirow{4}{*}{0.018} & 48.7 & 21.9 \\
\hline B & & & 42.9 & 19.3 \\
\hline $\mathrm{C}$ & & & 33.5 & 15.1 \\
\hline Average & & & 51.3 & 23.1 \\
\hline A & \multirow{3}{*}{$1 \times 10^{-5}$} & \multirow{3}{*}{0.18} & 50.2 & 22.6 \\
\hline B & & & 39.5 & 17.8 \\
\hline Average & & & 44.7 & 20.1 \\
\hline A & \multirow{3}{*}{$1 \times 10^{-4}$} & \multirow{3}{*}{1.80} & 41.3 & 18.6 \\
\hline B & & & 56.9 & 25.6 \\
\hline Average & & & 49.1 & 22.1 \\
\hline
\end{tabular}


Table 4.15: Flexural strength of UHP-FRC with $3 \%$ fiber.

\begin{tabular}{|c|c|c|c|c|}
\hline \multicolumn{5}{|c|}{ Quasi-Static and Low Speed Loadings (3\% Fiber) } \\
\hline Specimen & $\begin{array}{c}\text { Strain Rate } \\
\left(\mathrm{s}^{-1}\right)\end{array}$ & $\begin{array}{l}\text { Displacement Rate } \\
(\mathrm{mm} / \mathrm{min})\end{array}$ & $\begin{array}{l}\text { Maximum Load } \\
(\mathrm{kN})\end{array}$ & $\begin{array}{c}\text { Flexural Strength } \\
\text { (MPa) }\end{array}$ \\
\hline A & \multirow{3}{*}{$1 \times 10^{-6}$} & \multirow{3}{*}{0.018} & 86.4 & 38.9 \\
\hline B & & & 56.2 & 25.3 \\
\hline Average & & & 71.3 & 32.1 \\
\hline A & $1 \times 10^{-5}$ & 0.18 & 63.1 & 28.4 \\
\hline $\mathrm{A}$ & $1 \times 10^{-4}$ & 1.80 & 51.3 & 23.1 \\
\hline
\end{tabular}

The flexural load-displacement curves for UHP-FRC with different fiber contents under quasistatic loading at displacement rate of $0.018 \mathrm{~mm} / \mathrm{min}$ are shown in Figure 4.2.

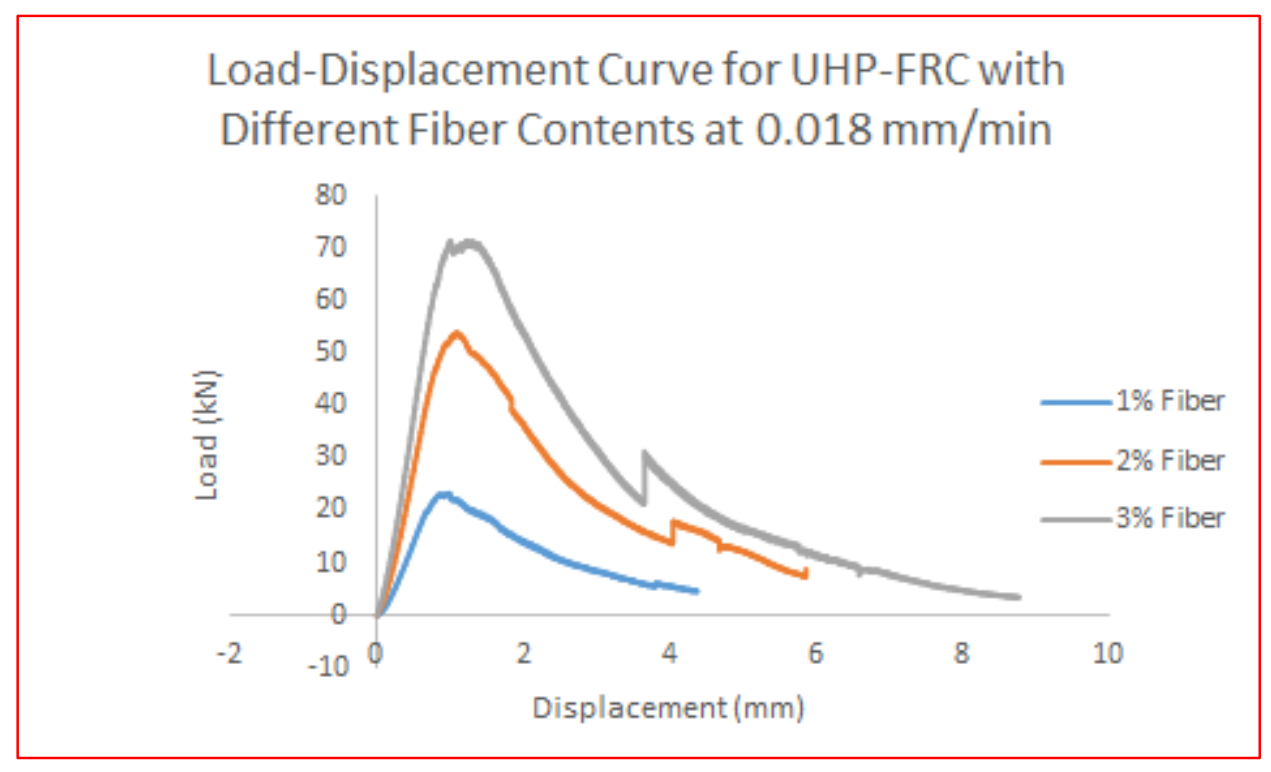

Figure 4.2: Load-displacement curves for UHP-FRC at $0.018 \mathrm{~mm} / \mathrm{min}$ rate.

the stress-displacement curves for UHP-FRC with different fiber contents under quasi-static loading at displacement rate of $0.018 \mathrm{~mm} / \mathrm{min}$ are shown in Figure 4.3. The average value was used as the flexural strength of the identical tested specimens. 


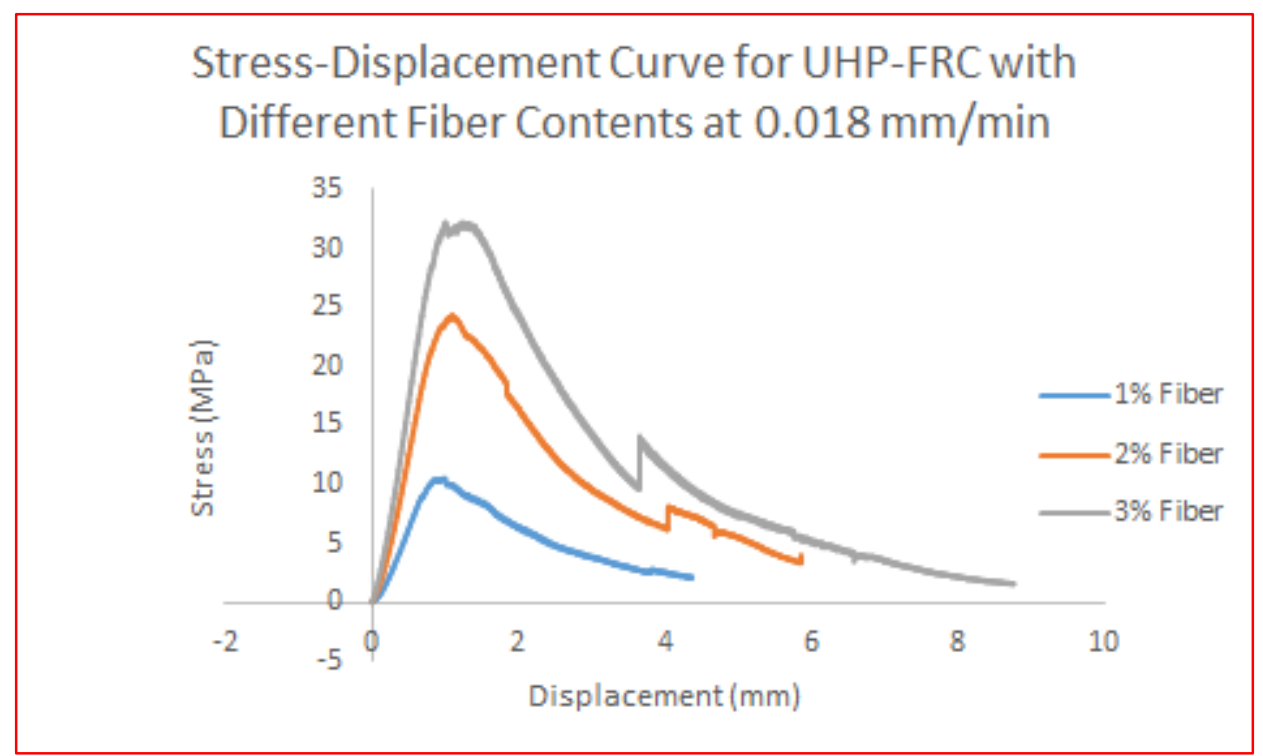

Figure 4.3: Stress-displacement curves for UHP-FRC at $0.018 \mathrm{~mm} / \mathrm{min}$ rate.

\subsubsection{Impact Test}

Prism specimens $(400 \times 100 \times 100 \mathrm{~mm})$ were used in flexural strength test under dynamic (impact) loading. For conducting this test, drop hammer weight equipment was used. Following each drop, load-time curve was obtained by processing the data extracted from the data acquisition system and then, loading rates and corresponding strain rates were computed. Figure 4.4 shows a UHPFRC prism specimen with 3\% fiber after being impacted by a weight rig, dropped from $1000 \mathrm{~mm}$ height.

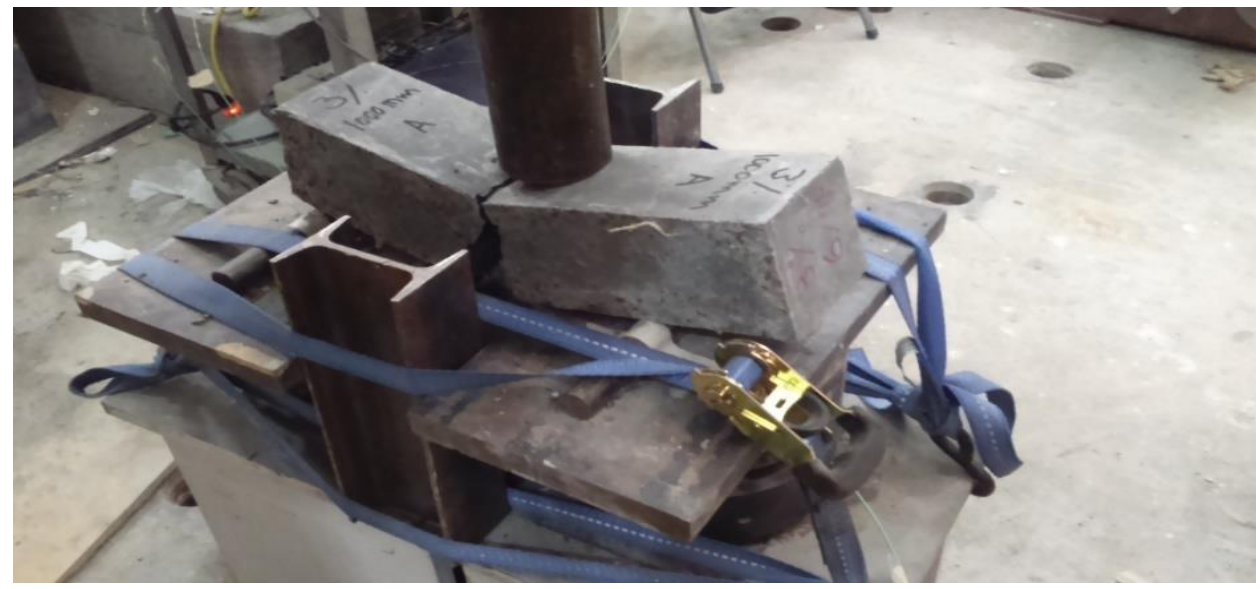

Figure 4.4: A UHP-FRC prism specimen after impact test. 
Loading rate was obtained by dividing the maximum load by the overall time from the onset of the impact to the point of maximum force. The maximum forces and loading rates were computed from the output data obtained from the two load cells. Force-time curve for UHP-FRC with 1\% fiber and $600 \mathrm{~mm}$ drop height can be found in Appendix E.

If the force-time curve for the drop height of $1000 \mathrm{~mm}$ shows the following values:

$\mathrm{F}=112 \mathrm{kN}$ and $\mathrm{t}=0.3 \times 10^{-3} \mathrm{sec}$.

Therefore, the loading rate can be calculated as:

$\mathrm{P}=\mathrm{F} / \mathrm{t}=112 / 0.0003=373333.3 \mathrm{kN} / \mathrm{s}$

Finally, the strain rate will be computed from equation (11):

$\varepsilon^{\cdot}=1.5 \mathrm{PL} / \mathrm{Ebd}^{2}=1.5(373333.3)(300) /(49.8)(100)(100)^{2}=3.37 \mathrm{~s}^{-1}$

Calculated loading rates, as well as corresponding strain rates for UHP-FRC specimens having different fiber contents with various drop heights are tabulated in Tables 4.16 to 4.18.

Table 4.16: Loading and strain rates for UHP-FRC with $1 \%$ fiber.

\begin{tabular}{|c|c|c|c|c|c|c|}
\hline Specimen & $\begin{array}{c}\text { Drop } \\
\text { Height } \\
(\mathrm{mm})\end{array}$ & $\begin{array}{c}\text { Maximum } \\
\text { Force } \\
(\mathrm{kN})\end{array}$ & $\begin{array}{c}\text { Flexural } \\
\text { Stress } \\
(\mathrm{MPa})\end{array}$ & $\begin{array}{c}\text { Impact } \\
\text { Duration } \\
\text { (MS) }\end{array}$ & $\begin{array}{c}\text { Loading } \\
\text { Rate } \\
(\mathrm{kN} / \mathrm{s})\end{array}$ & $\begin{array}{c}\text { Strain } \\
\text { Rate } \\
\left(\mathrm{s}^{-1}\right)\end{array}$ \\
\hline A & \multirow{3}{*}{600} & 71.6 & 32.2 & 0.51 & 140392.2 & 1.27 \\
\hline B & & 68.3 & 30.7 & 0.47 & 145319.1 & 1.31 \\
\hline Average & & 69.9 & 31.4 & 0.49 & 142855.6 & 1.29 \\
\hline $\mathrm{A}$ & \multirow{3}{*}{1000} & 68.2 & 30.7 & 0.22 & 309866.7 & 2.80 \\
\hline B & & 72.8 & 32.8 & 0.23 & 316521.7 & 2.86 \\
\hline Average & & 70.5 & 31.7 & 0.225 & 313194.2 & 2.83 \\
\hline
\end{tabular}


Table 4.17: Loading and strain rates for UHP-FRC with $2 \%$ fiber.

\begin{tabular}{|c|c|c|c|c|c|c|}
\hline Specimen & $\begin{array}{l}\text { Drop } \\
\text { Height } \\
(\mathrm{mm})\end{array}$ & $\begin{array}{c}\text { Maximum } \\
\text { Force } \\
(\mathrm{kN})\end{array}$ & $\begin{array}{c}\text { Flexural } \\
\text { Stress } \\
(\mathrm{MPa})\end{array}$ & $\begin{array}{c}\text { Impact } \\
\text { Duration } \\
\text { (MS) }\end{array}$ & $\begin{array}{c}\text { Loading } \\
\text { Rate } \\
(\mathrm{kN} / \mathrm{s})\end{array}$ & $\begin{array}{c}\text { Strain } \\
\text { Rate } \\
\left(\mathrm{s}^{-1}\right)\end{array}$ \\
\hline A & \multirow{3}{*}{600} & 68.0 & 30.6 & 0.46 & 147826.1 & 1.34 \\
\hline B & & 64.3 & 28.9 & 0.41 & 156829.3 & 1.42 \\
\hline Average & & 66.1 & 29.7 & 0.43 & 152327.7 & 1.38 \\
\hline A & \multirow{3}{*}{1000} & 69.4 & 31.2 & 0.19 & 365200 & 3.30 \\
\hline B & & 71.7 & 32.3 & 0.20 & 358560 & 3.24 \\
\hline Average & & 70.5 & 31.7 & 0.19 & 361880 & 3.27 \\
\hline
\end{tabular}

Table 4.18: Loading and strain rates for UHP-FRC with $3 \%$ fiber.

\begin{tabular}{|c|c|c|c|c|c|c|}
\hline Specimen & $\begin{array}{c}\text { Drop } \\
\text { Height } \\
(\mathrm{mm})\end{array}$ & $\begin{array}{c}\text { Maximum } \\
\text { Force } \\
(\mathrm{kN})\end{array}$ & $\begin{array}{c}\text { Flexural } \\
\text { Stress } \\
(\mathrm{MPa})\end{array}$ & $\begin{array}{c}\text { Impact } \\
\text { Duration } \\
(\mathrm{MS})\end{array}$ & $\begin{array}{c}\text { Loading } \\
\text { Rate } \\
(\mathrm{kN} / \mathrm{s})\end{array}$ & $\begin{array}{c}\text { Strain } \\
\text { Rate } \\
\left(\mathrm{s}^{-1}\right)\end{array}$ \\
\cline { 1 - 5 } $\mathrm{A}$ & \multirow{2}{*}{1000} & 112 & 50.4 & 0.30 & 373333.3 & 3.37 \\
\cline { 5 - 7 } $\mathrm{B}$ & 94.3 & 42.4 & 0.25 & 377200 & 3.41 \\
\cline { 5 - 7 } Average & 103.1 & 46.4 & 0.27 & 375266.6 & 3.39 \\
\hline
\end{tabular}

Figures 4.5 and 4.6 show the UHP-FRC prism specimens after impact test, classified based on various fiber contents, and different drop heights.

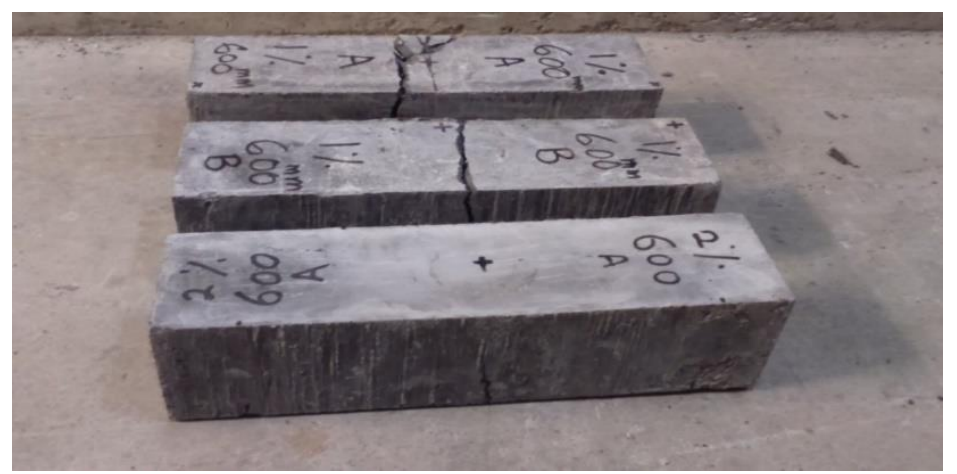

Figure 4.5: UHP-FRC specimens with $1 \& 2 \%$ fiber, after impact test (drop height: $600 \mathrm{~mm}$ ). 

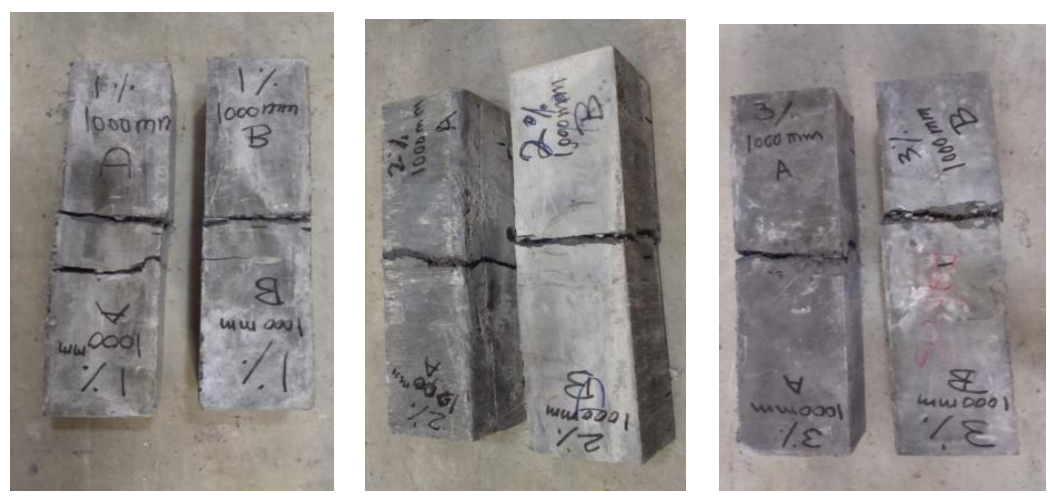

Figure 4.6: UHP-FRC specimens with 1, 2 \& 3\% fiber, after impact test (drop height: $1 \mathrm{~m}$ ).

Dynamic flexural stresses, strain rates, and the corresponding drop heights for UHP-FRC with different fiber contents are shown in Table 4.19.

Table 4.19: Dynamic flexural stress for UHP-FRC with different fiber contents.

\begin{tabular}{|c|c|c|c|c|}
\hline Specimen & $\begin{array}{c}\text { Fiber Content } \\
(\%)\end{array}$ & $\begin{array}{l}\text { Drop Height } \\
(\mathrm{mm})\end{array}$ & $\begin{array}{l}\text { Strain Rate } \\
\qquad\left(\mathrm{s}^{-1}\right)\end{array}$ & $\begin{array}{c}\text { Dynamic } \\
\text { Flexural } \\
\text { Stress, } \mathrm{f}_{\mathrm{cd}} \\
(\mathrm{MPa})\end{array}$ \\
\hline $\mathrm{A}$ & \multirow{6}{*}{1} & \multirow{3}{*}{600} & 1.27 & 32.2 \\
\hline B & & & 1.31 & 30.7 \\
\hline Average & & & 1.29 & 31.4 \\
\hline $\mathrm{A}$ & & \multirow{3}{*}{1000} & 2.80 & 30.7 \\
\hline B & & & 2.86 & 32.8 \\
\hline Average & & & 2.83 & 31.7 \\
\hline A & \multirow{6}{*}{2} & \multirow{3}{*}{600} & 1.34 & 30.6 \\
\hline B & & & 1.42 & 28.9 \\
\hline Average & & & 1.38 & 29.7 \\
\hline A & & \multirow{3}{*}{1000} & 3.30 & 31.2 \\
\hline B & & & 3.24 & 32.3 \\
\hline Average & & & 3.27 & 31.7 \\
\hline A & \multirow{3}{*}{3} & \multirow{3}{*}{1000} & 3.37 & 50.4 \\
\hline B & & & 3.41 & 42.4 \\
\hline Average & & & 3.39 & 46.4 \\
\hline
\end{tabular}




\subsubsection{Dynamic Increase Factor (DIF)}

Dynamic Increase Factor (DIF) for each specimen was computed by dividing the dynamic peak stress from each drop, by the static compressive strength under the quasi-static reference strain rate $\left(1 \times 10^{-6} \mathrm{~s}^{-1}\right)$. DIF for each specimen is shown in Table 4.20 .

Table 4.20: DIF under impact test.

\begin{tabular}{|c|c|c|c|c|}
\hline $\begin{array}{c}\text { Fiber Content } \\
(\%)\end{array}$ & $\begin{array}{l}\text { Loading } \\
\text { Type }\end{array}$ & $\begin{array}{l}\text { Strain } \\
\text { Rate } \\
\left(\mathrm{s}^{-1}\right)\end{array}$ & $\begin{array}{l}\text { Stress } \\
\text { (MPa) }\end{array}$ & DIF \\
\hline \multirow{5}{*}{1} & \multirow{3}{*}{$\begin{array}{c}\text { Quasi-Static and } \\
\text { Low Speed } \\
\text { Loadings }\end{array}$} & $1 \times 10^{-6}$ & 10.5 & 1.00 \\
\hline & & $1 \times 10^{-5}$ & 13.4 & 1.28 \\
\hline & & $1 \times 10^{-4}$ & 11.1 & 1.06 \\
\hline & \multirow{2}{*}{ Dynamic } & 1.29 & 31.4 & 2.99 \\
\hline & & 2.83 & 31.7 & 3.02 \\
\hline \multirow{5}{*}{2} & \multirow{3}{*}{$\begin{array}{c}\text { Quasi-Static and } \\
\text { Low Speed } \\
\text { Loadings }\end{array}$} & $1 \times 10^{-6}$ & 23.1 & 1.00 \\
\hline & & $1 \times 10^{-5}$ & 20.1 & 0.87 \\
\hline & & $1 \times 10^{-4}$ & 22.1 & 0.96 \\
\hline & \multirow{2}{*}{ Dynamic } & 1.38 & 29.7 & 1.29 \\
\hline & & 3.27 & 31.7 & 1.37 \\
\hline \multirow{4}{*}{3} & \multirow{3}{*}{$\begin{array}{c}\text { Quasi-Static and } \\
\text { Low Speed } \\
\text { Loadings }\end{array}$} & $1 \times 10^{-6}$ & 32.1 & 1.00 \\
\hline & & $1 \times 10^{-5}$ & 28.4 & 0.88 \\
\hline & & $1 \times 10^{-4}$ & 23.1 & 0.72 \\
\hline & Dynamic & 3.39 & 46.4 & 1.44 \\
\hline
\end{tabular}

Figure 4.7 shows the DIF-strain rate graph (fitted lines) for flexural strength of each UHP-FRC specimen under impact loads. 


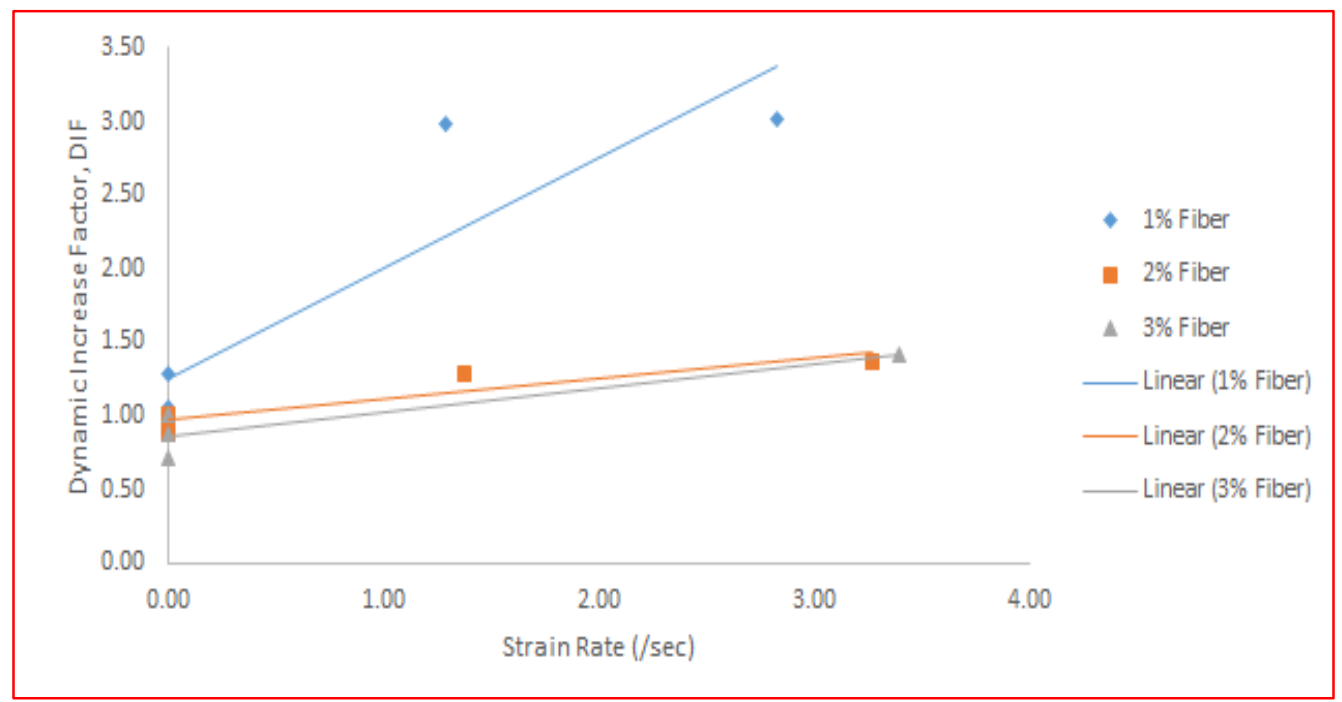

Figure 4.7: Experimental DIF-strain rate fitted lines for flexural strength of UHP-FRC under impact loads.

\subsection{Result Analysis and Discussion}

In this section, the effect of strain rates on UHP-FRC specimens with different fiber contents for compressive strength, tensile strength, and flexural strength is evaluated. Compressive strength tests for both quasi-static and dynamic loadings were conducted on cylindrical specimens in MTS 815 test system. Figure 3.9 shows that UHP-FRC specimens resist against spelling after reaching the maximum load. This is shown on the stress-strain diagram as a gradual lowering of the descending branch of the graph right after the point of maximum stress. High ductility of UHPFRC can be showed from the greater area under the graph compared to other types of concrete.

Compressive strength of UHP-FRC with various fiber contents, under quasi-static and dynamic loadings has been given in Tables 4.1 to 4.6. These tabulated results show that the compressive strength of UHP-FRC has significantly increased at higher strain rates so that compressive strength of UHP-FRC under dynamic load is greater than that under quasi-static load. Also, comparison of DIF-strain rate fitted lines for compressive strength of UHP-FRC specimens, shown in Figure 4.1, and specimens made from other types of concrete (NC or HSC), shows that UHP-FRC demonstrates less sensitivity to strain rates.

Tensile strength of UHP-FRC with different fiber contents, under quasi-static and low speed loading rates has been tabulated in Tables 4.10 to 4.12. These results show that the tensile strength of UHP- 
FRC has increased at higher strain rates so that tensile strength of UHP-FRC under dynamic load is greater than that under quasi-static, and low speed loading rates. The test results prove the role of fibers in achieving higher tensile strength for UHP-FRC.

Flexural strength tests under quasi-static and low speed loading rates were conducted on prism specimens. For UHP-FRC with different fiber contents, the maximum strain rate of $1 \times 10^{-4}$ has been experienced. For conducting flexural strength test under dynamic loading, prism specimens were tested under impact loading, using drop weight hammer test system at various drop heights of 600 and 1000 mm. Figures 4.5 and 4.6 show that UHP-FRC specimens performed very well under impact loading and they were not entirely broken after the test conducted from a drop height of $600 \mathrm{~mm}$. In order to have a complete fracture in UHP-FRC specimens with 2 and $3 \%$ fiber, the hammer was dropped from a height of $1000 \mathrm{~mm}$ as well. Prism specimens were failed under the impact test due to fiber pull out type of failure.

UHP-FRC specimens with $3 \%$ fiber were not completely broken even after impacted by the hammer from a height of $1000 \mathrm{~mm}$. As a result, UHP-FRC specimens with $3 \%$ fiber are considered stiffer compared to UHP-FRC with 1 or $2 \%$ fiber. Also, Figure 4.2 shows that the area under loaddisplacement curve for UHP-FRC with $3 \%$ fiber is greater than the areas under the curves plotted for the composites with 1 or $2 \%$ fiber.

Table 4.19 shows the impact test results at high strain rates. Based on this Table, flexural strength was increased after increasing the drop height of the hammer. Figure 4.7 illustrates the relationship between DIF and strain rate for flexural strength of UHP-FRC with different fiber contents under impact loads. The figure shows that, the UHP-FRC specimens with $1 \%$ fiber demonstrated higher sensitivity to strain rate compared to the specimens with $2 \%$ fiber. Also, the UHP-FRC specimens with $3 \%$ fiber demonstrated the least sensitivity to strain rate compared to the composites with 1 and $2 \%$ fiber.

Furthermore, the UHP-FRC specimens with 3\% fiber showed lower DIFs at corresponding strain rates compared to the composites with 1 or $2 \%$ fiber. Figure 4.7 demontrates that, the UHP-FRC specimens with $1 \%$ fiber have a steeper slope in DIF-strain rate graph compared to the UHP-FRC specimens with 2 or $3 \%$ fiber. Table 4.20 shows the Maximum strain rate of $3.39 \mathrm{~s}^{-1}$ with a DIF of 
1.44 which indicates that the UHP-FRC specimens with $3 \%$ fiber are less sensitive to the strain rate compared to the composites with 1 or $2 \%$ fiber.

While the UHP-FRC specimens with $3 \%$ fiber have a DIF of 1.44 at the strain rate of $3.39 \mathrm{~s}^{-1}$, the UHP-FRC specimens with 1 and 2\% fiber demonstrate DIFs of 3.02 and 1.37 at the strain rates of 2.83 and $3.27 \mathrm{~s}^{-1}$, respectively. Since UHP-FRC presents an outstanding performance under impact loading and shows low sensitivity to strain rate, it can be used as an excellent concrete material for structures subjected to dynamic loading such as impact and blast resistant structures. 


\section{Chapter 5 \\ CONCLUSIONS}

"Once we accept our limits, we go beyond them."

Albert Einstein (1879-1955)

This project aims to determine the strain rate effects on UHP-FRC with different fiber contents. The experimental program was designed for compressive strength, indirect tensile strength, and flexural strength tests under quasi-static and dynamic loading. For conducting flexural strength test under quasi-static loading rates, an advanced MTS 793 test system was used to deal with low strain rates while for conducting flexural strength test under dynamic loading rates with higher strain rates, a drop hammer test system was developed. The test results were used to calculate DIF for each UHP-FRC specimen in order to identify the effect of various strain rates on specimens with different fiber contents. A very good understanding of strain rate is essential to verify the performance of UHP-FRC specimens under dynamic loading including, but not limited to impact and blast loading.

\subsection{Research Findings}

In compressive strength test, the compressive strength of UHP-FRC cylindrical specimens were increased with the increase of the strain rate from quasi-static loading range to dynamic loading range. However, the addition of fiber did not significantly influence the compressive strength of UHPFRC specimens. UHP-FRC specimens showed outstanding performance even under higher loading rates.

Indirect tensile strength test was conducted to determine the effects of strain rate on tensile strength

of concrete. The results from tensile strength test show that high tensile strength and high ductility properties of UHP-FRC composites can be achieved through optimizing the packing density of the cementitious matrix.

Flexural strength test on prism specimens under quasi-static and low speed loading rates has revealed that UHP-FRC is not a brittle material and the contribution of fiber was showed in different areas. Fibers significantly improved the first-crack stress and reduced the brittleness 
of the composite, and provided ductility as cracks opened. The test also proved that it is possible to fully characterize the tensile performance of UHP-FRC specimens by means of three-point flexural tests.

Flexural strength test on prism specimens under dynamic loading rates using RU drop hammer test system demonstrated that the DIF of UHP-FRC specimens were increased with the increase of strain rate. The test results also showed that the flexural strength DIFs of UHP-FRC specimens are not high because UHP-FRC composites have low strain rate sensitivity due to their significant ductility.

\subsection{Recommendation for Future Work}

A wide range of various experimental programs have been developed worldwide to fulfill the requirements of increasing number of applications. Nevertheless, to close existing gaps of knowledge and to come to a widespread usual application based on comprehensive technical regulations, further research and development is necessary. The investigation carried out aimed to study the strain rate effects on UHP-FRC specimens with different fiber contents. However, due to the limitations of time, financial resources, laboratory equipment, and those limitations raised during the experimental program, the lack of deep investigation in some areas of study was unavoidable. Therefore, future work using enough UHP-FRC specimens with various fiber contents, based on the findings of this preliminary study is recommended to get more accurate results. Moreover, conducting direct tensile strength test on cylindrical specimens of UHP-FRC with different fiber contents is suggested. 


\section{BIBLIOGRAPHY}

[1] Nematollahi, B., Saifulnaz M. R., R., Saleh Jaafar, M., and Lei Voo, Y., “A Review on Ultra High Performance 'ductile' Concrete (UHPdC) Technology,” International Journal of Civil And Engineering, Vol. 2, No. 3, pp. 1003-1018, 2012.

[2] Wille, K., Naaman, A. E, EI-Tawil, S., and Parra-Montesinos, G., "Ultra-High Performance Concrete and Fiber Reinforced Concrete: Achieving Strength and Ductility without Heat Curing," Materials and Structures, Vol. 45, pp. 309-324, 2012.

[3] Naaman, A. E, "High Performance Fiber Reinforced Cement Composites," Department of Civil and Environmental Engineering University of Michigan, Ann Arbor, MI, 48109-2125, U.S.A.

[4] Imran Latif, Q. B., Rahman, I. A., Ahmad Zaidi, A. M., and Latif, K., "Critical Impact Energy for Spalling, Tunnelling and Penetration of Concrete Slab Impacted with Hard Projectile,” KSCE Journal of Civil Engineering, 2014.

[5] Kim, D., Naaman, A. E, and EI-Tawil, S., "High Performance Fiber Reinforced Cement Composites with Innovative Slip Hardending Twisted Steel Fibers," International Journal of Concrete Structures and Material, Vol. 3, No. 2, pp. 119$126,2009$.

[6] Malvar, L. J., and Ross, C. A., "Review of Strain Rate Effects for Concrete in Tension,” ACI Materials Journal, Vol. 95, No. 6, pp. 735-739, 1998.

[7] Aoude, H., Belghiti, M., Cook, W., and Mitchell, D., "Response of Steel FiberReinforced Concrete Beams with and without Stirrups," ACI Structural Journal, Vol. 109, No. 3, 2012. 
[8] Wille, K., Kim, D., and Naaman, A. E, "Strain-Hardening UHP-FRC with Low Fiber Contents," Materials and Structures, Vol. 44, pp. 583-598, 2011.

[9] Bindiganavile, V., Banthia N., and Aarup, B., "Impact Response of Ultra-High-Strength FibreReinforced Cement Composite," ACI Materials Journal, Vol. 99, No. 6, pp. 543-548, 2002.

[10] Lei Voo, Y., Nematollahi, B., and Bin Mohamed Siad, A. B., "Application of Ultra High Perfommance Fiber Reinforced Concrete - The Malaysia Perspective," Internation Journal of Sustainable Construction Engineering \& Technology," Vol. 3, No. 1, pp. 26-44, 2012.

[11] Kang, S.T., Lee,Y., Park, Y.D., and Kim, J.K., "Tensile Fracture Properties of an Ultra High Performance Fibre Reinforced Concrete (UHPFRC) with Steel Fiber, "Composite Structures, Vol. 92, No. 1, pp. 61-71, 2010.

[12] Nowodworski, H., and Rosiak, K., "Ultra-High Performance Concrete with Ductility," in 2nd Material Specialty Conference, Montreal, 2002.

[13] Rossi, P., Arca, A., Parant, E., and Fakhri P., "Bending and Compressive Behavior of a New Cement Composite," Cement and Concrete Research, Vol. 35, No. 1, pp. 27-33, 2005.

[14] Wille, K., Naaman, A. E., and Parra Montensinos, G. J., "Ultra-High Performance Concrete with Compressive Strength Exceeding $150 \mathrm{MPa}$ : A Simpler Way," ACI Materials Journal,Vol. 108, No. 1, pp. 46-54, 2011.

[15] Habel, K., Charron, J., Braike, S., Hooton, R., Gauvreau, P., and Massicotte, B., "UltraHigh Performance Fiber Reinforced Concrete Mix Design in Central Canada," Canadian Journal of Civil Engineering, Vol. 35, 2008, pp. 217-224. 
[16] Graybeal, H. G. and Russel B. A, "Ultra-High Performance Concrete: A State-of-theArt Report for the Bridge Community, "Federal Highway Administration FHWA-HRT-13060, U.S, 2013.

[17] Gao, X., Molyneaux, T., Patnaikunu, I., and Rahman, S., "Dynamic Properties of Fiber Reinforced and Plain Ultra High Performance Concrete," Melbourne, 2010.

[18] Habel, K., and Gavreau, P., "Response of Ultra-High Performance Fiber Reinforced Concrete (UHPFRC) to Impact and Static Loading," Cement and Composite Strucutres, Vol. 30, No. 10, pp. 938-946, 2008.

[19] G.B, "Material Property Characterization of Ultra-High Performance Concrete," FHWA, U.S. Department of Transportation, Report No. FHWA-HRT-06-103, McLean, Va, 2006.

[20] Habell, K., Viviani, M., Denarie, E., and Bruhwiler, E., "Development of the Mechanical Properties of an Ultra-High Performance Fiber Reinforced Concrete (UHPFRC)," Cement Cement and Cocnrete Research, Vol. 36, pp. 1362-1368, 2006.

[21] Naaman, A. E., "High Performance Fiber Reinforced Cement Composites: Classification and Application," in CBM-CI International Workshop, Pakistan, karachi, 2007.

[22] Tuan, NV.,Ye, G., Breugel, K, Copuroglu, O., "Hydration and Microstructure of Ultrahigh Performance Concrete Incorporating Rice Husk Ash,” Cem Concr Res 2011; 41:1104-11.

[23] Yang, SL., Millard, SG., Soutsos, MN., Barnett, SJ., Le, TT., "Influence of Aggregate and Curing Regime on the Mechanical Properties of Ultra-High Performance Fiber Reinforced Concrete (UHPFRC). Constr Build Mater 2009; 23:2291-8.

[24] Katrin H, Paul G., "Response of Ultra-High Performance Fiber Reinforced Concrete 
(UHPFRC) to impact and static loading," Cem Concr Compos 2008; 30: 938-46.

[25] Bragov AM, Petrov Yu V, Karihaloo BL, Konstantinov A Yu, Lamzin DA, Lomunov AK, et al., "Dynamic Strengths and Toughness of an Ultra-High Performance Fiber Reinforced Concrete," Eng Fract Mech 2013; 110:477-88.

[26] Martin, J., \& Stanton, J., "Experimental Testing to Determine Concrete Fracture Energy Using Simple Laboratory Test Setup,” ACI Materials Journal, 575-584, 2007.

[27] Fehling, E., and Leutbecher, T., "Design Relevant Properties of Hardened Ultra High Performance Concrete," International Symposium on Ultra High Performance Concrete, Vol. 3, pp. 327 - 338, 2004.

[28] N. C, "Ultra High Strength Steel Fiber Reinforced Concrete. Part 1: Basic Strength Properties of Composite Matrix. Part II: Structural Application of Composite," in University of Denmark, Denmark, 1995.

[29] Graybeal, B., \& Davis, M., "Cylinder or Cube: Strength Testing of 80 to $200 \mathrm{MPa}$ (11.6 to 29 ksi) Ultra-High-Performance Fiber-Reinforced Concrete,” ACI Materials Journal, Vol. 105, No. 6, pp. 603-609, 2008.

[30] Graybeal, B., "Practical Means for Determination of the Tensile Behavior of UltraHigh Performance Concrete," Journal of ASTM International, Vol. 3, No. 8, 2006.

[31] http://civil-engg-world.blogspot.ca/2009/04/relation-between-compressive-and.html

[32] http://ncdot.org

[33] http://quizlet.com

[34] Fujikake, K., Senga, T., Ueda, N., Ohno, T., and Katagiri, M., "Effects of Strain Rate on 
Tensile Behavior of Reactive Powder Concrete," Journal of Advanced Concrete Technology, Vol. 4, No. 1, pp. 79-84, 2006

[35] Wille, K., and Parra-Montesinos, G. J., "Effect of Beam Size, Casting Method, and Support Conditions on Flexural Behavior of Ultra-High-Performance Fiber-Reinforced Concrete,” ACI Materials Journal, 109, 379-388, 2012.

[36] Malogorzata, R., "The Influence of Strain Rate on the Strength of Concrete Taking into Account Experimental Techniques," Architecture Civil Engineering Enviriomernt, vol. 3, pp. 77-86, 2011.

[37] Grote, D. L., Park, S. W., Zhou, M., "Dynamic Behavior of Concrete at High Strain Rates and Pressures: Experimental Characterization," International Journal of Impact Engineeing, Vol. 25, No. 9, pp. 869-886, 2001.

[38] Lok, T., Zhao, P., "Impact Response of Steel Fiber Reinforced Concrete using a Split Hopkinson Pressure Bar," Journal of Materials in Civil Engineering, Vol. 16, pp. 54-59, 2004.

[39] C. E.-I. d. Beton, CEB-FIP Model Code 1990, Wiltshire: Redwood Books, 1993.

[40] Zhao, H., “A Study on Testing Techniques for Concrete-Like Materials under Compressive Impact Loading,” Cement and Concrete Composites, 20, 293-299, 1998.

[41] Ross, C.A., Tedesco, J.W., Kuennen, S.T., "Effects of Strain Rate on Concrete Strength," ACI Materials Journal, 92, 37-47, 1995.

[42] Bischoff ND, P., Perry, S., "Compressive Behavior of Concrete at High Strain Rates," Materials and Structures, Vol. 24, No. 6, pp. 425-450, 1991. 
[43] Malvar, L. J., and Crawford, J. E., "Dynamic Increase Factors for Concrete," Twentyeighth DDESB Seminar, Orlando, 1998.

[44] Cadoni, E., Meda, A., Plizzari, G. A., "Tensile Behavior of FRC under High Strain-Rate," Materials and Structures, 42, 1283-1294, 2009.

[45] Leppanen, J., "Concrete Subjected to Projectile and Fragment Impacts: Modelling of Crack Softening and Strain Rate Dependency in Tension,"International Journal of Impact Engineering, 32, 1828-1841, 2006.

[46] Brace, W.F., and Jones, A. H., "Comparison of uniaxial deformation in shock and static loading of three rocks," Journal of Geophysical Research, 76, 4913-4921, 1971.

[47] Walley, S. M., "Historical Review of High Strain Rate and Shock Properties of Ceramics Relevant to Their Application in Armour," Advances in Applied Ceramics, 109, 446-466, 2010.

[48] Millard, S., Molyneaux, T., Barnett, S., and Gao, X., "Dynamic Enhancemnet of BlastResistant Ultra High Performance Fiber-Reinforced Concrete under Flexural and Shear Loading," International Journal of Impact Engineering, Vol. 37, No. 4 pp. 405-413, 2010.

[49] http://www.fhwa.dot.gov/publications/research/infrastructure/structures/hpc/13060/002.cfm.

[50] Ngo, T., Mendis, P. and Krathammer, T., "Behavior of Ultra High-Strenght Prestressed Concrete Panels Subjected to Blast Loading," Journal Of Structural Engineering ASCE, Vol. 133, No. 11, pp. 1582-1590, 2007.

[51] Li, Z., Kulkarni, M., Shah, S.P., "New Test Method for Obtaining Softening Response of Unnotched Concrete Specimen under Uniaxial Tension," Experimental Mechanics, 33, 181$188,1993 b$. 
[52] Wille, K., El-Tawil, S., Naaman A. E., "Properties of Strain Hardening Ultra High Performance Fiber Reinforced Concrete (UHP-FRC) under Direct Tensile Loading," Cement and Concrete Composites, submitted, 2014.

[53] ASTM "Standard Test Method for Splitting Tensile Strength of Cylindrical Concrete Specimen" ASTM C 496-90, ASTM Annual Book of Standards, 04.02, ASTM Philadelphia, USA, pp. 269-272, 1992.

[54] RILEM, "Tension Splitting of Concrete Specimen" CPC6, 1975, Rilem Teclmical Recommendation for the Testing and Use of Construction Mate rials, pp. 21-22, E \& FN Spon, London, 1994.

[55] AENOR, "Ensayos de Hormigón-Rotura por Tracción Indirecta (Ensayo Brasileño)", UNE 83-36-85, Instituto Español de Normalización, Madrid, 1991.

[56] Bazant, Z.P., Kazemi, M.T., Hasegawa, T. and Mazars, J., "Size Effect in Brazilian SplitCylinder Test: Measurement and Analysis”, ACI Material Journal, 88, pp. 325-332, 1991.

[57] Tang, T., Shah, S.P. and Ouyang, C., "Fracture Mechanics and Size Effect of Concrete in Tension,” ASCE Journal of Structural Engineering, 118, pp. 3169-3185, 1992.

[58] Carmona, S., Gettu, R., Hurtado, C., and Martin, M.A., "Use of the Splitting-Tension Test to Characterize the Toughness of Fiber-Reinforced Concrete,"Anales de Mecanica de la Fractura, Vol. 12, pp. 233-238, 1995.

[59] Kolsky, H., “An Investigation of the Mechanical Properties of Materials at Very High Rates of Strain,” Proceedings of the Physical Society. Section B., 62, 676-700, 1949.

[60] Hauser, F.E., Simmons, J.A., Dorn, J.E., "Strain Rate Effects in Plastic Wave Propagation," in Response of metals to high velocity deformation (ed. P. G. Shewmon \& V. F. Zackay), 
93-109. New York: Interscience, 1961.

[61] Lindholm, U.S. and Yeakley, L.M., "High Strain-Rate Testing: Tension and Compression," Experimental Mechanics, 8, 1-9, 1968.

[62] Nicholas, T., "Tensile Testing of Materials at High Rates of Strain," Experimental Mechanics, 21, 177-185, 1981.

[63] Harding, J., and Welsh, L. M., “A Tensile Testing Technique for Fiber-Reinforced Composites at Impact Rates of Strain,” Journal of Materials Science, 18, 1810-1826, 1983.

[64] Staab, G.H., and Gilat, A., "A Direct-Tension Split Hopkinson Bar for High Strain-Rate Testing," Experimental Mechanics, 31, 232-235, 1991.

[65] Song, B., Connelly, K., Korellis, J., Lu, W-Y, and Antoun, B. R., "Improved Kolsky-Bar Design for Mechanical Characterization of Materials at High Strain Rates," Measurement Science and Technology, 20, 115701-1-8, 2009.

[66] Li, W., and Xu, J., "Impact Characterization of Basalt Fiber Reinforced Geopolymeric Concrete using a 100-mm-Diameter Split Hopkinson Pressure Bar," Materials Science and Engineering A, 513-514, 145-153, 2009.

[67] Owens, A. T., and Tippur, H. V., "Tensile Stress-Strain Response of Glass-Filled Epoxy under Elevated Rates of Loading using a Split Hopkinson Bar Apparatus,” Experimental Mechanics, 49, 799-811, 2009.

[68] Li, M., Wang, R., and Han, M-B., “A Kolsky Bar: Tension, Tension-Tension,” Experimental Mechanics, 33, 7-14, 1993a.

[69] Ross, C. A., "Split Hopkinson Pressure Bar Tests," Final Report, Air Force Engineering and Services Center, Tyndall AFB, Fl, ESL-TR-88-82, 1989. 
[70] Ross C.A., Thomson, P. Y., and Tedesco, J. W., "Split-Hopkinson Pressure-Bar Test on 185 Concrete and Mortar in Tension and Compression," ACI Materials Journal, 86, 475-481, 1989.

[71] Brara, A., Camborde, F., Klepaczko, J. R., and Mariotti, C., "Experimental and Numerical Study of Concrete at High Strain Rates in Tension," Mechanics of Materials, 33, 33-45, 2001.

[72] Cadoni, E., Labibes, K., Albertini, C., Berra, M., and Giangrasso, M., "Strain-Rate Effect on the Tensile Behaviour of Concrete at Different Relative Humidity Levels," Materials and Structures, 34, 21-26, 2001.

[73] Bindiganavile, V., "Dynamic Fracture Toughness of Fiber Reinforced Concrete," UBC, 2003.

[74] http://www.kniele.de/eng/kniele-mixingsys.html

[75] Aghajani-Namin, A., "Strain Rate Sensitivity of Ultra-High Performance Fiber Reinforced Concrete," MEng Project Report, 76, 2014.

[76] Acker, P., "Ultrahigh-Performance Concrete: Material Engineering by Nanoindentation Testing and Nanomechanical Analysis," NICOM 2: Proceedings of the 2nd International Symposium on Nanotechnology in Construction, Y. de Miguel, A. Porro and P.J.M. Bartos, RILEM Publications SARL, 2006, 257-267.

[77] Sbia, L. A., Peyvandi, A., Soroushian, P., and Balachandra, A. M., "Optimization of UltraHigh-Performance Concrete with Nano- and Micro-Scale Reinforcement," Cogent Engineering, 1, 1, 2014. 


\section{Appendix A}

\section{Sample of Test Results - Compressive Strength Test}

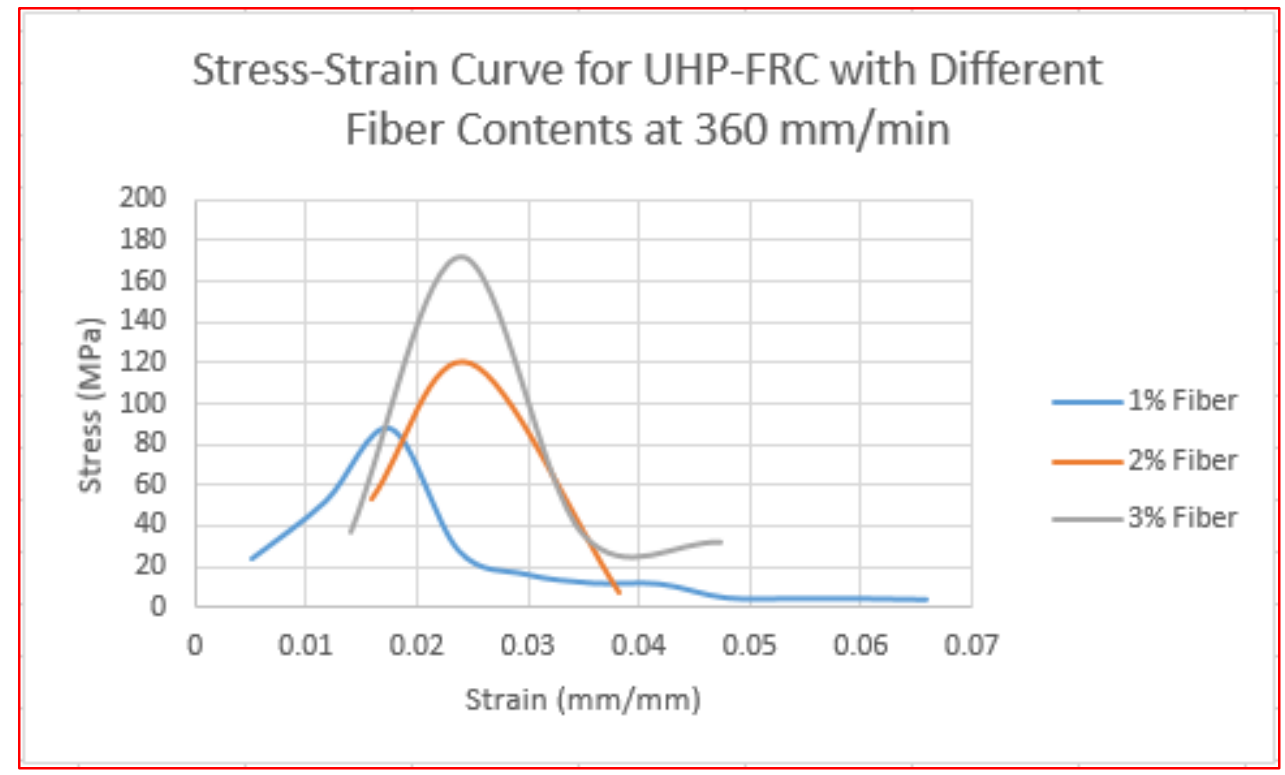

Figure 1: Stress-strain curve for UHP-FRC with different fiber contents at $360 \mathrm{~mm} / \mathrm{min}$ rate. 


\section{Appendix B}

\section{Sample of Test Results - Brazilian Test}

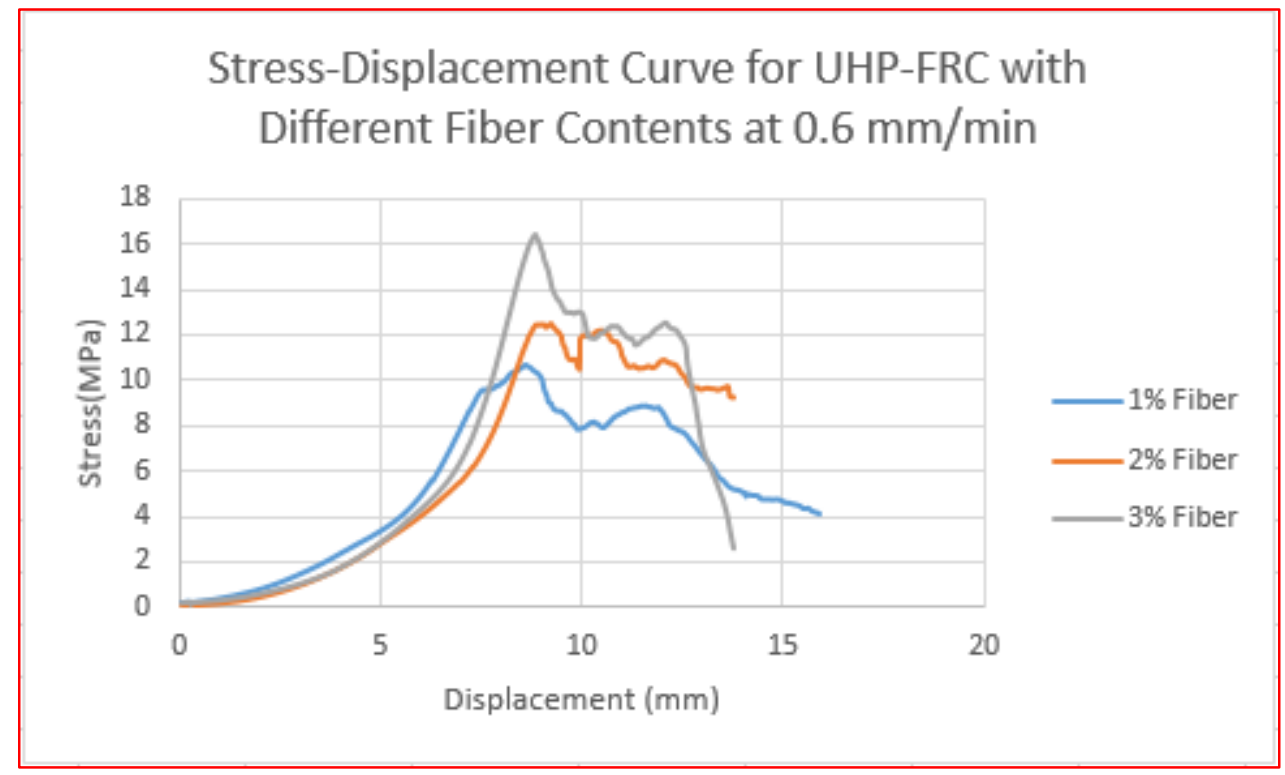

Figure 2: Stress-displacement curve for UHP-FRC with different fiber contents at $0.6 \mathrm{~mm} / \mathrm{min}$ rate. 


\section{Appendix C}

\section{Sample of Test Setup - Flexural Strength Test under \\ Quasi-Static, and Low Speed Loading Rates}

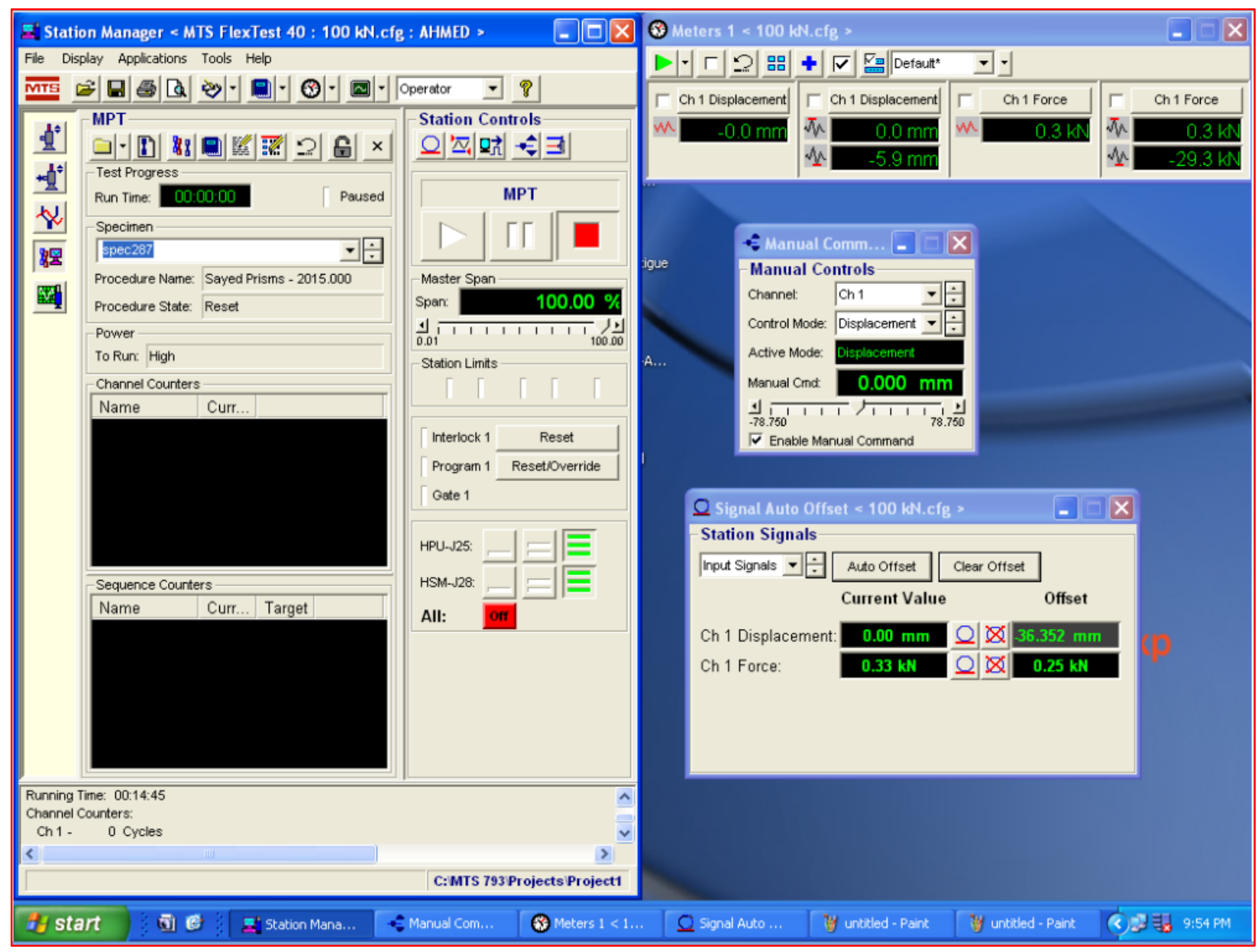

Figure 3: Station manager software setup for conducting flexural strength test. 


\section{Appendix D}

\section{Sample of Test Results - Flexural Strength Test under Quasi-Static, and Low Speed Loading Rates}

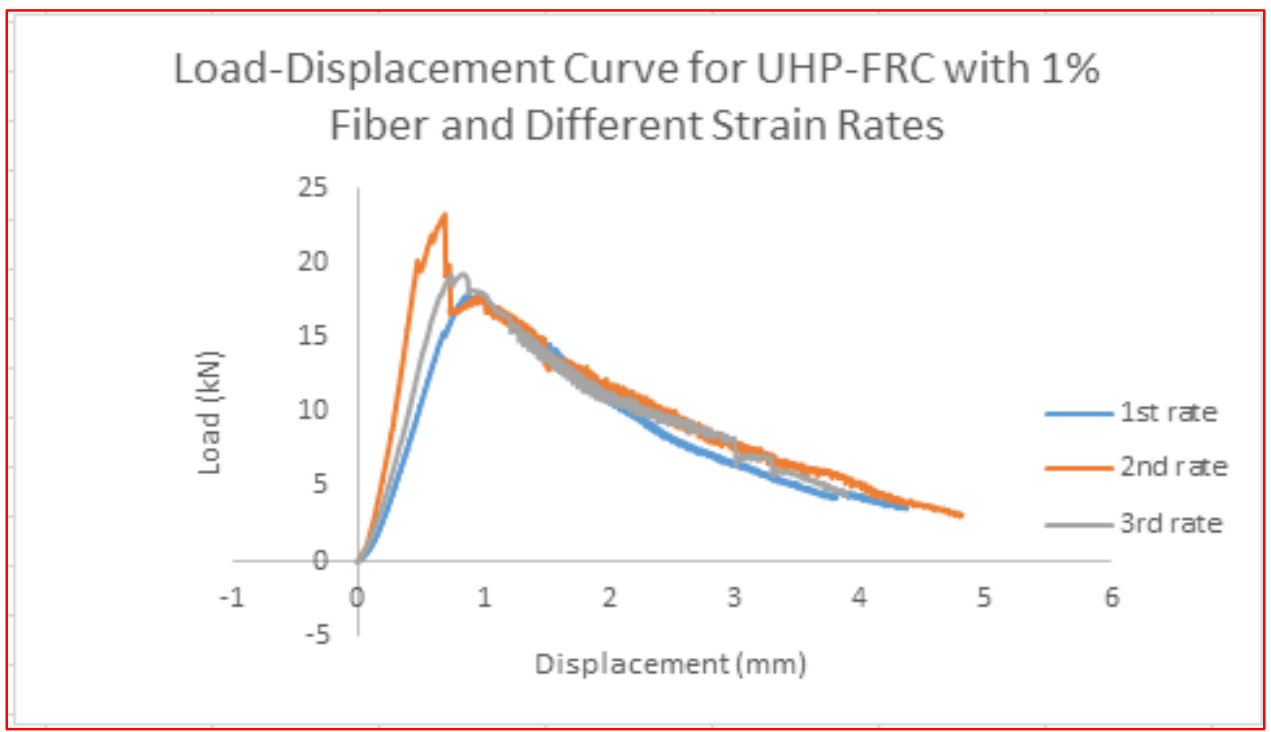

Figure 4: Load-displacement curve for UHP-FRC with $1 \%$ fiber and different strain rates.

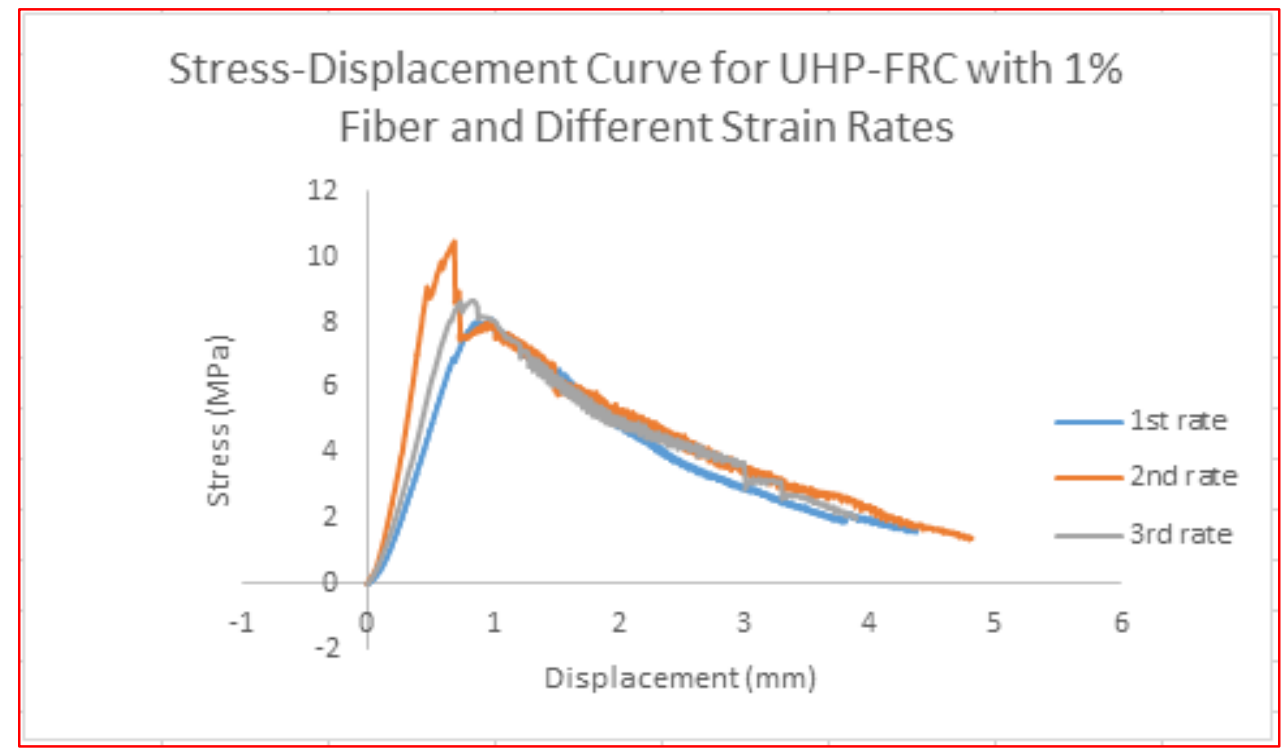

Figure 5: Stress-displacement curve for UHP-FRC with $1 \%$ fiber and different strain rates. 


\section{Appendix E}

Sample of Test Results - Flexural Strength Test under Dynamic (Impact) Loading

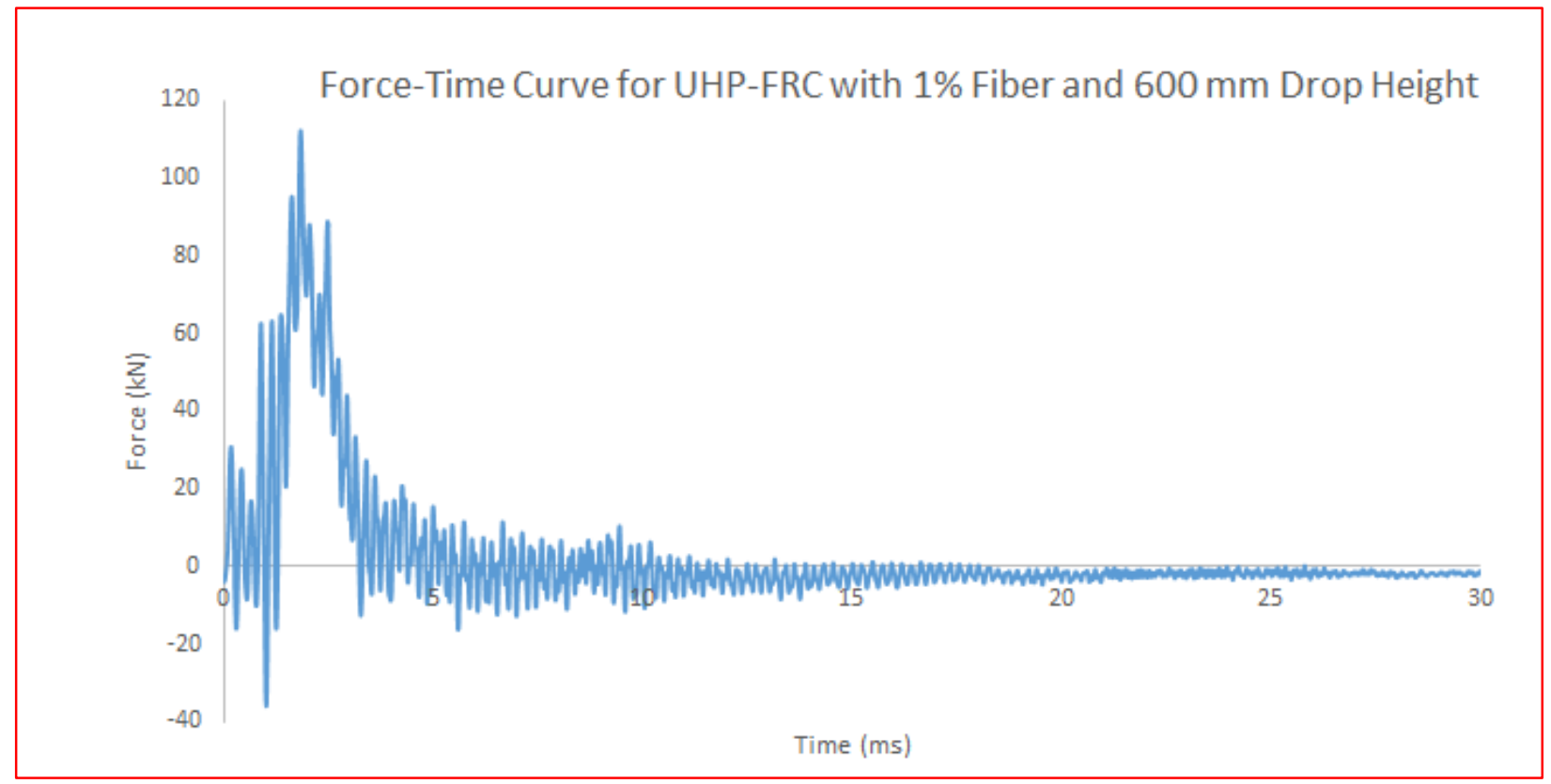

Figure 6: Force-time curve for UHP-FRC with $1 \%$ fiber and $600 \mathrm{~mm}$ drop height. 